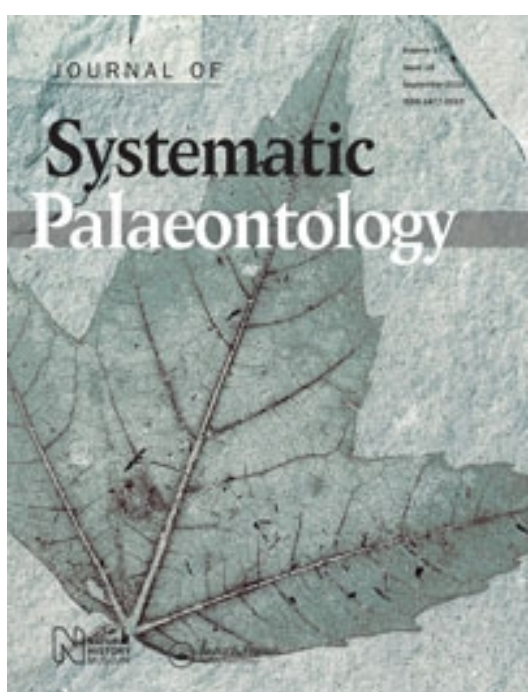

\title{
A re-examination of the anatomy and systematics of the tomistomine crocodylians from the Miocene of Italy and Malta
}

\begin{tabular}{|c|c|}
\hline Journal: & Journal of Systematic Palaeontology \\
\hline Manuscript ID & TJSP-2020-0057.R1 \\
\hline Manuscript Type: & Original Article \\
\hline Keywords: & Crocodiles, Mediterranean, Miocene, Neogene, Tomistoma, Tomistominae \\
\hline \multicolumn{2}{|c|}{$\begin{array}{l}\text { Note: The following files were submitted by the author for peer review, but cannot be converted to PDF. } \\
\text { You must view these files (e.g. movies) online. }\end{array}$} \\
\hline $\begin{array}{l}\text { Nicholl et al. } 2020 \text { FINAL.nex } \\
\text { Nicholl et al. } 2020 \text { FINAL.tnt }\end{array}$ & \\
\hline
\end{tabular}

\section{SCHOLARONE ${ }^{\text {TM }}$ \\ Manuscripts}




\section{A re-examination of the anatomy and systematics of the tomistomine crocodylians from the Miocene of Italy and Malta}

Cecily S. C. Nicholla ${ }^{*}$, Jonathan P. Rio ${ }^{b}$, Philip D. Manniona, and Massimo Delfinoc,d

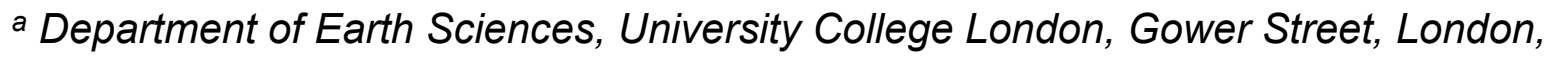
WC1E 6BT, UK

${ }^{b}$ Department of Earth Science and Engineering, Imperial College London, South Kensington Campus, London, SW7 2AZ, UK

c Dipartimento di Scienze della Terra, Università di Torino, Via Valperga Caluso 35, 10125 Torino, Italy

d Institut Català de Paleontologia Miquel Crusafont, Universitat Autònoma de Barcelona, Edifici ICTAICP, Carrer de les Columnes s/n, Campus de la UAB, 08193 Cerdanyola del Vallès, Barcelona, Spain

*Author for correspondence: cecily.nicholl@ucl.ac.uk

Running head: Miocene Mediterranean tomistomines 


\section{Abstract}

Once a much more globally widespread crocodylian clade, Tomistominae is today represented by just one species, Tomistoma schlegelii (the false gharial), restricted to southeast Asia. Although tomistomine fossil occurrences are recognised from the early Eocene ( $\sim 55 \mathrm{Ma})$ onwards, their remains are often incomplete, making appropriate taxonomic classification within the group problematic. This is especially pertinent to several taxa from the Miocene of Europe, which were historically erected from fragmentary remains. Here we re-examine and describe four approximately contemporaneous taxa from Malta and Italy to determine their taxonomy and phylogenetic affinities: Melitosaurus champsoides, Tomistoma calaritanum, Tomistoma gaudense, and Tomistoma lyceense. We place them into a phylogenetic analysis for the first time, comprising 70 taxa scored for 244 characters, several of which are revised or novel, and apply a number of character weighting strategies. Whereas 'Tomistoma lyceense' is deemed to be an indeterminate tomistomine, a unique combination of features confirms Melitosaurus champsoides, Tomistoma calaritanum, and Tomistoma gaudense as three distinct species. These three taxa are recovered as derived tomistomines, with characters such as a posterior maxillary process between the lacrimal and nasal, large supratemporal fenestrae that are wider than long, and the posteromedial alignment of the last three premaxillary teeth, suggesting a close relationship with the approximately contemporaneous European taxa, Tomistoma lusitanica and Gavialosuchus eggenburgensis. It is unlikely that any of these species belong to Tomistoma, with the possibility that they can all be classified under Melitosaurus and Gavialosuchus. However, we retain them in open nomenclature pending reassessment of the remaining European Miocene tomistomines. Our taxonomic and phylogenetic revision helps to elucidate past tomistomine diversity in the Miocene of the Mediterranean region, prior to the group's extirpation, and is an important first step in resolving the complicated history of European tomistomine systematics. 
Keywords: Tomistominae; Crocodiles; Mediterranean; Miocene; Neogene; Tomistoma.

\section{Introduction}

Today, the crocodylian clade Tomistominae is restricted to a single species, Tomistoma schlegelii (the 'false gharial'), living in southeast Asia (Bezuijen et al. 2010). However, it was once a much more diverse group with a near-global distribution (Brochu 2007; Piras et al. 2007; Jouve et al. 2015). Fossil remains referable to tomistomines extend back to the early Eocene (Ypresian; 56-47.8 Ma) (e.g. Mook 1955; Jonet \& Wouters 1977; Brochu 2007; Jouve et al. 2015) and are known from all continents, with the exception of Australasia and Antarctica (Piras et al. 2007; Jouve 2016), although these absences might reflect sampling biases (e.g. Mannion et al. 2019).

In addition to numerous specimens from the Eocene, tomistomine remains are common in Miocene deposits of the Mediterranean region (Piras et al. 2007) (Fig. 1), although they become less frequent towards the end of the epoch, and are absent from the Pliocene onwards (Kotsakis et al. 2004; Delfino et al. 2007; Piras et al. 2007). In total, seven species have been named from across the Miocene of Europe and North Africa (Piras et al. 2007) (Fig. 1). These include Gavialosuchus eggenburgensis from Austria (Toula \& Kail 1885), Tomistoma Iusitanica from Portugal (Vianna \& Moraes 1945; Antunes 1961), and Tomistoma dowsoni from Egypt and Libya (Fortau 1920; Agrasar 2004). The remaining four species come from fossiliferous beds in Italy and Malta (Kotsakis et al. 2004; Piras et al. 2007), and have all been referred to Tomistoma, comprising: T. lyceense (Costa 1848; Aldinio 1896), T. (Melitosaurus) champsoides (Owen 1849; Lydekker 1886), T. gaudense (Hulke 1871), and T. calaritanum (Gennari 1869; Capellini 1890a, b). Many additional contemporaneous fragmentary fossils (primarily isolated teeth, vertebrae, and osteoderms) from the Mediterranean region have also been identified as belonging to tomistomines (Delfino et al. 2003; Kotsakis et al. 2004; Delfino \& Ragazzini 2010; Zoboli et al. 2019), even if in some cases they do not belong to crocodylians (García-Marsà et al. 2018). 
The first of these four taxa to be described ( $T$. lyceense) was based on a mid-snout segment from southern Italy. It was initially assigned by Costa $(1848,1854,1864)$ to either the genus Streptospondylus or Steneosaurus (S. lyceensis in either case), before Aldinio (1896) referred it to Tomistoma (as T. lyceense). This referral to Tomistoma was criticised by Capellini (1897 [including reproduced correspondence from R. Lydekker]), and T. lyceense has since been considered to be either a nomen vanum (Delfino et al. 2003) or nomen dubium (Kotsakis et al. 2004). Today, the holotype cannot be located, but a cast of the specimen is available at the Museo Geologico Giovanni Capellini in Bologna. Melitosaurus champsoides, erected by Owen (1849), comprises the anterior-most portion of a longirostrine snout (NHMUK PV OR41151) from Gozo Island, Malta. Lydekker (1886) later assigned the species to Tomistoma, commenting (p. 20) that the specimen has 'no... characters which can be regarded as of generic value' The same deposits on Gozo Island are also the provenance of a fairly complete, but poorly preserved, skull, that forms the type specimen (NMNH-T11228) of 'Crocodilus' gaudensis (Hulke 1871). Lydekker (1886) subsequently regarded it as a species of Tomistoma, with the species name corrected to gaudense. Finally, a partial skull, some cervical vertebrae and ribs, and eight osteoderms were collected from Sardinia, Italy (MGGC 148). Gennari (1869) briefly described the specimen and proposed the name 'Croc. Caralitanus' (=Crocodylus caralitanus). However, it was subsequently described by Capellini (1890a, 1890b), who referred it to Tomistoma, as T. calaritanus (see Zoboli et al. 2019), later corrected to T. calaritanum (Kotsakis et al. 2004). The specimen was severely damaged by bombing during World War II, and only part of the skull and some osteoderms remain (Zoboli \& Pillola 2016).

With so many approximately contemporaneous, fragmentary fossil occurrences from a relatively small geographic region, the revision of these European taxa is important for determining the diversity of tomistomines in the Miocene of the Mediterranean region, as well as for elucidating their relationships with other members of the clade. Here, these four Italian and Maltese tomistomine taxa are re-described, and their taxonomy is revised. We also incorporate all sufficiently complete, named remains into a phylogenetic analysis for the first time in an attempt to determine their placement within Tomistominae. 
[Insert Fig. 1 here]

\title{
Institutional abbreviations
}

HLMD, Hessisches Landesmuseum Darmstadt, Darmstadt, Germany; MGGC (formerly MDLCA), Museo Geologico Giovanni Capellini, Bologna, Italy; NHMUK, Natural History Museum, London, United Kingdom; NMNH, National Museum of Natural History, Mdina, Malta.

\section{Systematic palaeontology}

\author{
Eusuchia Huxley, 1875 \\ Crocodylia Gmelin, 1789 (sensu Benton and Clark 1988) \\ Crocodyloidea Fitzinger, 1826 (sensu Brochu 2003) \\ Tomistominae Kälin, 1955 (sensu Brochu 2003) \\ Melitosaurus Owen, 1849 \\ Melitosaurus champsoides Owen, 1849
}

(Figs 2-4)

1849 Melitosaurus champsoides Owen: 115, pl. 2, fig. 2.

1886 Tomistoma champsoides Lydekker: 20, pl. 2, figs 1-2.

Type species. Melitosaurus champsoides Owen, 1849

Holotype. NHMUK PV OR41151: anterior portion of a longirostrine rostrum, comprising the premaxillae and the anterior sections of the maxillae, nasals, and dentaries (Figs 2-4). A left dentary fragment from an indeterminate position in the mandible is also preserved (Fig. 4).

Locality and horizon. Gozo Island, Malta; carbonate bed containing phosphate nodules within the Middle Globigerina Limestone Member; middle-upper Burdigalian ( 19-16 Ma). (Adams 1878; Pedley et al. 1976; Gruszczyński et al. 2008; Bianucci et al. 2011; Baldassini \& Di Stefano 2017). Present throughout the Maltese Islands, the Globigerina Limestone crops out across Gozo Island. Varying in thickness 
between 20-200 m (Pedley et al. 1976), the limestone comprises rapidly deposited yellow to light grey biomicritic carbonates composed largely of benthic and planktonic foraminifera at its lower and upper regions, and coccoliths in its central section (Pedley et al. 1976; Rehfeld \& Jahnsen 1995). The formation forms part of a transgressional marine succession deposited over the Pelagian carbonate platform (Rehfeld \& Jahnsen 1995).

Diagnosis. Melitosaurus champsoides differs from other tomistomines in its possession of a unique combination of characters: (1) a robust snout with a dorsoventral height to transverse width ratio of $\sim 1$; (2) anteroposteriorly elongate posterior premaxillary processes proportional to premaxilla length; (3) an external naris forming $50 \%$ of the mediolateral width of the rostrum; and (4) broad separation of the $3^{\text {rd }}$ and $4^{\text {th }}$ premaxillary teeth.

General Preservation. Although incomplete, the snout is generally well preserved; however, the surface of the bone is largely broken away along the left dorsolateral margin and around the naris. Both anterior mandibular fragments have been slightly rotated and shifted, so they are not in life position; otherwise, only minimal distortion has occurred, and the overall shape and proportions are assumed to be correct. Both mandibular fragments are attached to the upper snout by matrix, largely obscuring the view of the ventral surface of the rostrum. The separate posterior dentary fragment presents a similar preservation quality as the rest of the specimen.

\section{Description of Melitosaurus champsoides}

General shape. Despite being incomplete, the snout tip clearly belongs to a longirostrine crocodile; it maintains an approximately constant mediolateral width along its entire length, bar a slight transverse constriction which corresponds to the anterior extension of the lateral premaxilla-maxilla suture (Fig. 2). In lateral view, the dorsal margin of the premaxilla is very slightly domed, such that its maximum dorsoventral height is at the level of the third premaxillary tooth. At this level the transverse cross section through the snout is subcircular (dorsoventral height to transverse width ratio of 1 ). 
[Insert Fig. 2 here]

Cranial Openings. The external naris is entirely surrounded by the premaxillae and sits flush with them, making no contact with the nasals. This opening is very slightly anteroposteriorly elongate (anteroposterior length to mediolateral width ratio of 1.1) and displays a subtle mediolateral widening towards its anterior end (Fig 2). At its anterior margin, the naris is slightly intruded by small posterior processes emanating from each premaxilla, such that the margin is posteriorly concave. The inner surface of the naris cavity is entirely covered by matrix.

Premaxilla. Posterior to the external naris, the anteroposteriorly elongate premaxillae form an extensive contact with one another. The maximum anteroposterior length to maximum mediolateral width ratio of each premaxilla is 5.6. The paired premaxillae are mediolaterally broadest at the level of the fourth premaxillary tooth (Fig. 2). Although all premaxillary dentition is lost, the subcircular alveoli indicate the presence of five teeth. The second alveolus is the smallest, and the third the largest in diameter. Premaxillary tooth spacing is approximately homodont, except for the distance between the third and fourth teeth, which is around $25 \%$ greater than the other spacings (Table 2). The toothrow is aligned such that the posterior-most three alveoli form a mediodorsally orientated row. The most posterior point of the premaxilla coincides with the level of the $3^{\text {rd }}$ maxillary tooth, such that the distance between the posterior margin of the external naris to the posterodorsal extremity of the premaxilla is 1.7 times the length between the tip of the snout and the posterior margin of the external nares (Fig. 2).

Maxilla. The anterior-most section of the maxilla overlaps the premaxilla by approximately one third of the latter's anteroposterior length. The maxilla maintains an approximately constant height along the anteroposterior length of the specimen, excluding the region anterior to the first maxillary tooth, wherein it dorsoventrally shortens and is ultimately replaced by the premaxilla. The first four alveoli are preserved on the right maxilla, and the first three on the left, with a tooth fragment present in the most posterior alveoli of the latter. Measured from the centre of each alveolus (Table 2), the alveoli have approximately homodont spacing. In dorsal view, 
mild salients can be seen along the entire length of the maxilla; these are consistent with the location of alveoli.

Nasal. Although incomplete, the nasals are assumed to be anteroposteriorly elongate given that they extend anteriorly to the level of the first maxillary tooth. The posterior half of the nasal displays a continuous mediolateral width until the level of the third maxillary tooth; at this point it is characterised by a gradual mediolateral narrowing towards the anterior end of the snout, terminating at approximately the same level as the anterolateral tips of the maxillae. There is a significant separation between the posterior margin of the external naris and the anterior extent of the nasals (Table 1$)$.

Dentary. The right dentary preserves the first four alveoli, of which only the anteriormost houses an almost complete tooth (Fig. 3). Right alveoli 2 and 3 each preserve the base of a tooth. By contrast, the left dentary preserves six teeth; the $1^{\text {st }}$ to $3^{\text {rd }}$ are essentially whole, bar some damage at the apex, whereas the $4^{\text {th }}$ to $6^{\text {th }}$ are substantially broken (Fig. 4). On both dentary fragments, the teeth display approximately homodont spacing, excluding the $3^{\text {rd }}$ and $4^{\text {th }}$ teeth which are closer together (Table 2). On the left dentary (wherein this alveolus is fully preserved), the $4^{\text {th }}$ tooth has the largest basal diameter, though the $1^{\text {st }}$ tooth is only slightly smaller. The fourth tooth is hypertrophied such that the dorsal dentary surface at the corresponding level is significantly raised compared to all other preserved teeth. All teeth are directed anterodorsally, and the anterior-most tooth is mildly procumbent. The dorsoventral height of the dentary gradually increases posteriorly.

[Insert Figs 3 \& 4 here]

Dentition. In the anterior region of the snout, the teeth of the premaxilla, maxilla, and dentary are conical and have an approximately circular shape at their base (Fig. 5). They are curved posteriorly. In the posterior dentary fragment, the teeth are much more laterally compressed and are not curved. Tooth enamel includes thin, apicobasal ridges. Both the anterior and posterior tooth margins are characterised by smooth carinae. 
[Insert Fig. 5 here]

\author{
Tomistoma Müller 1846 \\ 'Tomistoma' gaudense (Hulke, 1871) \\ (Figs 6-9)
}

1871 Crocodilus gaudensis Hulke: 32.

1886 Tomistoma gaudense Lydekker: 21.

Locality and horizon. Gozo Island, Malta; Middle Globigerina Limestone Member; middle-upper Burdigalian ( 19-16 Ma).

Diagnosis. 'Tomistoma' gaudense can be differentiated from other tomistomines by a unique combination of characters: (1) sinusoidal lateral snout margins; (2) anteroposteriorly extended postorbital bars; (3) an enlarged $5^{\text {th }}$ maxillary tooth; (4) a posterior process between the lacrimal and nasal (present only on the left side); (5) a slightly medially depressed skull table; (6) a modest 'step' on the dorsal margin of the jugal; (7) an anterior jugal process which does not exceed the anterior margin of the frontal; (8) a broad interorbital bar; (9) a thin posterior edge of the supratemporal fenestra; (10) large, quadrangular supratemporal fenestra; and (11) a wide lacrimal approximately double the width of the prefrontal.

Holotype. NMNH-T11228: almost complete cranium and partial mandible. Both are missing their anterior portion, and the mandible is lacking a large section of its posterior end (Figs 6-9).

General Preservation. The specimen is quite poorly preserved, such that it is often difficult to accurately observe the precise position of sutures. In several locations (e.g. the fenestrae, orbits, and occipital surface of the skull), the matrix has not been fully removed, making it challenging to observe the detailed morphology. Hulke (1871) suggested that the skull might have been flattened slightly from the weight of the overburden, and thus its proportions might be slightly distorted. 


\section{Description of 'Tomistoma' gaudense}

General shape. The skull is anteroposteriorly elongate and approximately triangular in dorsal view (Fig. 6). The lateral margins of the posterior part of the rostrum converge anteriorly up to the level of the $6^{\text {th }}$ maxillary tooth, and are essentially parallel from that point until the anCterior tip of the snout. Anterior to the $6^{\text {th }}$ maxillary tooth, the lateral margins of the snout are highly sinusoidal, with each lateral convexity corresponding to the presence of a tooth (although this is likely exaggerated by dorsoventral compression). In transverse cross section, the snout is approximately elliptical (dorsoventral height to transverse width ratio of 0.7 at the level of the $5^{\text {th }}$ maxillary tooth), increasing in mediolateral width posteriorly. The dorsal surface of the snout slopes to face very slightly anterodorsally, such that the mediolateral width of the rostrum gradually narrows anteriorly. The dorsal surface of the snout is mildly convex transversely, although this effect is lessened by the dorsoventral compression of the skull.

[Insert Fig. 6 here]

Cranial Openings. The orbits are large and anteromedially-posterolaterally elongate. They are mediolaterally widest at their anterolateral margins, and narrow posterolaterally, forming a pear-like shape. Each orbital margin is upturned around its entire circumference, although this is most prominent along its anterior margin, which also bears two grooves, with a maximum diameter of $\sim 4 \mathrm{~mm}$. The medial-most groove runs anteriorly from the anteromedial corner of the orbit along the prefrontal, whereas the other groove extends from the anterior tip of the orbit along the prefrontal-lacrimal suture. This upturning of the orbits' medial margins results in a gentle concavity on the dorsal surface of the interorbital bar. At the orbital level, the ratio of the skull width to interorbital distance is approximately 6.7.

The supratemporal fenestrae are large (maximum diameter of each fenestra is approximately one third of the width of the skull table at the equivalent level) and mediolaterally wider than they are anteroposteriorly long (width to length ratio is 1.1). They form an approximately pentagonal shape, with a long posteromedial margin. 
The interfenestral bar is particularly narrow (approximately a tenth of the mediolateral width of a single fenestra). The margins of the fenestrae sit flush with the skull table. Matrix infills the interior cavity, meaning that the internal walls are not visible.

The infratemporal fenestra forms an anteroposteriorly elongate elliptical shape. Although its posterior margin is obscured, the dorsoventral and anteroventral margins are clearly well rounded. The anteroposterior axis of the infratemporal fenestra is approximately the same length as that of the supratemporal fenestra; however, the anterior margin of the former is situated more anteriorly.

The suborbital fenestrae are large and approximately triangular. They are anteroposteriorly elongate, although their full anterior extent is masked by the mandible and matrix. The posterolateral margin is the shortest, with the medial margin the longest.

The foramen magnum is transversely elongate and has a width to height ratio of 0.4 . It is unclear to what extent this has been affected by the dorsoventral compression of the specimen.

The choana is entirely surrounded by the pterygoids (Fig. 7). It projects posteroventrally and is essentially elliptical (the dorsoventral height to mediolateral width ratio is 0.5 ). Much of the neck surrounding the aperture has been broken away, meaning that the inside cavity is largely exposed; however, the choanal margins are moderately everted.

[Insert Fig. 7 here]

Premaxilla. The premaxillae are largely missing in the anterior section of the skull; however, an anteroposteriorly elongate shape and long medial contact is inferred based on their posterior extent, as well as the fact that their missing anterior section must surround at least the entirety of the external naris. Each premaxilla's most posterior point likely coincides with the approximate level of the 3rd maxillary tooth, although the specimen is heavily fractured in this region and so the true posterior 
extent is difficult to ascertain. No teeth or alveoli are preserved on either side of the specimen as the lateral edges of the bone have broken away. The premaxilla has a long medial contact with the nasal; the two bones share a border for at least the length of two to three maxillary teeth.

Maxilla. The maxillae are dorsally flattened and mediolaterally wide. The anteriormost section of the maxilla has a long suture with the premaxilla, over a distance of approximately three teeth; however, the anterior-most tips of the maxillae are missing and so their full extent is unknown. The premaxilla-maxilla suture is bowed; from its most posterior point it gradually curves laterally, although the position of its contact with the lateral margin of the snout cannot be determined. On the left side of the rostrum a short maxillary process projects between the lacrimal and nasal; however, this feature is not present on the right side, and instead the lacrimal maintains a longer contact with the nasal. The lateral maxillary margins bear prominent salients, most notably along their anterior half, and which correspond to the positioning of alveoli.

The left maxilla is the better preserved, with 14 alveoli present, of which nine have either whole or partial teeth (present in alveoli 2-6 and 8-12). Based on basal diameter, the fifth and tenth maxillary teeth are the largest (the fifth tooth is broken and so its apicobasal length cannot be discerned). Maxillary teeth 1-7 have approximately homodont spacing, with an intra-alveolar distance in the region of 22$27 \mathrm{~mm}$. Maxillary teeth 7-14 also have approximately even spacing, but are positioned more closely to one another, with an intra-alveolar distance between 15$22 \mathrm{~mm}$. The right maxilla is very poorly preserved along its lateral margin; however, some tooth fragments are still visible in positions 2, 4-6, and 8-10. Imprints of right maxillary teeth 9-11 can also be observed in the matrix surrounding the skull.

[Insert Fig. 8 here]

Nasal. The nasals extend from the level of the anterior region of the orbits to a position level with the $1^{\text {st }}$ maxillary tooth. They are mediolaterally widest at the anterior tip of the prefrontal, gradually narrowing towards the anterior end of the snout, and are well separated from the posterior margin of the external naris, 
although it is unclear by exactly how much given that the anterior tip of the snout is not preserved. The nasals meet the premaxillae at the approximate level of the third maxillary tooth and are entirely surrounded by the latter for the anterior fifth of their length.

Lacrimal. The lacrimals extend anteriorly to the approximate level of the $10^{\text {th }}$ maxillary tooth. Their anterior-most margin is situated well anterior to the prefrontal (the lacrimal is approximately twice the anteroposterior length of the prefrontal), and so a broad lacrimo-nasal contact is exhibited. In the anterior region, the lacrimomaxillary suture is very slightly jagged. The anterior margin of the left lacrimal forms a rounded arch shape; however, the right lacrimal differs in that its lateral margin curves anteromedially to meet the nasal, rather than curving back on itself to form the medial lacrimal margin. Medially, the lacrimals are separated by the prefrontals and the nasals. The posterior margin of the lacrimal sits entirely on the anterior border of the orbit, where it is dorsally upturned and heavily covered with pits.

Prefrontal. The prefrontals are anteroposteriorly elongate, extending anteriorly to the level of the $12^{\text {th }}$ maxillary tooth, at which point they terminate in a sharp, single point. At their widest, they are approximately half the mediolateral width of the lacrimals. Their anterior-most point reaches to halfway along the anteroposterior length of the lacrimal. Each prefrontal is separated medially by the nasals and the most anterior tip of the frontal. In their posterior region, the prefrontals are dorsally upturned and heavily pitted.

Frontal. The frontal is anteroposteriorly long and forms a simple acute point at its anterior margin that terminates at the approximate level of the $11^{\text {th }}$ maxillary tooth. Mediolaterally, the dorsal surface is mildly concave. Anteriorly, the dorsal surface of the frontal is less heavily pitted than in its posterior region. The fronto-parietal suture is positioned just anterior to the supratemporal fenestra and does not enter the interfenestral bar; it is very slightly curved posteriorly. The contact between the frontal and the postorbital is oriented anterolaterally. This suture intersects the orbit (anteriorly) and supratemporal fenestra (posteriorly) approximately halfway across the mediolateral width of both. 
Parietal. The parietal is well preserved, although its margins are difficult to identify due to a small breakage in the left posterolateral corner, and an unclear suture along the anterior margin. Anterior to the supratemporal fenestra, the parietal lateral process is thin, and reaches halfway along the fenestral margin. Posterior to the supratemporal fenestra, the parietal process is much thicker (approximately three times the mediolateral width of the anterior process), and on both sides its lateral extent reaches three quarters of the way along the posterior margin of the supratemporal fenestra. The centre of the dorsal margin of the parietal is intruded by an anterior notch. The dorsal surface is covered with pits in all regions other than the interfenestral bar.

Postorbital. The postorbital forms the posterolateral half of the orbital margin and meets the frontal along an anteroposteriorly orientated suture. Visible only on the right side of the skull, the postorbital bar is anteroposteriorly elongate and inclined anterolaterally, widening towards its base. It is unclear exactly where the postorbital is sutured to the squamosal.

Squamosal. The squamosal is only preserved on the right side of the skull and is incomplete along its posterolateral margin. There is a large, sub-oval depression located posterolaterally to the supratemporal fenestra; it is approximately $19 \mathrm{~mm}$ along its greatest diameter, though this feature is likely a result of poor preservation. The entire squamosal is sloped ventromedially, creating a medially depressed skull table. Given that the suture with the postorbital is not clearly discernible, it is not possible to determine the squamosal's anterior extent. Similarly, the quadratosquamosal suture cannot be observed, as matrix remains in this region. The posterior region of the squamosal is damaged and thus its posterior extent is also unclear. In lateral view, the squamosal groove can be seen to flare anteriorly, although this is subtle.

Jugal. The jugal is dorsoventrally tall in both its anterior and posterior regions, decreasing in height in its middle region. In lateral view, the ventral margin of the jugal is arched dorsally. Adjacent to the postorbital bar, the dorsal margin of the jugal forms a small, anteroposteriorly directed ridge; this creates a ventrally depressed region on the postorbital bar. Lateral to the bar, the dorsal edge of the jugal displays 
a subtle step, resulting in a dorsoventrally higher anterior jugal region (Fig. 9). Due to poor preservation, the anterior and posterior extent of the jugal cannot be determined.

[Insert Fig. 9 here]

Quadrate and quadratojugal. Although a fragment of the right quadrate remains, it is highly damaged, and little can be said about its appearance. Similarly, although a piece of the quadratojugal is preserved, little more can be said of its shape.

Palatine. The palatines are anteroposteriorly elongate, forming much of the length of the palate between the suborbital fenestrae (unfortunately the anterior and posterior margins cannot be determined due to poor preservation of the specimen, as well as the presence of matrix). For their entire length between the suborbital fenestrae, the palatines remain essentially the same mediolateral width.

Ectopterygoid and pterygoid. Although preserved to some extent on both sides of the specimen, the ectopterygoids are damaged and their margins are not easily discernible. Similarly, although the pterygoid is largely preserved, little can be said about its precise features due to breakages and loss of the surface bone layer. However, the pterygoid clearly surrounds the choana entirely, despite being highly damaged in this region.

Supraoccipital. Although the lateral and ventral margins of the supraoccipital are unclear, the dorsal margin is intruded ventrally by a semi-circular notch. A prominent midline ridge is present; it is most prominent in its dorsal region but flattens towards the foramen magnum.

Exoccipital. Although much of the exoccipital is preserved, it is damaged such that the most lateral sections of the paraoccipital processes are incomplete, and the proportions of the bone are unclear. Furthermore, the region is obscured by matrix, and so much of the detailed morphology of the exoccipital is obscured. 
Dentary. A left dentary fragment is preserved from the middle section of the snout, corresponding in length to the distance between maxillary teeth $3-11$. It is attached to the cranium by matrix. The lateral surface of two teeth, positioned approximately halfway along the anteroposterior length of the mandibular fragment, can be observed; further dentition is likely present, but is largely obscured by matrix. The two visible teeth are positioned at the level of the $6^{\text {th }}$ to $7^{\text {th }}$ and $7^{\text {th }}$ to $8^{\text {th }}$ maxillary teeth. In ventral view, the six anterior-most alveoli are visible due to removal of the ventral region of the bone. The dorsoventral height of the dentary varies, with its highest point along its posterior region. It is also raised at the point of the posteriormost preserved dentary tooth. A small right dentary fragment is also preserved, but is very incomplete and poorly preserved, providing no further anatomical information.

Splenial. The splenial is included in the mandibular symphysis over a length of approximately three to four dentary teeth. Damage to the specimen prohibits a clear boundary being determined between the splenial and the dentary, and its medial surface is largely obscured by sediment.

Dentition. The teeth are conical, sharply pointed, and are curved slightly posteriorly. They have sharp, non-serrated anterior and posterior margins. Generally, they are laterally compressed, especially towards their apices. In the posterior region of the snout, the maxillary teeth are blunter and more laterally compressed than those in the anterior region. Observable along their broken cross sections, the teeth have a thick enamel coating, which on the lateral tooth surface is further characterised by apicobasal striations. Nearer to the base, these striations are more widely separated, but they converge towards the apex, gradually becoming thinner as they do so.

\section{'Tomistoma' calaritanum Capellini, 1890a}

(Figs 10-14)

1868 Crocodylus caralitanus Gennari: 127.

1890a, b Tomistoma calaritanus Capellini: 507, pls 1-4. 
2004 Tomistoma calaritanum Kotsakis et al.: 70.

Diagnosis. 'Tomistoma' calaritanum can be differentiated from other tomistomines by a unique combination of characters: (1) a relatively narrow interorbital bar; (2) a splenial which participates in the mandibular symphysis over the length of two to five teeth; (3) a large external naris forming $77 \%$ of the snout width; (4) anteroposteriorly extended postorbital bars; an enlarged $5^{\text {th }}$ maxillary tooth; (5) a posterior process between the lacrimal and nasal; (6) a gentle 'step' on the dorsal margin of the jugal; (7) an anterior jugal process which does not exceed the anterior margin of the frontal; (8) a thin posterior edge of the supratemporal fenestra; (9) a frontal extending well anterior to the prefrontal; and (10) elongate premaxillary processes.

Holotype. MGGC 148: a partially complete longirostrine skull missing most of the bone surrounding and posterior to the orbits. Much of the shape of the posterior skull region was preserved in the enclosing rock, allowing Capellini (1890a, b) to make detailed descriptions and drawings of the specimen. Unfortunately, due to bombing during World War II, most of the specimen has now been destroyed; however, the posterior section of the snout and the rock surrounding the orbits remains (Figs 1014).

Locality and horizon. Is Mirrionis, Cagliari, Sardinia; Tramezzario lithofacies in the Calcari di Cagliari Formation; upper Tortonian-lower Messinian ( 10-7 Ma) (Zoboli et al. 2019). Though mostly cropping out in the north of Sardinia, the Calcari di Cagliari Formation is also exposed in the hills surrounding Cagliari in the south. This formation represents a carbonate succession formed of three distinct lithofacies (Gandolfi \& Porcu 1967; Cherchi 1974). From the base to the top, these are the 'Pietra Cantone', 'Tramezzario', and 'Pietra Forte' lithofacies. The middle 'Tramezzario' lithofacies comprises off-white bioclastic limestones and biocalcarenites deposited in infralittoral to circalittoral zones (Leone et al. 1992).

General Preservation. Even before the specimen was partially destroyed, it was poorly preserved (Fig. 10). Although the snout was almost entirely present, it was highly fractured, and the surface of the bone had been removed in several places. In 
the region surrounding and posterior to the orbits, the bone had largely been removed; however, suture lines were generally still visible as imprints in the enclosing sediment. Limited distortion has occurred, and so proportions are likely correct. The specimen can now only be observed in dorsal and lateral views because matrix cements the cranial and mandibular sections together; however, a photograph of the ventral snout region was provided in Capellini (1890b). Our description below combines information directly observable from the existing specimen with information presented in Capellini (1890a,b). Although Capellini (1890b) briefly mentioned the bones exposed on the posterior surface of the cranium, he generally did not describe their shape or exact features. In some instances, he provided specific measurements; however, given that the skull was not figured in posterior view, we are unable to comment further on this region.

[Insert Figs $10 \& 11$ here]

\section{Description of 'Tomistoma' calaritanum}

General Shape. The skull is longirostrine, with the snout (measured from its rostral tip to the anterior margin of the orbits) forming $65 \%$ of the total skull length. It has an approximately triangular shape in dorsal view. The rostro-cranial transition is gradual: the lateral margins of the cranium converge from the level of the quadrate articular surface until the position of maxillary tooth six/seven. Anterior to this, the lateral margins are approximately parallel, narrowing only at the premaxilla-maxilla suture. In lateral view, two subtle convexities can be observed on the dorsal margin of the rostrum. These convexities correspond with the level of the $3^{\text {rd }} 4^{\text {th }}$ maxillary teeth and the $3^{\text {rd }}$ premaxillary tooth. In transverse cross section, the snout is essentially round at the level of the $3^{\text {rd }}$ premaxillary teeth (dorsoventral height to transverse width ratio is 0.9 ).

Cranial Openings. Based on Capellini (1890b), the external naris is elliptical, with an anteroposterior length to mediolateral width ratio of 1.2. The posterior margin of the naris is shaped by a small triangular incision ( $20 \mathrm{~mm}$ in length) which intrudes into the premaxillae. However, it is unclear whether this is the result of the premaxillary suture having been pulled apart. The naris is entirely surrounded by the 
premaxillae, with which it sits flush, and its posterior margin makes no contact with the nasals. The ventral margin of the nasal cavity is composed entirely of the premaxillae: it is excavated by an elongate, tear-shaped incisive foramen which tapers to a point towards the anterior end of the snout. This foramen is anteroposteriorly elongate and is approximately $60 \%$ of the length of the external naris in dorsal view. Capellini (1890b) remarked that the dorsoventral distance from the dorsal surface of the snout to the base of the narial opening was $30 \mathrm{~mm}$, which is approximately half the height of the entire rostrum.

The shapes of both orbits are inferred from imprints in the surrounding rock. They are large, with a well-rounded anteromedial margin, and a long axis that is orientated anteromedially-to-posterolaterally. Along this axis, the orbits are widest in their anteromedial region, but narrow towards the postorbital bar. The orbital margin is upturned most prominently along the orbit's anterior and lateral edges, but also shows a slight deflection along the dorsal margin. The ratio of skull width (at the level of the orbits) to interorbital distance is 6.7. The interorbital bar is narrow and is approximately half the mediolateral width of one orbit.

As with the orbits, the shape of the supratemporal fenestrae was largely inferred by Capellini (1890b) using imprints in the surrounding rock. These fenestrae are slightly pentagonal in shape and have an anteroposterior length to mediolateral width ratio of 0.8. Each fenestra is just under one third of the width of the skull table at the same anterodorsal level. The fenestrae are separated from one another by a narrow interfenestral bar that is one fourth of the width of a single fenestra. Capellini's (1890b) drawings appear to show a slight upturning of the fenestral margins, especially along their anterior margin, although this was not specifically mentioned in his description.

An infratemporal fenestra is well preserved on the left side of the specimen. Forming an approximately triangular shape with a concave ventral margin, it has an anteroposterior length to dorsoventral ratio of 1.7. Its ventral margin has approximately the same anteroposterior length as that of the long axis of the orbit (Table 1). The ventrolateral margin is composed of the jugal along its anterior half, and the quadratojugal for its posterior half. Although the quadrate contributes to the 
posterodorsal margin of the fenestra, it is unclear to what extent. It is also unclear as to where the quadrate meets the squamosal along the infratemporal fenestra border.

Although not illustrated, the foramen magnum was described by Capellini (1890b) as being elliptical in shape, with a mediolateral width to dorsoventral height ratio of 1.4. Capellini (1890b) also described the presence of a triangular external auditory meatus bordered in its ventral region by the quadrate, although he noted that the squamosal largely restricted the view of its posterior margin.

[Insert Fig. 12 here]

Premaxilla. Prior to their destruction, both premaxillae were fairly complete, except for some damage in their anterodorsal extremity. Posterior to the external naris, the anteroposteriorly elongate premaxillae form an extensive contact with one another. The maximum anteroposterior length to maximum mediolateral width ratio of each premaxilla is 5.9. The premaxillae are mediolaterally broadest at the level of the third tooth. Each premaxilla has five teeth; Capellini (1890b) noted that the right premaxilla preserves teeth 2, 4 and 5 , as well as a partially extruded first tooth (though note that the $2^{\text {nd }}$ tooth is missing in Fig. 14), whereas the left premaxilla preserves only the $2^{\text {nd }}$ tooth. The third alveolus is the largest in diameter on the left premaxilla, whereas the $4^{\text {th }}$ is the largest on the right element. The second and fifth alveoli are the smallest and were approximately equidimensional. All alveoli are essentially circular in shape, although in some cases could be considered as very slightly anteroposteriorly elongate. On the right side of the specimen the premaxillary tooth spacing is approximately homodont, except for the distance between the third and fourth teeth, which is $\sim 25 \%$ greater than the anterior spacings (Table 2 ). However, this tooth spacing varies significantly from that of the left premaxilla, in which the third alveolus is much closer to the fourth. Capellini (1890b) attributed this to the third tooth being 'supplementary', as is the case in Tomistoma schlegelii. The toothrow is aligned such that the posterior-most three alveoli form a mediodorsally orientated row. The distance between the posterior margin of the external naris to the posterodorsal extremity of the premaxilla is 1.7 times the length between the tip of the snout and the posterior margin of the external naris. 
Maxilla. Both maxillae were preserved, although the right showed significant damage in its dorsomedial region. However, from Capellini's (1890b) sketches we see that the maxilla is anteroposteriorly elongate, narrowing anteriorly until its suture with the premaxilla (in both dorsal and ventral views, the posterior-most point of this suture corresponds with the level between the $2^{\text {nd }}$ and $3^{\text {rd }}$ maxillary teeth). On the dorsal surface of the snout, the maxilla joins the premaxilla along a smoothly curved suture; however, on the ventral surface, the premaxilla-maxilla suture forms a 'zigzag' shape. Using imprints in the surrounding matrix, it can be inferred that a short maxillary process was present between the lacrimal and nasal. Although now largely destroyed, Capellini (1890b) noted that 14 teeth/alveoli were preserved in the right maxilla (either whole or fragmentary teeth were present in all bar the $3^{\text {rd }}, 4^{\text {th }}$, and $14^{\text {th }}$ alveoli), and 13 in the left maxilla (either whole or fragmentary teeth were present in all bar the $1^{\text {st }}$ to $5^{\text {th }}, 8^{\text {th }}$, and $13^{\text {th }}$ alveoli). The fifth maxillary tooth is the largest; its expanded diameter causes subtle mediolateral snout enlargement at the same level. Despite not being fully prepared from the matrix at the time, Capellini (1890b) was fairly certain that a $14^{\text {th }}$ tooth did not exist on the left side and was reluctant to induce damage to the specimen by freeing it further from the matrix. Capellini (1890b) reported a distance of approximately $15 \mathrm{~mm}$ between the anterior and posterior margins of the $1^{\text {st }}$ to $4^{\text {th }}$ alveoli, a larger interalveolar space $(25 \mathrm{~mm})$ between the $4^{\text {th }}$ and $5^{\text {th }}$ maxillary alveoli, and then a consistent interalveolar length of approximately $12 \mathrm{~mm}$ between each of the alveoli in positions five to eight. The dorsal and lateral surfaces of the maxilla are covered in small pits which become more densely spaced towards the anterior end of the snout.

Nasal. The nasals were once partially preserved; however, both lacked their posterior extremity (approximately $70 \mathrm{~mm}$ on the right, and $45 \mathrm{~mm}$ on the left) and some anterior portions, although Capellini (1890b) noted that he could still determine their general morphology based on the rock imprints. Today, only mid-to-posterior fragments of the nasals remain, although the shapes of the posterior ends are preserved in the matrix that infilled the skull. The nasals are anteroposteriorly elongate, extending from the anterior region of the orbits to the same level as the anterior-most point of the premaxilla-maxilla suture. From their widest mediolateral point at the level of the $8^{\text {th }}$ maxillary tooth, they exhibit a gradual mediolateral narrowing towards the anterior end of the snout, eventually pinching out in an acute 
point. There is a significant separation between the posterior margin of the external naris and the anterior extent of the nasals (Table 1).

[Insert Figs $13 \& 14$ here]

Lacrimal. Only the tip of the right lacrimal is still preserved; however, the overall shape of both lacrimals can be inferred from the imprint in the surrounding rock. The lacrimal is anteroposteriorly elongate, extending to approximately the level of the $10^{\text {th }}$ maxillary tooth. Its anterior margin is rounded, forming a broad, arched shape that is situated well beyond the anterior margin of the prefrontal, resulting in a broad, lacrimo-nasal contact. The lacrimal-prefrontal suture is oriented anteromediallyposterolaterally and its posterior margin lies entirely along the anterior border of the orbit. The lacrimals are approximately three times the mediolateral width and two times the anteroposterior length of the prefrontals (Table 1).

Prefrontal. The shapes of the prefrontals are preserved only as imprints in the surrounding rock. They extend anteriorly to the approximate level of the $12^{\text {th }}$ maxillary tooth and are separated medially by the nasals and the frontal. Each prefrontal terminates anteriorly in a sharp, single point, and there is no process extending into the nasal.

Frontal. Capellini (1890b) noted that the frontal once consisted of two fragments, but that its overall shape was inferred from imprints in the surrounding rock. The frontal is anteroposteriorly elongate and approximately half of this length results from a process which forms a simple acute point at its anterior margin, approximately level with the $11^{\text {th }}$ maxillary tooth. This anterior process extends further anteriorly than the prefrontals and its anterior-most point is situated just posterior to the anterior margin of the lacrimals. The fronto-parietal suture is entirely anterior to the supratemporal fenestra and is essentially straight. In its posteriormedial region, the surface of the frontal is heavily covered in pits and ridges. Its dorsal surface is medially depressed.

Parietal. Only a small fragment of the parietal was preserved; however, imprints in the rock indicate its overall shape. The lateral processes immediately anterior to the supratemporal fenestra are anteroposteriorly narrow (approximately half the width of 
the lateral process posterior to the fenestra). The interfenestral bar is mediolaterally narrow (a third of the width of a single supratemporal fenestra).

Postorbital. Only the left postorbital was preserved before the specimen was further damaged. It is located directly posterior to the lateral half of the orbit and meets the frontal along an anterolaterally directed suture. On the skull table, the postorbital contributes minimally to the posterior margin of the orbit; however, it forms the entire anterolateral edge of the supratemporal fenestra. Its dorsal surface is covered in large pits and grooves. The postorbital bar is anteroposteriorly elongate, with its long axis anterolaterally inclined. Capellini (1890b) noted that the postorbital was difficult to differentiate from the squamosal.

Squamosal. The left squamosal was originally well preserved, situated at the posterolateral margin of the skull table (Capellini 1890b). On the lateral surface of the squamosal, there is a well-developed, anteroposteriorly oriented crest that is scoured with deep transverse furrows. Contacts with the parietal are too undefined to be identified, as is the suture with the quadrate. Squamosal prongs reach almost as far as the posterior margin of the quadratojugal and are deflected posteroventrally at an angle of approximately $45^{\circ}$ to the horizontal.

Quadrate. Although no longer present, the quadrate was once well-preserved on the left side of the specimen, and the general shape of the right side was inferred from the surrounding rock (Capellini, 1890b). The quadrate-quadratojugal suture appears to have been extensive and anteromedially orientated; however, Capellini (1890b) noted that the contact with the squamosal is not well defined. The quadrate extends anteriorly to form part of the posterior margin of the infratemporal fenestra. At its articular surface, the mediolateral width of the quadrate ramus is approximately twice the dorsoventral height of the quadrate condyle. Although Capellini (1890b) mentioned the presence of the foramen aereum, he did not comment on its size or positioning, and it is not visible in his figures.

Quadratojugal. Capellini (1890b) noted the preservation of the quadratojugal on the left side of the specimen. It has a long contact with both the squamosal and the 
jugal, and forms the posteroventral margin of the infratemporal fenestra. The suture between the quadratojugal and jugal meets the infratemporal fenestra on its lateral margin (approximately halfway along its anteroposterior length). This intersection coincides with the anterior-most point of the quadratojugal and is approximately level with the anterior margin of the supratemporal fenestra. The quadratojugal posteriormost margin is unclear. Capellini (1890b) did not comment on whether a spina quadratojugalis is present, and it is not possible to determine this from his illustrations.

Jugal. The left jugal was almost completely preserved, along with parts of the right element. It extends anteriorly to approximately the same level as the anterior point of the prefrontal. Its lateral surface is relatively smooth posterior to the postorbital bar, but is adorned with pits and grooves anteriorly. The posterior-most point of the jugal terminates at approximately the same level as the posterior margin of the parietal. In lateral view, the ventral margin of the jugal is arched dorsally. The jugal broadens dorsoventrally towards its anterior end so that it is approximately twice the dorsoventral height of the jugal bar at its tallest point midway along the anteroposterior length of the orbit. Poor preservation means that the exact contribution of the jugal to the postorbital bar is unclear; however, anterolateral to the bar, the dorsal edge of the jugal displays a gentle step, resulting in a dorsoventrally higher anterior jugal region. A large foramen is present on the jugal's anterodorsal surface.

Mandibular openings. The mandibular fenestra is preserved on the right side of the skull. It is large and approximately elliptical in shape; its longest axis is orientated posterodorsally-anteroventrally. On the lateral surface of the skull, much of the dorsal and posterior margin is formed by the surangular, the anterior margin by the dentary, and the posteroventral margin by the angular.

Dentary. Only the posterior-most sections of the dentaries are currently preserved; however, the right dentary was once essentially complete. The preserved fragment contains four whole or partial teeth in its anterior end, and one alveolus in the posterior-most position of the tooth row. The teeth are spaced approximately evenly, although there is a very slight trend towards more closely positioned dentition 
posteriorly. The left posterior fragment has four teeth; the anterior two are partial, whereas the posterior two are complete. Interalveolar spacing is approximately homodont. Both preserved fragments increase in dorsoventral height posteriorly. The right dentary fragment forms the anterior margin of the external mandibular fenestra; it meets the angular approximately half-way along the anterodorsal length of this opening. Although no longer preserved, the anterior and middle regions of the dentaries can be viewed in Capellini's (1890b) figures. Dorsoventrally tallest at the level corresponding to the anterior tip of the surangular, the dentary shows a gradual narrowing towards the anterior end of the snout. Anteriorly, the lateral margins are approximately parallel until the level of the $10^{\text {th }}$ tooth, at which point they diverge laterally. In lateral view, it can be seen that the dentary is slightly ventrally bowed along its anteroposterior length. Its surface is covered in small pits, although these are most densely spaced along its ventral margin. When completely preserved, both dentaries had 17 alveoli, with teeth present in all but the $3^{\text {rd }}$ alveolus on the left side, and all except for the $2^{\text {nd }}, 4^{\text {th }}, 9^{\text {th }}$, and $17^{\text {th }}$ alveoli on the right side. Several posterior teeth on the left side were damaged during excavation (Capellini 1890b). The $1^{\text {st }}$ and $4^{\text {th }}$ dentary teeth are the largest. The $2^{\text {nd }}-3^{\text {rd }}$ and $5^{\text {th }}-7^{\text {th }}$ teeth are slightly smaller but are approximately equidimensional to one another; by contrast, the $8^{\text {th }}$ tooth is slightly more robust.

Splenial. The splenial participates in the mandibular symphysis for one third of the symphyseal length (approximately equivalent to 4-5 teeth). Its anterior-most point is approximately equivalent to the $8^{\text {th }}$ dentary tooth. From their anterior-most point, the splenials diverge from one another at an angle of $26^{\circ}$. Though not visible in any figures, Capellini (1890b) noted that the splenials cover a significant part of the medial surface of the dentaries.

Angular. Once preserved fully on the left side and partially on the right (Capellini, $1890 b)$, the angular is now only preserved in its anterior region on the right side of the skull. It extends only slightly anteriorly to the external mandibular fenestra, in which it participates posteroventrally. In lateral view, it forms an anteroventrally directed suture with the dentary, which meets the ventral margin of the mandibular fenestra approximately half-way along its anteroposterior length. Its contact with the 
surangular creates a junction with the mandibular fenestra at the latter's posteriormost point.

Surangular. Although originally preserved in its entirety on the left side of the skull (Capellini, 1890b), the surangular is now best preserved on the right side of the specimen, where it forms almost the entire posterior and dorsal margins of the external mandibular fenestra. The surangular extends anteriorly to the level of the midpoint of the anteroposterior length of the orbit. Its posterior-most point extends to the retroarticular process. A ridge runs posteriorly from the posterodorsal corner of the mandibular fenestra, curving dorsally at the anterior level of the articular.

Articular. Originally preserved in whole on the left side of the specimen, the articular has since been destroyed. However, illustrations in Capellini (1890b) show that it forms the dorsal surface of the retroarticular process.

Dentition. Teeth are weakly striated, with parallel apicobasal ridges and grooves. The anterior and posterior margins are characterised by smooth carinae. In the anterior-middle portion of the snout, the premaxillary, maxillary, and dentary teeth are all mildly recurved; however, in the posterior-most snout region, the teeth are essentially straight. Moreover, the posterior teeth are slightly apicobasally shorter, and their apices blunter. Capellini (1890b) noted that the cross section of the teeth is approximately circular up to and including the $10^{\text {th }}$ dentary tooth; posterior to this, the teeth are: 'compressed into an elliptical shape so that the major axis corresponding to the carinae of the teeth is obliquely directed from the inside to the outside facing backwards' (Capellini, 1890b: p. 22 [translated from the Italian]).

\section{Tomistominae indet.}

(Fig. 15)

1864 Streptospondylus lyceensis Costa: 27, pl 4-6.

1864 Steneosaurus lyceensis Costa: 68. 
1896 Tomistoma lyceense Aldinio: 2, pl. 1, figs 1-2.

Holotype. Fragment of the rostrum from the middle region of the snout, including sections of the maxilla, nasals, and palatines. The holotype specimen can no longer be located; however, a cast is present at the Capellini Museum, in Bologna (MGGC \#2-4511) (Fig. 15).

Locality and horizon. Iola, Lecce, southeastern Italy; Pietra Leccese Limestone; upper Burdigalian to lower Messinian ( 17-7 Ma) (Kotsakis et al. 2004; Mazzei et al. 2009). The Pietra Leccese Formation crops out in the Salentine Peninsula in the Apulia Region of southern Italy, most extensively to the north of the city of Lecce (Mazzei 2009). The formation comprises a homogenous yellow foraminiferal biomicrite containing planktonic foramina (Mazzei 2009). Reaching a maximum thickness of $90 \mathrm{~m}$ in some areas, the Pietra Leccese is interpreted to have been deposited by repeated marine currents that inhibited sediment deposition, and/or eroded previous deposits (Mazzei 2009).

General Preservation. Preservation is poor, especially on the anterodorsal surface of the specimen, where the outer bone has been largely removed. The left dorsolateral region has completely broken off. Despite this, distortion appears to be minimal and so proportions are assumed to be correct.

[Insert Fig. 15 here]

\section{Description of 'Tomistoma lyceense'}

General shape. The specimen comprises approximately $260 \mathrm{~mm}$ of a longirostrine snout from the mid-portion of the rostrum (Fig. 15). Its dorsal surface is mildly convex and is ornamented with shallow pits and ridges. The lateral margins of the snout converge anteriorly for approximately two thirds of the length of the specimen, diverging laterally just posterior to the large anterior maxillary tooth. Two distinct dorsal convexities in the anterior region of the snout correspond to the position of the enlarged anterior-most maxillary teeth, although they are likely exaggerated due to the removal of the outer bone. In lateral view, the dorsal surface of the rostrum is 
essentially straight, sloping towards the anterior end of the snout, such that the dorsoventral height of the rostrum gradually decreases anteriorly. The snout fragment is mediolaterally widest at its posterior end and at the level of the large anterior maxillary teeth. It is narrowest between the second and third alveoli.

Maxilla. The maxillae extend for the entire length of the preserved specimen. They narrow anteriorly until the posterior margin of the large anterior maxillary teeth at which point their mediolateral width increases. The dorsomedial half of the bone slopes very slightly towards the lateral edge of the snout; however, the lateral margins are steeper. At the palatal region, the maxillae are essentially flat. A small groove (approximately $2-4 \mathrm{~mm}$ wide) runs perpendicular to the toothrow on its medial side. It remains $\sim 30 \mathrm{~mm}$ from the lateral margin of the snout along its length and is less deeply incised along its anterior half. Close to the posterior end of the left maxilla, there is a shallow fossa approximately half-way between the medial margin of the alveoli and the lateral margin of the palatine. The left maxilla preserves one tooth and three partial alveoli, and the right preserves six almost complete alveoli. The anterior two teeth are the largest and are approximately the same size, although on both sides of the skull the second alveolus is broken slightly in its lateral region. The middle two alveoli are smaller; however, they are heavily broken, and so their full extent cannot be determined. The diameter of the posterior two alveoli are an intermediate size between the anterior and middle alveoli. All alveoli are elliptical, with the long axis orientated anteromedially. Tooth spacing is approximately homodont.

Nasal. The nasals are anteroposteriorly elongate. Their lateral margins gradually converge towards anteriorly for the entire length of the specimen. A very minor dextral deflection of the nasal bones approximately half-way along the specimen is attributed to a fracture and subsequent reconstruction.

Palatine. The anterior-most $90 \mathrm{~mm}$ of the palatines is preserved at the posterior region of the snout. Each palatine forms an elongate triangular shape, the lateral margins of which diverge at an angle of approximately $30^{\circ}$ from the midline at their anterior-most point. The palatine-maxillary suture is slightly serrated, especially towards its posterior end. 
Dentition. The one remaining tooth protrudes from the maxilla by $\sim 75 \mathrm{~mm}$ and is mildly elliptical at its base $(28 \times 25 \mathrm{~mm})$. Its major axis is directed anteromedially; however, the tooth is posteromedially curved. Overall the tooth is conical, although the apex is slightly blunt. Costa (1848) referred to two carinae running for $51 \mathrm{~mm}$ from the tooth tip, corresponding with the presence of red/yellow enamel. Towards the base of the tooth, Costa (1848) noted a transition to white enamel covered with longitudinal ridges that thinned towards the apex. Finally, Costa (1848) also reported a shallow longitudinal groove on the medial surface of the tooth. Unfortunately, the cast does not preserve the finer scale features of the tooth surface, and so we cannot confirm the presence of these subtle features.

[Insert Tables $1 \& 2$ here]

\section{Comparisons}

\section{Comparisons between the Italian and Maltese tomistomines}

Although similar in overall form, the Italian and Maltese taxa display several clear differences in morphology (Fig. 16). Despite all specimens possessing a longirostrine snout shape and an essentially triangular skull, 'Tomistoma' gaudense differs from the other specimens in that the lateral margins of its snout are far more undulatory in the mid-section of the rostrum, with mediolateral widening corresponding to tooth positionings. Although we acknowledge that this might be emphasized by dorsoventral compression of the skull, the corresponding lateral margins in 'Tomistoma' calaritanum and 'Tomistoma lyceense' are essentially straight (the relevant region is not preserved in Melitosaurus champsoides).

Melitosaurus champsoides and 'Tomistoma' calaritanum share the presence of elongate premaxillae which extend posteriorly to the level of the $3^{\text {rd }}$ maxillary tooth, with the posterior premaxillary processes forming just over a third of the total premaxillary length in both taxa (Fig. 16). Both Melitosaurus champsoides and 'Tomistoma' calaritanum also have 5 premaxillary teeth. In terms of tooth alignment, Melitosaurus champsoides most closely resembles the right side of 'Tomistoma' calaritanum, in which there is a large interalveolar distance between the $3^{\text {rd }}$ and $4^{\text {th }}$ 
alveoli, and all other teeth are approximately evenly spaced. However, on the left side of 'Tomistoma' calaritanum the largest interalveolar distance is between the $2^{\text {nd }}$ and $3^{\text {rd }}$ tooth. We do not see this latter tooth arrangement in any other taxa, and therefore it could be considered as autapomorphic; however, given the fact that it only occurs on one side of the specimen, and tooth spacing/occurrence is known to vary significantly throughout ontogeny (Brochu 1999), it is perhaps not appropriate to consider it as such. As in Melitosaurus champsoides, the $3^{\text {rd }}$ and $4^{\text {th }}$ premaxillary teeth have the largest basal diameter in 'Tomistoma' calaritanum.

The external nares of both Melitosaurus champsoides and 'Tomistoma' calaritanum are similar in their anteroposterior length to mediolateral width ratio (1.1 and 1.2 respectively); however, the naris of 'Tomistoma' calaritanum is significantly larger with respect to the mediolateral snout width at the same level (Fig. 16). In 'Tomistoma' calaritanum, the naris makes up $77 \%$ of the snout width, whereas this contribution is only $50 \%$ in Melitosaurus champsoides.

Both 'Tomistoma' gaudense and 'Tomistoma' calaritanum display long, thin maxillae with a toothrow containing 14 teeth in the former, and 13 (left side) or 14 (right side) in the latter. In all specimens, the nasals are long and (where preserved) are separated from the external naris, terminating at the approximate level of the anterior-most premaxilla-maxilla suture. In both 'Tomistoma' gaudense and 'Tomistoma' calaritanum, the nasals are preserved in their posterior region; they are mediolaterally wider in 'Tomistoma' gaudense. The frontals are anteroposteriorly elongate. with long anterior processes in both 'Tomistoma' calaritanum and 'Tomistoma' gaudense. In both, the frontal extends well beyond the anterior-most point of the prefrontal, although slightly more so in 'Tomistoma' calaritanum, in which it reaches almost to the anterior extent of the lacrimal. This elongation largely results from anteroposteriorly long frontal processes which form just over $50 \%$ of the frontal in both 'Tomistoma' calaritanum and 'Tomistoma' gaudense. Although only present on the left side of 'Tomistoma' gaudense, a small posterior process of the maxilla intrudes between the lacrimal and nasal; this is not seen in 'Tomistoma' calaritanum, in which a long lacrimo-nasal contact is exhibited. 
As depicted by Capellini (1890b), the supratemporal fenestrae in 'Tomistoma' calaritanum are slightly smaller than those in 'Tomistoma' gaudense. A single fenestra forms $\sim 31 \%$ of the total skull table width at the same anteroposterior level and has a length to width ratio of 0.94 in 'Tomistoma' calaritanum. In 'Tomistoma' gaudense, each fenestra forms $36 \%$ of the skull table width and is mediolaterally wider than that of Tomistoma calaritanum, with a length to width ratio of 0.84 . The dentary of Melitosaurus champsoides differs from that of 'Tomistoma' calaritanum in that at the level of the fourth tooth that of the former taxon is significantly dorsoventrally expanded. Although the $1^{\text {st }}$ and $4^{\text {th }}$ dentary teeth are the largest in 'Tomistoma' calaritanum, the dentary appears to gradually increase in dorsoventral height posteriorly rather than dramatically altering its height in correspondence to individual tooth positioning.

Hulke (1870: p. 32) commented on the slight difference in dentition between Melitosaurus champsoides and 'Tomistoma' gaudense, suggesting that the former displays 'stouter, much less sharply pointed, and less tapering' teeth with 'much more finely wrinkled' enamel. However, it is important to note that both the premaxillary and maxillary teeth are largely missing or heavily damaged in Melitosaurus champsoides, and the teeth are mainly only preserved in the dentary, whereas the dentary teeth are largely obscured in 'Tomistoma' gaudense. Furthermore, the anterior snout region of 'Tomistoma' gaudense is not preserved, and so teeth in corresponding positions to those of Melitosaurus champsoides are unknown. It has already been noted that tooth shape in the more complete specimens discussed here varies along the length of the toothrow, and so this difference noted by Hulke (1970) might not be entirely meaningful taxonomically. In 'Tomistoma' calaritanum the largest maxillary tooth is the $5^{\text {th }}$, although the $6^{\text {th }}$ is close in size. In 'Tomistoma' gaudense the $5^{\text {th }}$ maxillary tooth is also large, and the $10^{\text {th }}$ has an almost equal diameter at its base.

Finally, the known skull of 'Tomistoma' gaudense is from a significantly smaller individual than those of Melitosaurus champsoides, 'Tomistoma' calaritanum, and 'Tomistoma lyceense'. Although this variation in size might merely reflect ontogenetic stage, the general proportions are similar between taxa, and thus it is possible that 'Tomistoma' gaudense does represent a smaller-bodied species. 


\section{Comparisons with other crocodylians}

The fragmentary nature of the Italian and Maltese specimens means that comparisons with other taxa are somewhat limited. Comparisons here are predominantly focused on European Miocene crocodylians that preserve the snout (Fig. 16), although some broader comparisons are also discussed.

The longirostrine snout shape displayed by all of the specimens is consistent with tomistomines, although the feature is not restricted to this clade, as it is also present in gavialoids (e.g. Salas-Gismondi et al. 2016). As seen in other members of Tomistominae (e.g. Brochu 2007; Jouve et al. 2015), the lateral snout margins of 'Tomistoma' calaritanum and 'Tomistoma' gaudense converge gradually, such that there is a smooth rostro-cranial transition, contrasting with the typically abrupt rostrocranial transition of gavialoids (e.g. Gavialis). As with many tomistomine taxa (e.g. Tomistoma schlegelii, Thecachampsa, Kentisuchus, and Maroccosuchus zennaroi [e.g. Leidy 1852; Mook 1955; Erickson \& Sawyer 1996; Jouve et al. 2015; Jouve 2016; Weems 2018]), the $5^{\text {th }}$ maxillary tooth is the largest in 'Tomistoma' gaudense and 'Tomistoma' calaritanum. This contrasts with other tomistomines that exhibit alveolar enlargements at the $4^{\text {th }}$ (Gavialosuchus eggenburgensis [Toula \& Kail 1885]), and $7^{\text {th }}$ tooth positions (Toyotamaphimeia machikanensis and Penghusuchus pani [Kobayashi et al. 2006; Shan et al. 2009; lijima \& Kobayashi 2019]), or homodonty ('Tomistoma' cairense [Müller 1927]).

[Insert Fig. 16 here]

In Melitosaurus champsoides and 'Tomistoma' calaritanum the external naris projects dorsally, as is the case in all other tomistomines. The shape and relative dimensions of the external naris in Melitosaurus champsoides are similar to those of 'Tomistoma' lusitanica (Antunes 1961); both are fairly well rounded with a slightly flattened anterior margin, and they display a length/width ratio of just greater than 1.0 (1.13 and 1.38 respectively). 'Tomistoma' calaritanum has a length/width ratio of 1.31. The ratio of naris width to snout width (at the same anteroposterior level) in Melitosaurus champsoides is similar to that of 'Tomistoma' Iusitanica (50\% and $48 \%$ respectively) (Antunes 1961). By contrast, in Gavialosuchus eggenburgensis (Toula 
\& Kail 1885), the condition is similar to 'Tomistoma' calaritanum, in which the naris occupies a much wider area (66\% and $77 \%$ of the snout width, respectively).

The choanae of 'Tomistoma' gaudense are sub-circular, with a modest everted anterolateral margin. This condition is similar to Maroccosuchus zennaroi, Maomingosuchus petrolica, 'Tomistoma' cairense, and Tomistoma schlegelii (Müller 1927; Jouve et al. 2015; and Shan et al. 2017), but contrasts with the subtriangular, anteriorly tapering choanae that characterise Thecachampsa antiqua, Thecachampsa carolinensis, Penghusuchus pani, and 'Tomistoma' lusitanica (e.g. Leidy 1852; Antunes 1961; Erickson \& Sawyer 1996; Shan et al. 2009; Weems 2018).

In dorsal view, the premaxillary processes of Melitosaurus champsoides and 'Tomistoma' calaritanum are moderately anteroposteriorly elongate, extending to just beyond the third maxillary alveolus. This is similar to most other tomistomines, including European and North African taxa such as 'Tomistoma' Iusitanica, Gavialosuchus eggenburgensis, 'Tomistoma' dowsoni, Dollosuchoides densmorei, Maroccosuchus zennaroi, as well as the North American species Thecachampsa antiqua and Thecachampsa carolinensis (Toula \& Kail 1885; Fourtau 1918; Antunes 1961; Erickson \& Sawyer 1996; Brochu 2007; Jouve et al. 2015; Weems 2018), in which the processes extend to either the third or fourth maxillary teeth. In several taxa, such as Toyotamaphimeia machikanensis and Megadontosuchus arduini (Kobayashi et al. 2006; Piras et al. 2007), the premaxillae are even more elongate, extending posteriorly as far as the $5^{\text {th }}$ or $6^{\text {th }}$ maxillary tooth.

The last three premaxillary teeth in both Melitosaurus champsoides and 'Tomistoma' calaritanum form a posteromedial line, a feature also seen in approximately contemporaneous European tomistomines such as Gavialosuchus eggenburgensis and 'Tomistoma' lusitanica (e.g. Toula \& Kail 1885; Antunes 1961) as well as in the North American taxon Thecachampsa (Erickson \& Sawyer 1996; Weems 2018), whereas in most other tomistomines (e.g. Kentisuchus spenceri, Megadontosuchus arduini, Penghusuchus pani, Maroccosuchus zennaroi, Maomingosuchus petrolica) the last three teeth are in a laterally curved row (e.g. Mook 1955; Brochu 2007; Shan et al. 2009; Jouve et al. 2015; Shan et al. 2017; lijima \& Kobayashi 2019). All other 
crocodylians outside of Tomistominae, with the exception of several gavialoids, display a straight or slightly curved alignment (e.g. Jouve 2016).

In Melitosaurus champsoides, and on the right side of the skull of 'Tomistoma' calaritanum, the premaxillary teeth are arranged so that the $1^{\text {st }}, 2^{\text {nd }}$, and $3^{\text {rd }}$ are approximately equally spaced, unlike in almost all tomistomines (excluding Dollosuchoides densmorei [Brochu, 2007]), in which the $2^{\text {nd }}$ tooth is separated from the $1^{\text {st }}$ and is closer to the $3^{\text {rd }}$. On the left side of 'Tomistoma' calaritanum, the teeth are positioned so that the $2^{\text {nd }}$ and $3^{\text {rd }}$ are the most distantly spaced. Melitosaurus champsoides and the left side of the skull of 'Tomistoma' calaritanum retain penultimate and antepenultimate premaxillary teeth that are equal in size. This feature is true of most tomistomines, but not Megadontosuchus arduini, Maroccosuchus zennaroi, or the Asian taxa Toyotamaphimeia machikanensis and Maomingosuchus petrolica (Kobayashi et al. 2006; Piras et al. 2007; Jouve et al. 2015; Shan et al. 2017).

As in most tomistomines (e.g. Gavialosuchus eggenburgensis, 'Tomistoma' Iusitanica, Thecachampsa antiqua, and Thecachampsa carolinensis [Toula \& Kail 1885; Antunes 1961; Erickson \& Sawyer 1996; Weems, 2018]), the nasals are well separated from the naris and contact the premaxillae over a significant distance in Melitosaurus champsoides, 'Tomistoma' calaritanum, and 'Tomistoma' gaudense. By contrast, the nasals contact the naris in Megadontosuchus arduini, Maroccosuchus zennaroi, and Kentisuchus spenceri (Mook, 1955; Piras et al. 2007; Jouve et al. 2015).

Postorbital bars that are 'massive' and anteroposteriorly expanded are plesiomorphic in Crocodylia (Brochu 1997), for example characterising gavialoids. By contrast, most brevirostrines exhibit slender, anteroposteriorly narrow postorbital bars, including several derived European Miocene tomistomines such as Gavialosuchus eggenburgensis and 'Tomistoma' Iusitanica (Toula \& Kail 1885; Antunes 1961). 'Tomistoma' gaudense and 'Tomistoma' calaritanum exhibit the plesiomorphic condition, along with Maroccosuchus zennaroi, Kentisuchus, Dollosuchoides densmorei, Thecachampsa antiqua, Thecachampsa carolinensis, and 
Maomingosuchus petrolica (e.g. Leidy 1852; Mook 1955; Erickson \& Sawyer 1996; Brochu 2007; Jouve et al. 2015; Jouve 2016; Shan et al. 2017, Weems 2018).

The dorsal margins of the orbits are slightly upturned in Melitosaurus champsoides and 'Tomistoma' gaudense, as is the case in almost all tomistomines (e.g. Jouve et al. 2015). The margins are not so extremely telescoped as in some gavialoids (e.g. Brochu 1997).

On the skull table, the frontoparietal suture is essentially straight in both 'Tomistoma' gaudense and 'Tomistoma' calaritanum. This feature varies throughout Tomistominae (e.g. Jouve et al. 2015), although a linear suture, such as that present in the taxa described here, is also present in forms such as Tomistoma schlegelii and 'Tomistoma' Iusitanica (Antunes 1961). Concavo-convex sutures can be observed in Eocene tomistomines such as Kentisuchus and Maroccosuchus zennaroi (Mook 1955; Jouve et al. 2015; Jouve 2016), as well as the Oligocene and Miocene taxa Thecachampsa carolinensis, Thecachampsa antiqua, and 'Tomistoma' coppensi (Pickford 1994; Erickson \& Sawyer 1996; Weems 2018).

As is the case with all European and North African tomistomines, with the exception of Dollosuchoides densmorei (e.g. Brochu 2007; Jouve et al. 2015), the anterior tip of the frontal forms a simple, acute point in both 'Tomistoma' calaritanum and 'Tomistoma' gaudense. In both of these latter taxa, this acute frontal tip extends well beyond the anterior point of the prefrontal, as is the case in 'Tomistoma' lusitanica, Paratomistoma courti, and Megadontosuchus arduini (Antunes 1961; Brochu \& Gingerich 2000; Piras et al. 2007), as well as Thecachampsa antiqua and Thecachampsa carolinensis (Erickson \& Sawyer 1996; Weems 2018). This is not the case in all tomistomine taxa, e.g. 'Tomistoma' cairense (Muller 1927), in which the anterior tip of the frontal does not even extend beyond the anterior margin of the orbit. Taxa such as Kentisuchus, 'Tomistoma' coppensi, Penghusuchus pani, and Dollosuchoides densmorei (Mook 1955; Pickford 1994; Brochu 2007; Shan et al. 2009; Jouve 2016), also exhibit anteroposteriorly short frontal processes.

As exhibited in all tomistomines except Penghusuchus pani (Shan et al. 2009), 'Tomistoma' calaritanum and 'Tomistoma' gaudense both possess a lacrimal that 
terminates more anteriorly than the prefrontal. In these latter two taxa, the maxilla sends a process between the lacrimal and the nasal, although this is only present on the left side of 'Tomistoma' gaudense. This is also present in Gavialosuchus eggenburgensis (Toula \& Kail 1885). By contrast, this process protrudes into the anterior lacrimal margin in Tomistoma schlegelii, Maroccosuchus zennaroi, Kentisuchus, and Thecachampsa antiqua (Leidy 1852; Mook 1955; Jouve et al. 2015; Jouve 2016), and is absent altogether in other tomistomines (e.g. 'Tomistoma' Iusitanica, 'Tomistoma' cairense, Maomingosuchus petrolica, and Paratomistoma courti [Müller 1927; Antunes 1961; Brochu \& Gingerich 2000; Shan et al. 2017]). A long lacrimonasal contact is still present in 'Tomistoma' gaudense and 'Tomistoma' calaritanum despite the intrusion of the maxilla.

The lacrimal is approximately twice as wide as the prefrontal in both 'Tomistoma' calaritanum and 'Tomistoma' gaudense. This is the case in the majority of the derived European forms, such as 'Tomistoma' Iusitanica and Gavialosuchus eggenburgensis (Toula \& Kail 1885; Antunes 1961), but also characterizes Maroccosuchus zennorai, Thecachampsa antiqua, Thecachampsa carolinensis, and Tomistoma schlegelii (e.g. Erickson \& Sawyer 1996; Jouve et al. 2015; Weems 2018). In most other tomistomine taxa, the lacrimal is mediolaterally narrower relative to the prefrontal (e.g. Jouve et al. 2015).

In 'Tomistoma' calaritanum and 'Tomistoma' gaudense, the dorsal margin of the jugal forming the ventral orbital margin exhibits a small step, similar to Gavialosuchus eggenburgensis and Thecachampsa antiqua among other tomistomines (Leidy 1852; Toula \& Kail 1885). By contrast, the dorsal jugal margin slopes posteroventrally without a step in all other tomistomines where known, similar to all other crocodyloids (e.g. Jouve et al. 2015).

The interfenestral bars of both 'Tomistoma' calaritanum and 'Tomistoma' gaudense are narrow (especially in the latter), forming only one quarter and one tenth of the mediolateral width of the supratemporal fenestra, respectively. This especially narrow morphology observed in 'Tomistoma' gaudense is otherwise known only in 'Tomistoma' lusitanica, Gavialosuchus eggenburgensis, and Thecachampsa antiqua (Toula \& Kail 1885; Antunes 1961; Myrick 2001). In most other tomistomines, e.g. 
Maroccosuchus zennaroi, Megadontosuchus arduini, and Tomistoma schlegelii, the interfenestral bars are more mediolaterally enlarged (Piras et al. 2007; Jouve et al. 2015).

The dorsally notched supraoccipital that characterises 'Tomistoma' gaudense is shared by Tomistoma schlegelii, 'Tomistoma; cairense, and Kentisuchus spenceri (Müller 1927; Mook 1955). This notch is absent in Maroccosuchus zennaroi, Maomingosuchus petrolica, 'Tomistoma' dowsoni, 'Tomistoma' Iusitanica, Gavialosuchus eggenburgensis, Thecachampsa, and Toyotamaphimeia machikanensis (e.g. Leidy 1852; Toula \& Kail 1885; Fourtau 1918; Antunes 1961; Erickson \& Sawyer 1996; Kobayashi et al. 2006; Jouve et al. 2015; Shan et al. 2017).

In 'Tomistoma' calaritanum and 'Tomistoma' gaudense, the splenial participates in the mandibular symphysis over the length of four to five teeth. This is similar to 'Tomistoma' lusitanica, 'Tomistoma' coppensi, Maroccosuchus zennaroi, Kentisuchus spenceri, Dollosuchoides densmorei, and Maomingosuchus petrolica (Mook 1955; Antunes 1961; Pickford 1994; Brochu 2007; Jouve et al. 2015; Shan et al. 2017). The participation of the splenial in the mandibular symphysis is greater in Toyotamaphimeia machikanensis, Penghusuchus pani, Thecachampsa, Tomistoma schlegelii, and 'Tomistoma' cairense, reaching the level of five to seven teeth (Müller 1927; Erickson \& Sawyer 1996; Shan et al. 2009; Weems 2018; lijima \& Kobayashi 2019).

\section{Taxonomic status of additional materials referred to the Italian and Maltese taxa}

Multiple crocodylian occurrences from the Miocene of southern Europe have been tentatively attributed to 'Tomistoma' calaritanum, consisting of isolated teeth and fragmentary postcranial remains (e.g. Zbyszewski 1949; see reviews in Kotsakis et al. 2004 and Zoboli et al. 2019). Nearly all of these are from Italy and have since been identified either as indeterminate crocodylians or referred to as cf. Tomistoma sp. (Kotsakis et al. 2004; Delfino \& Ragazini 2010; Zoboli et al. 2019), with which we 
agree. However, remains from Portugal attributed to 'Tomistoma' calaritanum by Zbyszewski (1949) have yet to be reviewed. These remains consist of several teeth, two of which are figured (Zbyszewski 1949: pl. XXII, figs $153 \& 160$ ), from the Burdigalian of Lisbon. The teeth are conical and recurved, with apicobasally oriented striations. At their base they are almost circular. Zbyszewski (1949 p. 67 [translated from the French]) noted that 'teeth with a more deteriorated surface have a series of longitudinal grooves which can be more or less well marked'. Due to apparent differences with the tooth morphology of Melitosaurus champsoides, 'Tomistoma' gaudense, and 'Tomistoma' Iusitanica, and their 'extremely close' resemblance to 'Tomistoma' calaritanum, Zbyszewski (1949) referred them to the latter taxon. However, owing to the absence of any diagnostic characters associated with tomistomines, we refer the teeth to Crocodylia indet.

In addition, a poorly preserved partial rostrum (HLMD V-4001) from the Burdigalian of southern Germany was referred by Rossmann et al. (1999) to Gavialosuchus cf. gaudensis (note that there was no explanation for this new taxonomic combination). Rossmann (1999 p. 323) described how: 'all bones are broken in several places and weathered externally, so that the dorsal surface of the rostrum maxillae is crushed and not sculptured. Therefore, sutures are not easily identifiable'. The specimen is clearly longirostrine and, as in 'Tomistoma' calaritanum and Melitosaurus champsoides, the lateral margins of the snout region are straight, except for a slight constriction at the premaxilla-maxilla boundary. Although heavily damaged, the dorsally projecting external naris is entirely surrounded by the premaxillae, and is separated from the nasals, as is the case throughout Tomistominae (e.g. Jouve et al. 2015). The total number of teeth in both the premaxillae and maxillae is unknown in HLMD V-4001; however at least eight teeth are present on the left maxilla. Of the teeth that are preserved, the $2^{\text {nd }}$ to $5^{\text {th }}$ are the largest, having a mediolateral alveolar width of $14 \mathrm{~mm}$ (Rossmann et al. 1999); however, the posterior teeth are only very slightly smaller ( $13 \mathrm{~mm}$ and $12 \mathrm{~mm}$ for the $7^{\text {th }}$ and $8^{\text {th }}$ teeth respectively). This differs from 'Tomistoma' calaritanum and 'Tomistoma' gaudense, in which the fifth tooth is significantly larger than those anterior to it. Furthermore, HLMD V-4001 differs notably from the Italian and Maltese specimens in that the maxillary teeth are closely spaced: 'The interdenticular distances between the teeth are smaller than the mesiodistal length of their alveoli' (Rossman et al. 1999: p. 324). We find no 
autapomorphies or combination of features that warrant the assignment of this specimen to any of the Italian or Maltese taxa, and instead allocate HLMD V-4001 to Tomistominae indet.

\section{Phylogenetic analysis and results}

\section{Material and methods}

We incorporated the type specimens of Melitosaurus champsoides, 'Tomistoma' calaritanum, and 'Tomistoma' gaudense into a revised version of the data matrix presented by Jouve (2016). This matrix is derived from previous matrices (e.g. Brochu 1999; Jouve et al. 2015) and is composed of an extensive sample of taxa from throughout the crocodylian tree (including most tomistomines), with Bernissartia fagesii as the outgroup taxon. Characters 7, 42, 46, 64, 68, 71, 75, 124, 145, 151, 161, 177, 238 were modified, and one new character (244) was added (see Appendix A). Following other recent approaches to resolving crocodylian phylogenetic relationships (Groh et al. 2020; Rio et al. 2020), multistate characters were also re-evaluated, and 31 were ordered $(7,30,37,62,64,75,78,81,87,91$, $95,103,124,131,145,151,152,153,156,161,169,171,173,174,176,177,179$, 194, 195, 206, 238). We were able to score Melitosaurus champsoides for 27 characters $(11 \%)$, 'Tomistoma' calaritanum for 95 characters $(39 \%)$, and 'Tomistoma' gaudense for 83 characters (34\%). The updated dataset is provided as both a nexus and TNT file in the electronic supplementary material, alongside the full modified character list.

The data matrix was analysed under maximum parsimony using the 'Stabilize Consensus' option in the 'New Technology Search' in TNT vs. 1.5 (Goloboff, Farris \& Nixon 2008). The search was executed using sectorial searches, drift, and tree fusing, and the consensus was stabilized five times, prior to using the resultant trees as the starting trees for a 'Traditional Search' using Tree Bisection-Reconstruction. To compare the effect of weighting on tree topology, we used four different weighting schemes: equal weighting, extended implied weighting with a $k$-value of 4 , extended implied weighting with a $k$-value of 8 , and extended implied weighting with a $k$-value of 12. Developed by Goloboff (2014), extended implied weighting downweights 
characters in relation to their average homoplasy whilst minimizing the potential impact of missing data. Lower $k$-values have been shown to downweight homoplastic characters more severely than higher values (Goloboff et al. 2017). The three k-values were selected following Rio et al. (2020) and Groh et al. (2020). Although the data matrix includes other crocodylians, we only present results pertaining to Tomistominae (Table 3).

[Insert Table 3 here]

\section{Analyses including all three taxa}

Run under equal weighting and with the inclusion of all three Italian and Maltese taxa, the analysis produces a consensus tree in which Tomistominae is poorly resolved (Fig. 17A); however, two clades are recovered. The first shows Thecachampsa to be the sister taxon to two tomistomines from Asia (Toyotamaphimeia machikanensis + Penghusuchus pani), with Dollosuchoides densmorei the closest relative to this group. The second clade is formed of European Miocene taxa ('Tomistoma' calaritanum, 'Tomistoma' gaudense, Melitosaurus champsoides, 'Tomistoma' Iusitanica, and Gavialosuchus eggenburgensis), plus 'Tomistoma' cairense, Paratomistoma courti, Tomistoma schlegelii, 'Tomistoma' coppensi, and Maomingosuchus petrolica; however, these taxa form a polytomy. The relationships between the stratigraphically earliest taxa (Maroccosuchus zennaroi, Megadontosuchus arduini, and Kentisuchus) remain unclear.

When run under extended implied weighting ( $k=4, k=8, k=12)$, all analyses recover the same overall tree topology (Fig. 18A). Here, Maroccosuchus zennaroi + Kentisuchus forms the earliest diverging tomistomine clade, with Megadontosuchus arduini recovered as the sister taxon to all remaining tomistomines. The latter are split into two main clades. The first consists of Dollosuchoides densmorei as the sister taxon to a clade comprising Thecachampsa + (Penghusuchus pani + Toyotamaphimeia machikanensis). As with the analysis run using equal weights, resolution in the second clade is poor, and a polytomy of seven taxa is formed, containing 'Tomistoma' calaritanum, 'Tomistoma' gaudense, Melitosaurus champsoides, 'Tomistoma' Iusitanica, 'Tomistoma' coppensi, Gavialosuchus eggenburgensis, and Tomistoma schlegelii. This polytomy forms the sister taxon to a 
clade comprising Maomingosuchus petrolica and Paratomistoma courti, with 'Tomistoma' cairense recovered as the most 'basal' member of this second tomistomine clade (Fig. 18A).

\section{Analyses pruning Melitosaurus champsoides}

When Melitosaurus champsoides is pruned a posteriori under equal weights and extended implied weighting (under all three $k$-values), the large polytomy containing European Miocene taxa is largely resolved (Figs 17B, 18B). 'Tomistoma' calaritanum and 'Tomistoma' gaudense are recovered as sister taxa, with Gavialosuchus eggenburgensis as their closest relative, and 'Tomistoma' lusitanica as the sister taxon to this clade (Figs 17B, 18B). Tomistoma schlegelii is recovered as the sister taxon to this European clade.

\section{Analyses including only Melitosaurus champsoides}

To attempt to resolve the position of Melitosaurus champsoides, we re-ran our analyses with 'Tomistoma' calaritanum and 'Tomistoma' gaudense excluded a priori. In all analyses in which only Melitosaurus champsoides is included as an operational taxonomic unit (OTU), this taxon is found to be deeply nested within Tomistominae, as the sister taxon to 'Tomistoma' Iusitanica (Figs 17C, 18C,D) (Table 3). These two taxa form a poorly supported clade with Gavialosuchus eggenburgensis (Bremer value $=1$ under equal weighting). When using equal weights, Tomistoma schlegelii and 'Tomistoma' cairense are recovered as successive sister taxa to this European clade (Fig. 17C). Using extended implied weighting with $k$-values of 8 and 12 , 'Tomistoma' cairense forms the sister taxon to this group (Fig. 18C); however, with a $k$-value of 4 , Tomistoma schlegelii is found to be most closely related to this clade instead (Fig. 18D).

\section{Discussion}

\section{Phylogenetic relationships of the Italian and Maltese tomistomines}


The overall topology is largely consistent between the different versions of our analyses and with those of previous studies based on this dataset (e.g. Jouve et al. 2015; Jouve 2016). As such, our use of different weightings, ordering of characters, and character revisions, has little overall impact on tomistomine interrelationships, although there are two notable exceptions. Firstly, the 'base' of the clade alters in its topology; whereas equal weighting of characters recovers a polytomy with no resolution amongst the stratigraphically earliest tomistomines (Fig. 17), extended implied weighting places Kentisuchus + Maroccosuchus as the sister taxon to all other tomistomines (Fig. 18). Secondly, when Melitosaurus champsoides is added as the sole new OTU, the topology amongst the most derived tomistomines changes depending on the weighting scheme applied. With equal weighting (Fig. 17C) and extended implied weighting values of $k=8$ and $k=12$ (Fig. 18C), 'Tomistoma' cairense shifts from an early-diverging to a more nested position. This placement is inconsistent with all other analyses in this study run under extended implied weighting, including those with all taxa included (Fig. 18A), those in which Melitosaurus champsoides is not included (Fig. 18B), and analyses run using extended implied weighting with a $k$-value of 4 (Fig. 18D). The nested placement of the middle Eocene species 'Tomistoma' cairense is less stratigraphically congruent than those analyses which find it to be an earlier-diverging tomistomine.

Anatomical comparisons and phylogenetic analyses both provide support for the inclusion of Melitosaurus champsoides, 'Tomistoma' calaritanum, and 'Tomistoma' gaudense within Tomistominae. The nested position of these taxa within Tomistominae is supported by several morphological features, including: (1) a posterior maxillary process between the lacrimal and nasal (preserved in all three taxa); (2) large supratemporal fenestrae that are wider than long (preserved in 'Tomistoma' calaritanum and 'Tomistoma' gaudense); and (3) the posteromedial alignment of the last three premaxillary teeth (preserved in Melitosaurus champsoides and 'Tomistoma' calaritanum). These three features are also observed in the European Miocene taxa Gavialosuchus eggenburgensis and 'Tomistoma' Iusitanica, which are recovered as the closest relatives to the Italian and Maltese taxa in all of our analyses. By contrast, these features are absent in earlier diverging tomistomines, such as Kentisuchus astrei and Maroccosuchus zennaroi (Jouve et al. 2015; Jouve 2016). 
In all analyses in which all three of Melitosaurus champsoides, 'Tomistoma' calaritanum, and 'Tomistoma' gaudense were included, these taxa are recovered in a large polytomy with other tomistomines (Figs 17A, 18A). However, via pruning in TNT, all three taxa are recovered in similar positions, with Melitosaurus champsoides as the sister taxon of 'Tomistoma' lusitanica, and 'Tomistoma' calaritanum + 'Tomistoma' gaudense forming a sister taxon relationship with Gavialosuchus eggenburgensis (Figs 17B,C, 18B-D).

Although poor resolution results from the incorporation of both Melitosaurus champsoides and 'Tomistoma' calaritanum in the same analysis, both taxa are consistently recovered as derived tomistomines, and are clearly similar in morphology. Twenty-five characters overlap in both taxa, all of which receive the same score. After removing characters undiagnostic of tomistomines, and those that show irrelevant variation in their scores (e.g. due to a local autapomorphy), only characters 191 and 192 appear to be particularly informative; however, on their own, these are insufficient to justify the synonymy of Melitosaurus champsoides and 'Tomistoma' calaritanum. Furthermore, both taxa differ in features not captured by characters included in our matrix: (1) the external naris of 'Tomistoma' calaritanum is considerably larger with respect to the surrounding snout width than that of Melitosaurus champsoides; (2) the dentary of Melitosaurus champsoides is dorsoventrally expanded at the level of the $4^{\text {th }}$ tooth, whereas in 'Tomistoma' calaritanum the dorsoventral height of the dentary increases gradually towards the posterior; and (3) on the left premaxilla of 'Tomistoma' calaritanum the largest interalveolar distance is between the $2^{\text {nd }}$ and $3^{\text {rd }}$ teeth, whereas in Melitosaurus champsoides it is between the $3^{\text {rd }}$ and $4^{\text {th }}$ teeth. When added to the analyses independently, Melitosaurus champsoides is recovered under all weightings as the sister taxon to 'Tomistoma' Iusitanica (Figs 17C, 18C,D). Although 'Tomistoma' calaritanum is also found to be closely related to 'Tomistoma' lusitanica, it instead forms a closer relationship with Gavialosuchus eggenburgensis (Figs 17B, 18B). Finally, although both specimens were recovered from the same geographically small region, they are separated temporally: Melitosaurus champsoides is middlelate Burdigalian in age (19-16 Ma), whereas 'Tomistoma' calaritanum is from the late Tortonian to early Messinian (10-7 Ma). 
Despite limited anatomical overlap, nine characters can be scored for both Melitosaurus champsoides and 'Tomistoma' gaudense. None of these characters are particularly informative given that most tomistomines share the same scores. A clear difference between the two taxa concerns the rostrum of 'Tomistoma' gaudense being mediolaterally broader with respect to its dorsoventral height; however, as already discussed, this might have been accentuated by dorsoventral crushing. A second possible difference pertains to the premaxillary processes: these seem to extend slightly more posteriorly in Melitosaurus champsoides, although the relevant region is heavily damaged in 'Tomistoma' gaudense. These subtle differences in morphology are perhaps not enough to confirm that Melitosaurus champsoides and 'Tomistoma' gaudense are distinct from one another. Our phylogenetic analyses do not fully resolve this issue either, but suggest that Melitosaurus champsoides is most closely related to 'Tomistoma' Iusitanica (Figs 17C, 18C,D), whereas 'Tomistoma' gaudense is more closely related to Gavialosuchus eggenburgensis (Figs 17B, 18B). Given that the two taxa are both from the same geographic region (the Maltese island of Gozo) and approximately the same stratigraphic age (middle-upper Burdigalian), it might be reasonable to assume that they are synonymous. However, given their incompleteness, subtle anatomical variation, clear body size differences, and uncertainty pertaining to their phylogenetic interrelationships, we contend that there is currently insufficient information to warrant their synonymisation.

As a result of their recovered sister taxon relationship once Melitosaurus champsoides is pruned (Figs 17B, 18B), further consideration is necessary to determine whether 'Tomistoma' calaritanum and 'Tomistoma' gaudense represent distinct taxa. Of the 53 overlapping characters for which they can both be scored, all but four receive the same score. These relate to the following features: (i) contact of the lacrimal and nasal (C93); (ii) depression of the skull table (C123); (iii) width of the interorbital distance (C177); and (iv) the relative sizes of the orbit and supratemporal fenestra (C244). The first of these characters (C93) is polymorphic in 'Tomistoma' gaudense (scores of ' 0 ' and ' 3 ') because of asymmetry, whereas it is scored as ' 3 ' in 'Tomistoma' calaritanum. Given the variation in the remaining three character scores, and numerous additional differences in morphology that are not captured in existing characters (e.g. relative size and shape of the supratemporal fenestra, 
extent of festooning on the lateral snout margins, and size of the prefrontals), 'Tomistoma' calaritanum can be clearly distinguished from 'Tomistoma' gaudense. Finally, the two taxa are separated temporally, with 'Tomistoma' gaudense from the early Miocene ( 19-16 Ma) and 'Tomistoma' calaritanum from the late Miocene ( 10-7 Ma). As such, we regard them as distinct, albeit closely related, taxa.

\section{Systematics and evolution of the Miocene European tomistomines}

Revision of the Italian and Maltese Miocene tomistomines demonstrates their close relationship with other contemporaneous European taxa. This re-evaluation suggests that Melitosaurus champsoides is most closely related to the Portuguese species 'Tomistoma' lusitanica, whereas 'Tomistoma' calaritanum and 'Tomistoma' gaudense form a clade with Gavialosuchus eggenburgensis, known from Austria. The extant (and type) species of Tomistoma ( $T$. schlegelii) is recovered as the sister taxon to this European clade in most of our topologies. As such, either all of these European species should be assigned to Tomistoma, or none of them belong to this genus. However, pending a much-needed revision of Gavialosuchus eggenburgensis and 'Tomistoma' Iusitanica, each known from a complete skull (Toula \& Kail 1885; Antunes 1961), as well as additional undescribed contemporaneous European remains (e.g. Delfino et al. 2003), we consider any further taxonomic revisions premature and retain these 'Tomistoma' species in open nomenclature. It also remains possible that some of the Italian and Maltese taxa are synonymous with these two species. One hypothesis to be tested is that these five European species represent one or two genera, with Melitosaurus having priority. It could be that 'Tomistoma' Iusitanica is a second species of Melitosaurus, whereas 'Tomistoma' calaritanum and 'Tomistoma' gaudense are additional species of Gavialosuchus (Fig. 19).

Regardless of taxonomy, our study demonstrates the presence of a clade of tomistomines throughout the Miocene of the northern Mediterranean region, with evidence for more than one contemporaneous species at least during some of this time interval (Fig. 19). However, as with other crocodylians in this region, Mediterranean tomistomines appear to have declined in the latest Miocene and were extirpated prior to the Pliocene (Kotsakis et al. 2004; Delfino et al. 2007; Delfino \& Rossi 2013). 


\section{Conclusions}

Several fragmentary and historically neglected tomistomine taxa from the Miocene of Italy and Malta are re-evaluated to determine their taxonomy and phylogenetic affinities. Our revision recognises the presence of three distinct species. Whereas one of these already has an available genus name (Melitosaurus champsoides), the other two are currently included as species of Tomistoma ( $T$. calaritanum and $T$. gaudense). Given that these three species appear to be most closely related to other Miocene European taxa (Gavialosuchus eggenburgensis and 'Tomistoma' Iusitanica) in need of re-evaluation, we refrain from further taxonomic revision. However, it is possible that all of these species can be classified under Melitosaurus and Gavialosuchus, and it seems unlikely that any of them are referable to Tomistoma.

\section{Acknowledgements}

We would like to thank Paul Barrett, Susannah Maidment, and Sandra Chapman for providing access to crocodylian material in the NHMUK, as well as John Borg (NMNH, Malta) for providing additional photographs of Tomistoma gaudense, and for hosting C.S.C.N in the NMNH collections. Daniel Zoboli kindly provided access to the manuscript of Capellini (1890b) and provided the photographs used in Figs 5, 12 , and 13. We are also grateful to Alessandro Chiarenza for helping with the translation of Capellini (1890b) and Sebastian Groh for providing several photographs of crocodylian specimens. Comments by Evan Whiting and an anonymous reviewer improved an earlier version of this manuscript, and we gratefully acknowledge the Willi Hennig Society, which has sponsored the development and free distribution of TNT. C.S.C.N. is funded by a Royal Society grant (RGF\R1\180020) awarded to P.D.M. J.P.R. is funded by a NERC PhD studentship. P.D.M.'s research is supported by a Royal Society University Research Fellowship (UF160216) and an additional Royal Society grant (RGFIEAl201037). M.D.'s research is supported by Fondi di Ateneo dell'Università di Torino (2019-2020), Generalitat de Catalunya (CERCA Program), and Spanish Agencia Estatal de Investigación (CGL2016-76431-P, AEI/FEDER, EU). 


\section{References}

Agrasar, E. L. 2004. Crocodile remains from the Burdigalian (lower Miocene) of Gebel Zelten (Libya). Geodiversitas, 26, 309-321.

Aldinio, P. 1896. Sul Tomistoma (Gavialosuchus) lyceensis del calcare miocenico di Lecce. Atti dell'Accademia Gioenia di Scienze Naturali in Catania, Serie 4, 9, 1-11.

Antunes, M.T. 1961. Tomistoma lusitanica, crocodilien du Miocéne du Portugal. Revista da Facultade de Ciências Universidad de Lisbõa, 9, 3-88.

Baldassini, N. \& Di Stefano, A. 2017. Stratigraphic features of the Maltese Archipelago: a synthesis. Natural Hazards, 86, 203-231. doi: 10.1007/s11069-0162334-9

Benton, M. J. \& Clark, J. M. 1988. Archosaur phylogeny and the relationships of the Crocodilia. Pp. 295-338 in M. J. Benton (ed.) The phylogeny and classification of tetrapods. Volume 1, Systematics association special volume no. 35A Amphibians, reptiles, birds. Clarendon Press Oxford, UK.

\section{Bezuijen, M. R., Shwedick, B. M., Sommerlad, R., Stevenson, C. \& Steubing, R.} B. 2010. Tomistoma Tomistoma schlegelii. Pp. 133-138 in S. C. Manolis \& C. Stevenson (eds) Crocodiles. Status Survey and Conservation Action Plan. Third Edition, Crocodile Specialist Group, Darwin.

Bianucci, G., Gatt, M., Catanzariti, R., Sorbi, S., Bonavia, C. G., Curmi, R. \& Varola, A. 2011. Systematics, biostratigraphy and evolutionary pattern of the OligoMiocene marine mammals from the Maltese Islands. Geobios, 44, 549-585. doi: 10.1016/j.geobios.2011.02.009 
Brochu, C. A. 1999. Phylogenetics, taxonomy, and historical biogeography of Alligatoroidea. Journal of Vertebrate Paleontology, Memoir 6, 9-100. doi: $10.1080 / 02724634.1999 .10011201$

Brochu, C. A. 2000. Phylogenetic relationships and timing of Crocodylus based on morphology and fossil record. Copeia, 46, 657-673.

Brochu, C. A. 2007. Systematics and taxonomy of Eocene tomistomine crocodylians from Britain and northern Europe. Palaeontology, 50, 917-928. doi: 10.1111/j.1475-4983.2007.00679.x

Brochu, C. A. \& Gingerich P. D. 2000. New tomistomine crocodylian from the Middle Eocene (Bartonien of Wadi Hitan, Fayum Province, Egypt). Contribution from the Museum of Paleontology, University of Michigan, 30, 251-268.

Capellini, G. 1890a. Sul coccodrilliano garialoide (Tomistoma calaritanus) scoperto nella collina di Cagliari nel 1868. Rendiconti della Reale Accademia dei Lincei, serie $4,6,149-151$.

Capellini, G. 1890b. Sul coccodrilliano garialoide (Tomistoma calaritanus) scoperto nella collina di Cagliari nel MDCCCLXVIII. Atti della Reale Accademia Lincei, Memorie della Classe di Scienze Fisiche, Matematiche e Naturali, serie 4, 6, 507533.

Capellini, G. 1897. A proposito di Tomistoma lyceensis. Rivista Italiana di Paleontologia, 3, 18-20.

Cherchi, A. 1974. Appunti biostratigrafici sul Miocene della Sardegna (Italia). Mémoires du BRGM, 78 (1), 433-445.

Costa, O. G. 1848. Paleontologia del regno di Napoli. Parte I. Tramater, Napoli, 203 pp.

Atti Accademia Pontaniana 
Costa, O. G. 1854. Cenni intorno alle scoperte fatte nel Regno riguardanti la paleontologia nel corso dell'anno 1853. Rend. Accademia Pontaniana, 2 (1), pp. 1 26

Costa, O. G. 1864. Paleontologia del regno di Napoli. III. Atti Accademia Pontaniana, 8, pp. 1-198

Delfino, M. \& Ragazzini, S. 2010. Fossil amphibians and reptiles from Abruzzi and Molise: old data and new evidences. Pp. 515-519 in L. Di Tizio, A. R. Di Cerbo, N. Di Francesco \& A. Cameli (eds) Proceedings VIII Congresso Nazionale Societas Herpetologica Italica, lanieri Edizioni, Pescara, 584 pp.

Delfino, M. \& Rossi, M. A. 2013. Fossil crocodylid remains from Scontrone (Tortonian, Southern Italy) and the late Neogene Mediterranean biogeography of crocodylians. Geobios, 46, 25-31. doi: 10.1016/j.geobios.2012.10.006

Delfino, M., Pacini, M., Varola, A., \& Rook, L. 2003. The crocodiles of the "Pietra Leccese" (Miocene of southern Italy). P. 18 in Abstracts of 1st Meeting of the European Association of Vertebrate Palaeontologists, Basel.

Delfino, M., Böhme, M. \& Rook, L. 2007. First European evidence for transcontinental dispersal of Crocodylus (late Neogene of southern Italy). Zoological Journal of the Linnean Society, 149, 293-307. doi: 10.1111/j.10963642.2007.00248.x

Gandolfi, R. \& Porcu, A. 1967. Contributo alla conoscenza delle microfacies mioceniche delle colline di Cagliari (Sardegna). Rivista Italiana di Paleontologia e Stratigrafia, 73, 313-348.

Gennari, P. 1868. Di un coccodrillo fossile nel terreno pliocenico di Cagliari. Atti della Regia Accademia dei Fisiocritici di Siena, serie 2, 5, 127-130. 
Groh, S. S., Upchurch, P., Barrett, P. M. \& Day, J. J. 2020. The phylogenetic relationships of neosuchian crocodiles and their implications for the convergent evolution of the longirostrine condition. Zoological Journal of the Linnean Society , 188, 473-506. doi: 10.1093/zoolinnean/zlz117

Gruszczyński, M., Marshall, J. D., Goldring, R., Coleman, M. L., Małkowski, K., Gaździcka, E., Semil, J. \& Gatt, P. 2008. Hiatal surfaces from the Miocene Globigerina Limestone Formation of Malta: biostratigraphy, sedimentology, trace fossils and early diagenesis. Palaeogeography, Palaeoclimatology, Palaeoecology, 270, 239-251. doi: 10.1016/j.palaeo.2008.01.035

Hulke, J. W. 1871. Note on some reptillian fossils from Gozo. Quarterly Journal of the Geological Society, 27, 29-33.

lijima, M. \& Kobayashi, Y. 2019. Mosaic nature in the skeleton of East Asian crocodylians fills the morphological gap between "Tomistominae" and Gavialinae. Cladistics, 35, 623-632. doi: 10.1111/cla.12372

Jouve, S., Bouya, B., Amaghzaz, M. \& Meslouh, S. 2015. Maroccosuchus zennaroi (Crocodylia: Tomistominae) from the Eocene of Morocco: phylogenetic and palaeobiogeographical implications of the basalmost tomistomine. Journal of Systematic Palaeontology, 13, 421-445. doi: 10.1080/14772019.2014.913078

Jouve, S. 2016. A new basal tomistomine (Crocodylia, Crocodyloidea) from Issel (Middle Eocene; France): palaeobiogeography of basal tomistomines and palaeogeographic consequences. Zoological Journal of the Linnean Society, 177: 165-182. doi: 10.1111/zoj.12357

Kobatake, N., Chiji, M., Ikebe, N., Ishida, S., Kamei, T., Nakaseko, K. \& Matsumoto, E. 1965. Discovery of crocodile fossil from the Osaka Group. The Quaternary Research (Daiyonki-Kenkyu), 4, 49-58. 
Kotsakis, T., Delfino, M. \& Piras, P. 2004. Italian Cenozoic crocodilians: taxa, timing and palaeobiogeographic implications. Palaeogeography, Palaeoclimatology, Palaeoecology, 210, 67-87. doi: 10.1016/j.palaeo.2004.03.013

Leidy, J. 1852. Description of a new species of crocodile from the Miocene of Virginia. Journal of the Academy of Natural Sciences of Philadelphia. 2, 135-138.

Leone, F., Pontillo, C., Spano, C., Carmignani, L. \& Sassi, F.P. 1992. Benthic paleocommunities of the middle-upper Miocene lithostratigraphic units from the Cagliari hills (Southern Sardinia, Italy). Contribution to the Geology of Italy with Special Regard to the Paleozoic Basement. IGCP Project, 276, 151-158.

Lydekker, R. 1886. Indian Tertiary and post-Tertiary Vertebrata: Siwalik Crocodilia, Lacertilia, and Ophidia. Palaeontologica Indica, Series 10, 3, 209-240.

Mannion, P. D., Chiarenza, A. A., Godoy, P. L. \& Cheah, Y. N. 2019.

Spatiotemporal sampling patterns in the 230 million year fossil record of terrestrial crocodylomorphs and their impact on diversity. Palaeontology, 62, 615-637. doi: 10.1111/pala.12419

Mazzei, R. 1985. The Miocene sequence of the Maltese Islands: biostratigraphic and chronostratigraphic references based on nannofossils. Atti della Societa Toscana di Scienze Naturali Residente in Pisa, Memorie, Processi Verbali, Serie A, 92, pp.165197.

Mazzei, R., Margiotta, S., Foresi, L.M., Riforgiato, F. \& Salvatorini, G. 2009. Biostratigraphy and chronostratigraphy of the Miocene Pietra Leccese in the type area of Lecce (Apulia, southern Italy). Bollettino della Società Paleontologica Italiana, 48 (2), 129-145.

Mook, C. C. 1955. Two new genera of Eocene crocodilians. American Museum Novitates, 1727, 1-4. 
Müller, L. 1927. Ergebnisse der Forschungsreisen Prof. E. Stromers in den Wiisten Agyptens. V. T ertike Wirbeltiere. 1. Beitrage zur Kenntnis der Krokodilier des agyptischen Tertiars. Abhandlungen der Bayerischen Akadernie der Wissenschaften Mathematisch-natunvissenschaftliche Abteilung, 31, 1-96.

Myrick, A.C. 2001. Thecachampsa antiqua (Leidy, 1852) (Crocodylidae, Thoracosaurinae) from fossil marine deposits at Lee Creek Mine, Aurora, North Carolina, USA. Pp. 219-225 in C. E. Ray and D.J. Bohaska (Eds.), Geology and Paleontology of the Lee Creek Mine, North Carolina, III. Smithsonian Contributions to Paleobiology, 90. Smithsonian Institution Press, Washington DC.

Ösi, A. Clark, J. M. \& Weishampel, D. B. 2007. First report on a basal eusuchian crocodyliform with multicusped teeth from the Upper Cretaceous (Santonian) of Hungary. Neues Jahrbuch für Geologie und Paläontologie, Abhandlungen, 243, 169-177. doi: 10.1127/0077-7749/2007/0243-0169

Owen, R. 1849. A history of British fossil reptiles. Volume 1. Cassell, London, 657 pp.

Pedley, H. M., House, M. R. \& Waugh, B. 1976. The geology of Malta and Gozo. Proceedings of the Geologists' Association, 87, 325-341.

Pedley, H.M., House, M.R. \& Waugh, B. 1978. The geology of the Pelagian block: the Maltese Islands. In The ocean basins and margins (pp. 417-433). Springer, Boston, MA.

Piras, P., Delfino, M., Del Favero, L. \& Kotsakis, T. 2007. Phylogenetic position of the crocodylian Megadontosuchus arduini and tomistomine palaeobiogeography. Acta Palaeontologica Polonica, 52, 315-328.

Rehfeld, U. \& Janssen, A.W. 1995. Development of phosphatized hardgrounds in the Miocene Globigerina Limestone of the Maltese archipelago, including a 
description of Gamopleura melitensis sp. nov.(Gastropoda, Euthecosomata). Facies, 33 (1), 91-106.

Rio, J. P., Mannion, P. D., Tschopp, E., Martin, J. E. \& Delfino, M. 2020.

Reappraisal of the morphology and phylogenetic relationships of the alligatoroid crocodylian Diplocynodon hantoniensis from the late Eocene of the United Kingdom. Zoological Journal of the Linnean Society, 188, 579-629. doi:

10.1093/zoolinnean/zlz034

Salas-Gismondi, R., Flynn, J. J., Baby, P., Tejada-Lara, J. V., Claude, J. \& Antoine, P. O. 2016. A new 13 million year old gavialoid crocodylian from protoAmazonian mega-wetlands reveals parallel evolutionary trends in skull shape linked to longirostry. PLoS One, 11, p.e0152453. doi: 10.1371/journal.pone.0152453

Shan, H-Y., Wu, X-C., Cheng, Y-N. \& Sato, T. 2009. A new tomistomine (Crocodylia) from the Miocene of Taiwan. Canadian Journal of Earth Sciences, 46, 529-555. doi: 10.1139/E09-036

Shan, H.Y., Wu, X.C., Cheng, Y.N. \& Sato, T. 2017. Maomingosuchus petrolica, a restudy of 'Tomistoma' petrolica Yeh, 1958. Palaeoworld, 26, 672-690. doi: 10.1016/j.palwor.2017.03.006

Toula, F. \& Kail, J. A. 1885. Über einen Krokodil-Schädel aus den Tertiärablagerungen von Eggenburg in Niederösterreich: eine paläontologische Studie. Denkschriften der Keiserlichen Akademie der Wissenschaften von Wien, Mathematisch-naturwissenschaftliche Klasse, 50, 299-355.

Vianna, A. \& Moraes, A. 1945. Sur un crâne de crocodile fossile decouvert dans le Miocène de Lisbonne. Boletim de la Sociedade Geológica de Portugal, 4, 161-170.

Weems, R. E. 2018. Crocodilians of the Calvert Cliffs. Pp 213-240 in S. J. Godfrey (Ed.), The Geology and Vertebrate Paleontology of Calvert Cliffs, Maryland, USA. 


\section{Smithsonian Contributions to Paleobiology, 100. Smithsonian Institution Press,} Washington DC.

Zbyszewski, G. 1949. Les vertébrés du Burdigalien supérieur de Lisbonne. Services géologiques du Portugal, Lisbonne, $77 \mathrm{pp}$.

Zoboli, D. \& Pillola, G. L. 2016. I rettili miocenici conservati nel Museo Sardo di Geologia e Paleontologia Domenico Lovisato (Cagliari, Italia). Museologia Scientifica, Nuova Serie, 10, 81-87.

Zoboli, D., Sanciu, L., Pillola, G. L. \& Delfino, M. 2019. An overview of the crocodylian fossil record from Sardinia (Italy). Annales de Paléontologie, 105, 123137. doi: 10.1016/j.annpal.2019.05.001

\section{FIGURE CAPTIONS}

Figure 1. Present-day geographical map and geological time scale showing the spatiotemporal distribution of named European and north African tomistomine occurrences. Blue stars indicate specimens focused on in this work.

Figure 2. The holotype snout of Melitosaurus champsoides (NHMUK PV OR41151) in dorsal view. A, interpretive drawing; B, photograph. Abbreviations: d, dentary alveolus/tooth. Scale bar $=100 \mathrm{~mm}$.

Figure 3. The holotype snout of Melitosaurus champsoides (NHMUK PV OR41151) in right lateral view. $\mathbf{A}$, interpretive drawing; $\mathbf{B}$, photograph. Abbreviations: $d$, dentary alveolus/tooth; m, maxillary alveolus/tooth, pm, premaxillary alveolus/tooth. Scale bar $=100 \mathrm{~mm}$.

Figure 4. The holotype snout of Melitosaurus champsoides (NHMUK PV OR41151). A, left lateral view; $\mathbf{B}$, ventral view, $\mathbf{C}$, left lateral view of posterior dentary fragment. Abbreviations: $d$, dentary alveolus/tooth; $m$, maxillary alveolus/tooth, pm, premaxillary alveolus/tooth. Scale bar $=100 \mathrm{~mm}$. 
Figure 5. Teeth from: A, left dentary of Melitosaurus champsoides (NHMUK PV OR41151); B, left maxilla and dentary of 'Tomistoma' gaudense (NMNH -T11228); C, right maxilla and dentary of 'Tomistoma' calaritanum (MDLCA 148) in buccal view. Scale bars $=10 \mathrm{~mm}$.

Figure 6. The holotype skull of 'Tomistoma' gaudense (NMNH -T11228) in dorsal view. A, interpretive drawing; $\mathbf{B}$, photograph. Scale bar $=100 \mathrm{~mm}$.

Figure 7. The holotype skull of 'Tomistoma' gaudense (NMNH -T11228) in ventral view. A, interpretive drawing; $\mathbf{B}$, photograph. Abbreviations: $\mathrm{m}$, maxillary alveolus/tooth. Scale bar $=100 \mathrm{~mm}$.

Figure 8. The holotype skull of 'Tomistoma' gaudense (NMNH -T11228) in left lateral view. A, interpretive drawing; B, photograph. Abbreviations: $m$, maxillary alveolus/tooth; d, dentary alveolus/tooth. Scale bar $=100 \mathrm{~mm}$.

Figure 9. The posterior skull region of the holotype of 'Tomistoma' gaudense (NMNH $-\mathrm{T} 11228$ ) in $\mathbf{A}$, dorsolateral and $\mathbf{B}$, posterior view. Scale bars $=100 \mathrm{~mm}$.

Figure 10. The holotype skull of 'Tomistoma' calaritanum (MDLCA 148) in dorsal view. A, interpretive drawing of specimen before restoration; $\mathbf{B}$, photograph of skull before restoration from the original plates of Capellini (1890b). C, photograph of skull in its current state. Scale bar $=100 \mathrm{~mm}$.

Figure 11. Capellini's (1890b) interpretive drawings of the restored holotype (MDLCA 148) of 'Tomistoma' calaritanum (MDLCA 148) in A, right lateral view; B, dorsal view. Scale bar represents $100 \mathrm{~mm}$.

Figure 12. The holotype skull of 'Tomistoma' calaritanum (MDLCA 148) in right lateral view. A, interpretive drawing; B, photograph. Scale bar $=100 \mathrm{~mm}$.

Figure 13. The holotype skull of 'Tomistoma' calaritanum (MDLCA 148) in A, left lateral view; $\mathbf{B}$, anterior view. Scale bar $=100 \mathrm{~mm}$. 
Figure 14. Lost type material of 'Tomistoma' calaritanum from the original plates of Capellini (1890b). A, premaxillae and maxillae in ventral view; $\mathbf{B}$, dentaries and splenials in ventral view. Scale bar $=100 \mathrm{~mm}$.

Figure 15. A cast of the lost holotype snout fragment of 'Tomistoma lyceense' (Cast \#2-4511). Line drawings in A, dorsal view; $\mathbf{B}$, ventral view; C, right lateral view. Photographs in D, dorsal view; E, ventral view; F, right lateral view. Abbreviations: $\mathrm{Im}$, left maxillary alveolus/tooth; rm, right maxillary alveolus/tooth. Scale bar $=100$ $\mathrm{mm}$.

Figure 16. Comparisons of the overall skull morphology for several European and north African tomistomine taxa: A, 'Tomistoma' calaritanum; B, Melitosaurus champsoides; C, 'Tomistoma' gaudense; D, 'Tomistoma lyceense'; E, 'Tomistoma' Iusitanica; F, 'Tomistoma' dowsoni; G, Gavialosuchus eggenburgensis. Skulls are not drawn to scale with each other.

Figure 17. Strict consensus trees showing the relationships of tomistomines using equal weighting of characters. A, topology from addition of Melitosaurus champsoides, 'Tomistoma' calaritanum, and 'Tomistoma' gaudense. B, topology when Melitosaurus champsoides is pruned a posteriori. C, topology from addition of solely Melitosaurus champsoides. Numbers at the nodes indicate Bremer support values. Green circle indicates the node for Tomistominae.

Figure 18. Strict consensus trees showing the relationships of tomistomines using extended implied weighting. A, topology from addition of Melitosaurus champsoides, 'Tomistoma' calaritanum, and 'Tomistoma' gaudense ( $k=4,8$, and 12). B, topology when Melitosaurus champsoides is pruned a posteriori $(k=4,8$, and 12). C, topology from addition of solely Melitosaurus champsoides at $k=8$ and $k=12$. D, topology from the addition of solely Melitosaurus champsoides at $k=4$. Green circle indicates the node for Tomistominae.

Figure 19. Time-calibrated phylogenetic topology showing the hypothesised relationships of tomistomines, based on extended implied weights analyses. 


\section{TABLE CAPTIONS}

Table 1. Skull measurements for Melitosaurus champsoides (NHMUK PV OR41151), 'Tomistoma' calaritanum (MDLCA 148), and 'Tomistoma' gaudense (NMNH-T11228).

Table 2. Interalveolar measurements for Melitosaurus champsoides (NHMUK PV OR41151), 'Tomistoma' calaritanum (MDLCA 148), and 'Tomistoma' gaudense (NMNH-T11228). Measurements are taken from the centre of one alveolus to the centre of the next.

Table 3. Summary of results from the phylogenetic analyses. 
Figure 1. Present-day geographical map and geological time scale showing the spatiotemporal distribution of named European and north African tomistomine occurrences. Blue stars indicate specimens focused on in this work. 

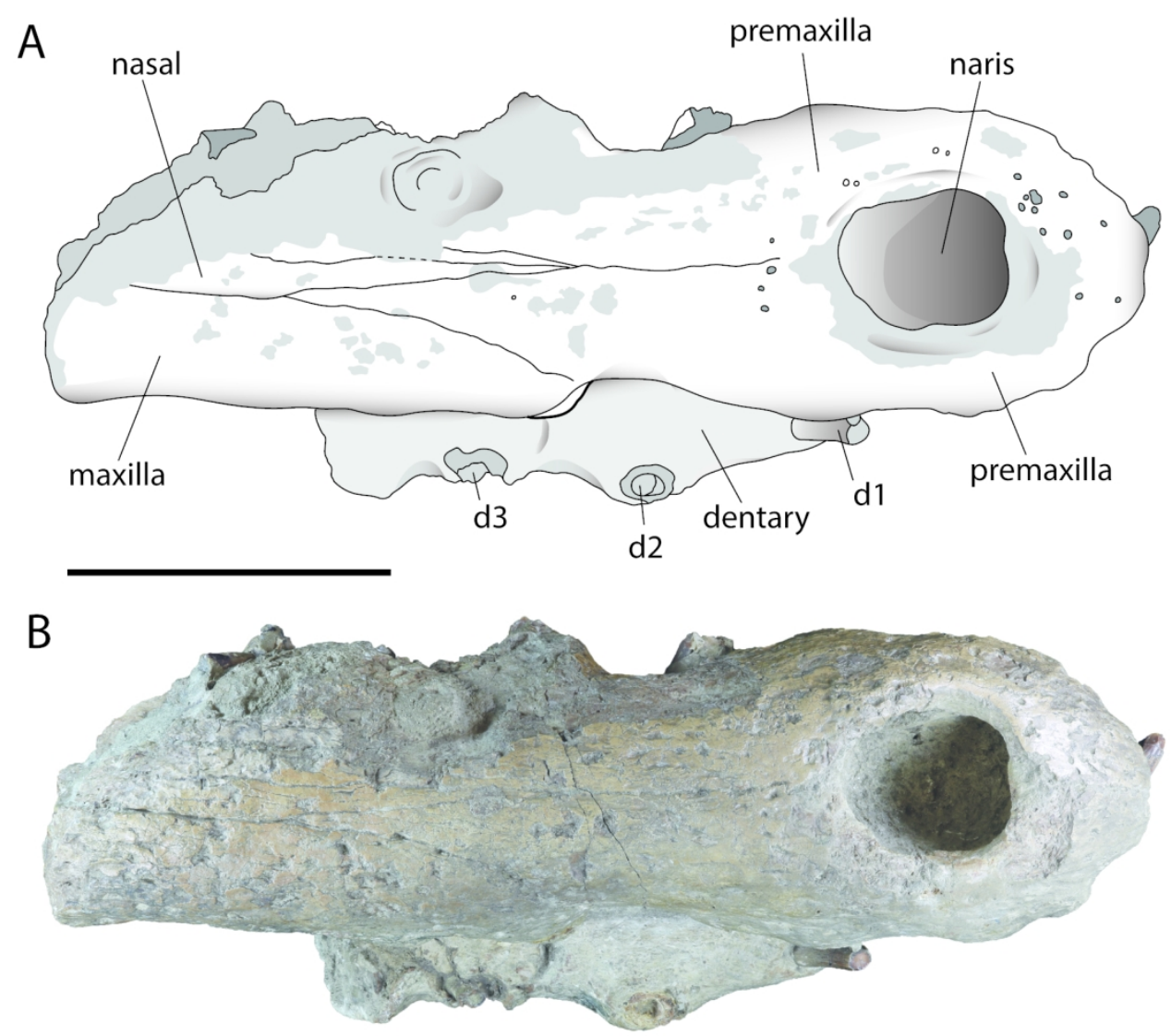

Figure 2. The holotype snout of Melitosaurus champsoides (NHMUK PV OR41151) in dorsal view. A, interpretive drawing; B, photograph. Abbreviations: d, dentary alveolus/tooth. Scale bar $=100 \mathrm{~mm}$. 
A

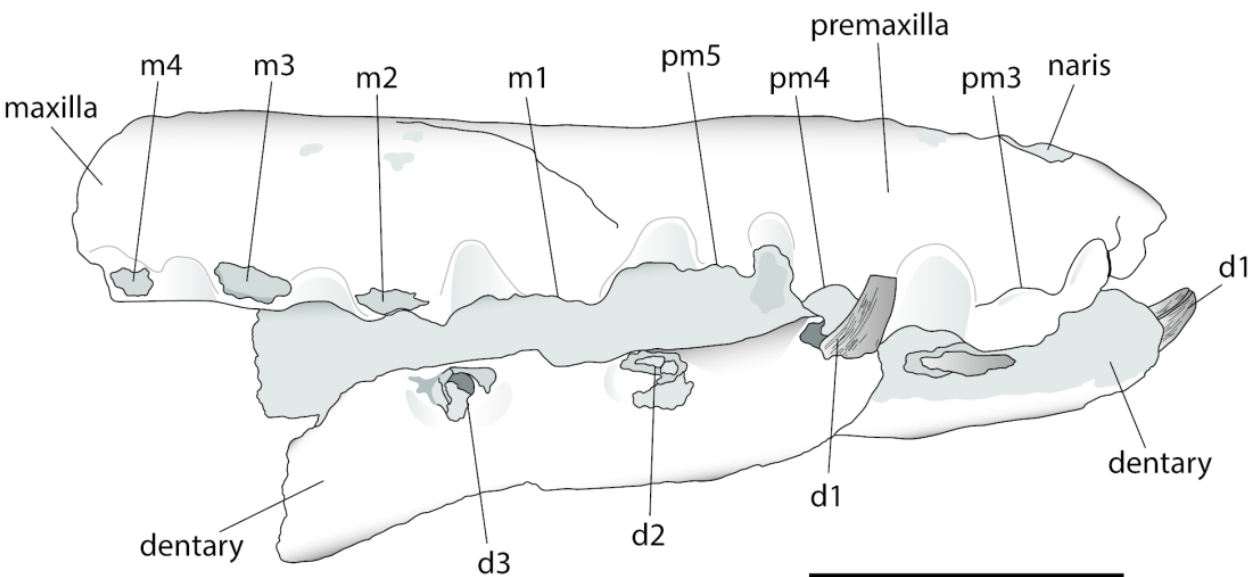

B

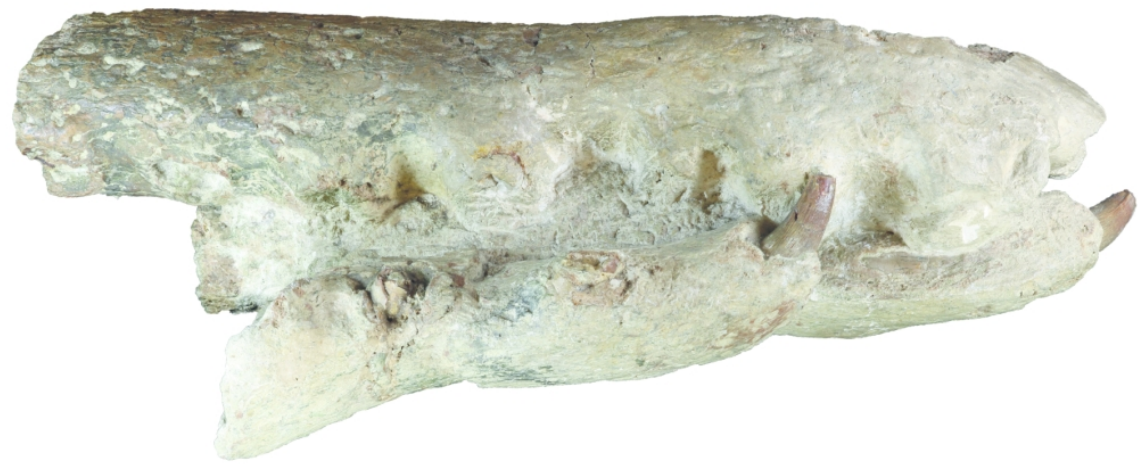

Figure 3. The holotype snout of Melitosaurus champsoides (NHMUK PV OR41151) in right lateral view. A, interpretive drawing; B, photograph. Abbreviations: d, dentary alveolus/tooth; m, maxillary alveolus/tooth, pm, premaxillary alveolus/tooth. Scale bar $=100 \mathrm{~mm}$ 
A
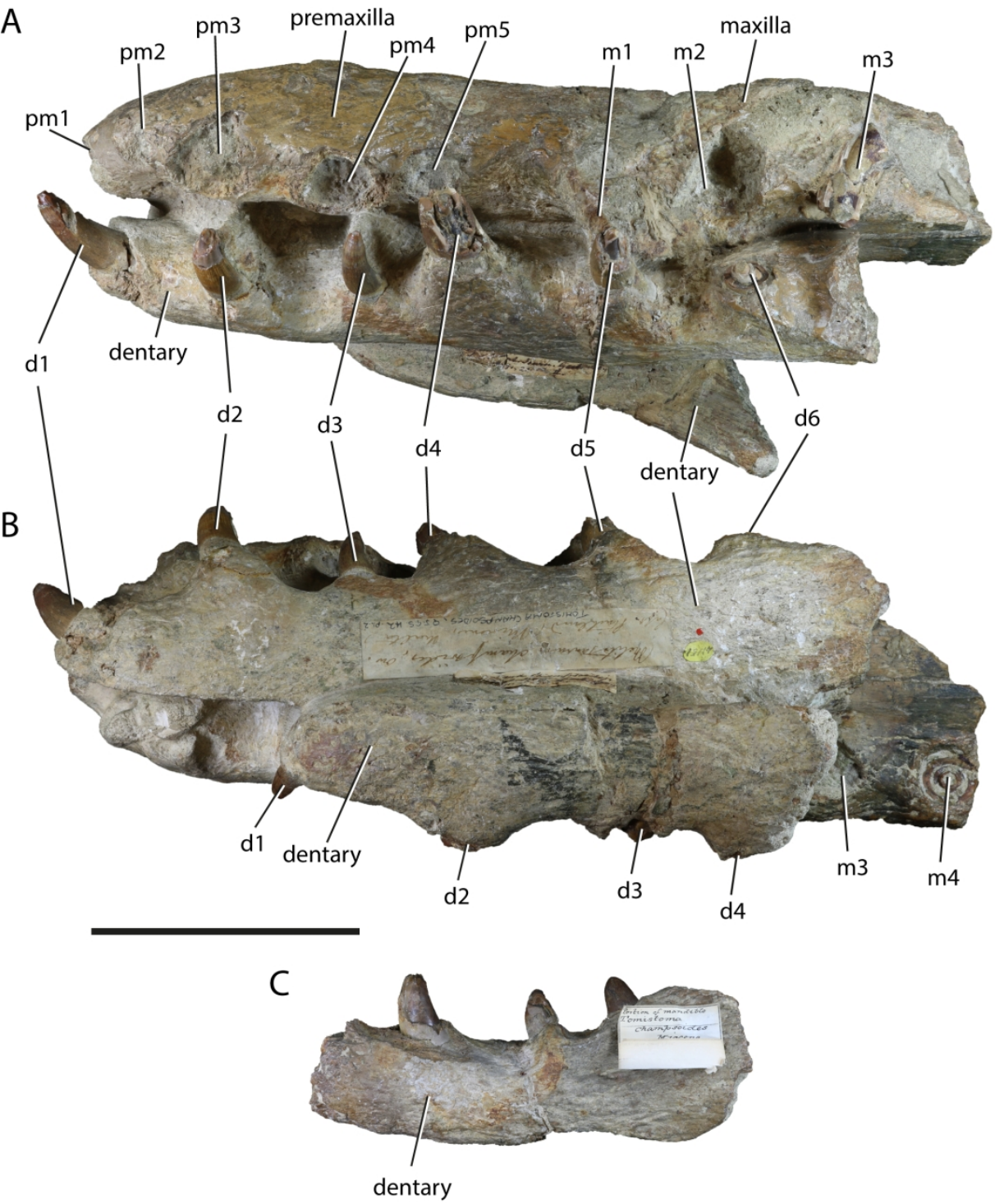

Figure 4. The holotype snout of Melitosaurus champsoides (NHMUK PV OR41151). A, left lateral view; B, ventral view, C, left lateral view of posterior dentary fragment. Abbreviations: d, dentary alveolus/tooth; $\mathrm{m}$, maxillary alveolus/tooth, pm, premaxillary alveolus/tooth. Scale bar $=100 \mathrm{~mm}$. 


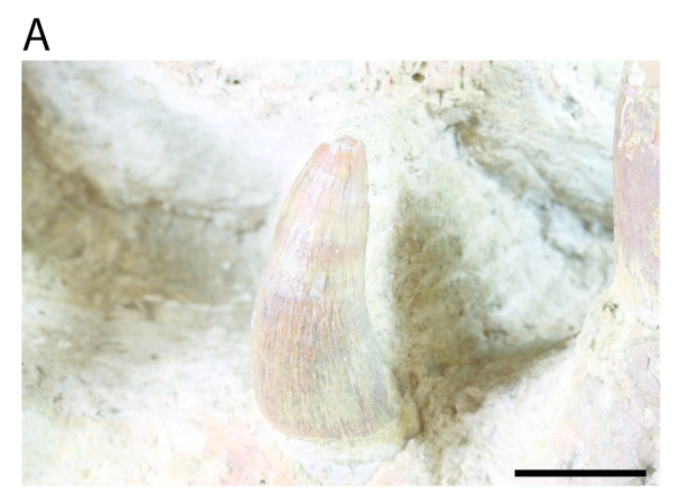

B

C
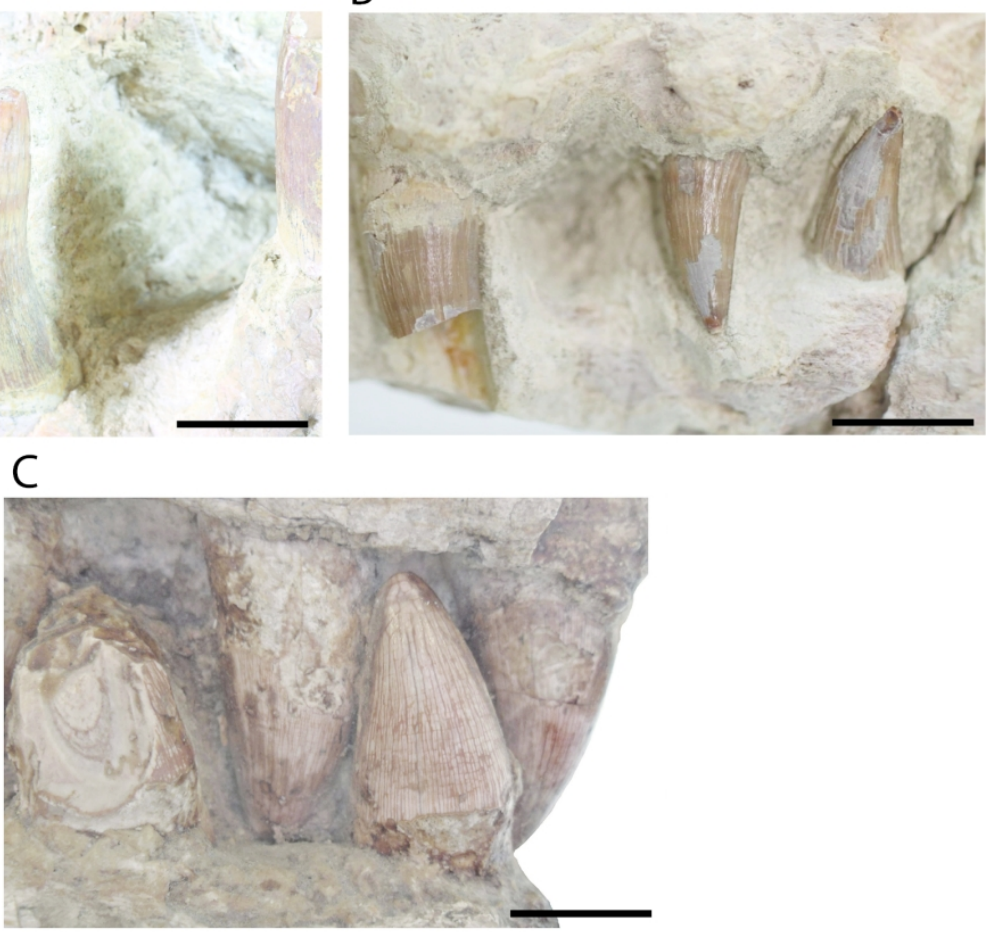

Figure 5. Teeth from: A, left dentary of Melitosaurus champsoides (NHMUK PV OR41151); B, left maxilla and dentary of 'Tomistoma' gaudense (NMNH -T11228); C, right maxilla and dentary of 'Tomistoma' $<$ I $>$ calaritanum (MDLCA 148) in buccal view. Scale bars $=10 \mathrm{~mm}$. 

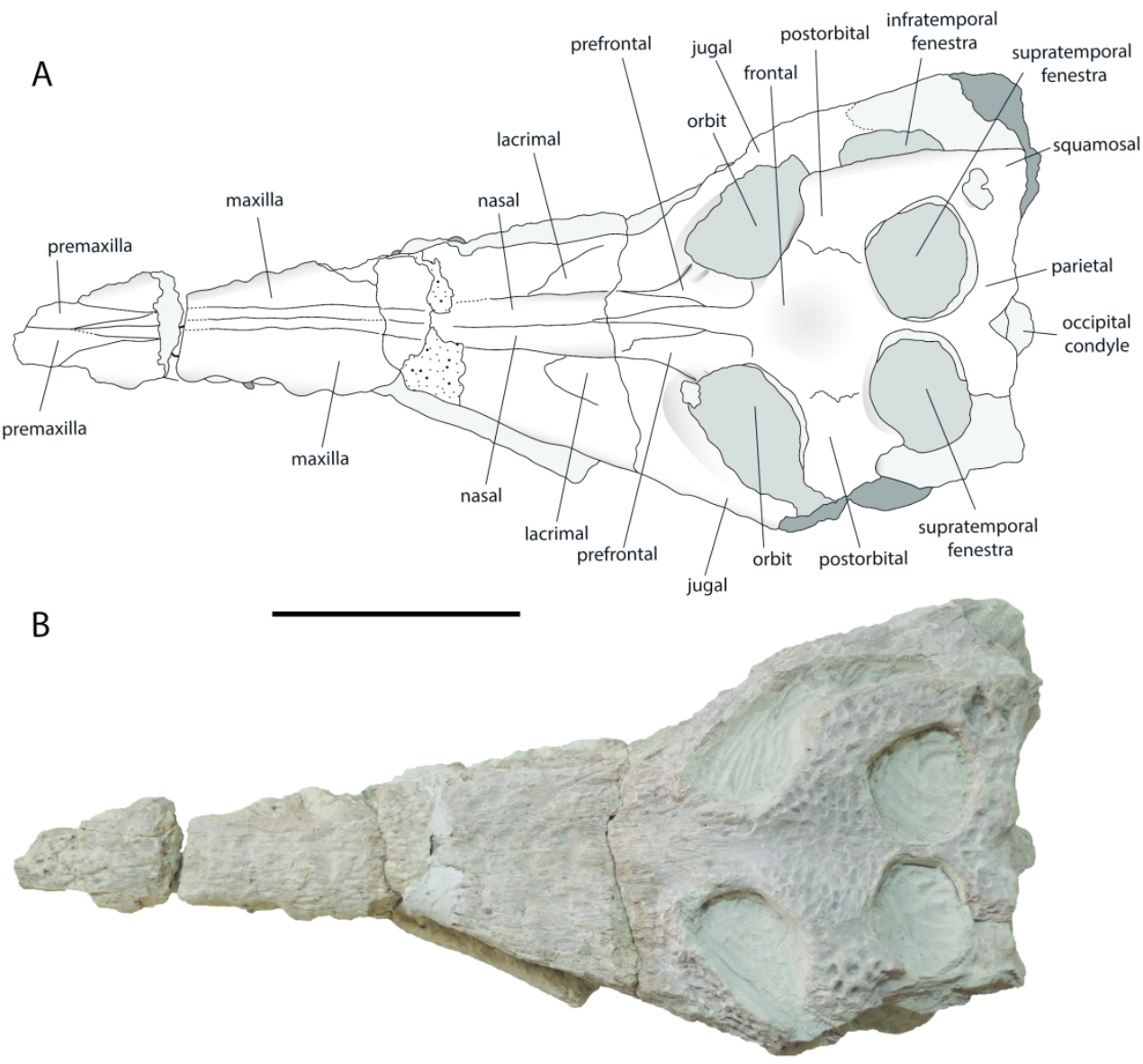

Figure 6. The holotype skull of 'Tomistoma' gaudense (NMNH -T11228) in dorsal view. A, interpretive drawing; B, photograph. Scale bar $=100 \mathrm{~mm}$. 


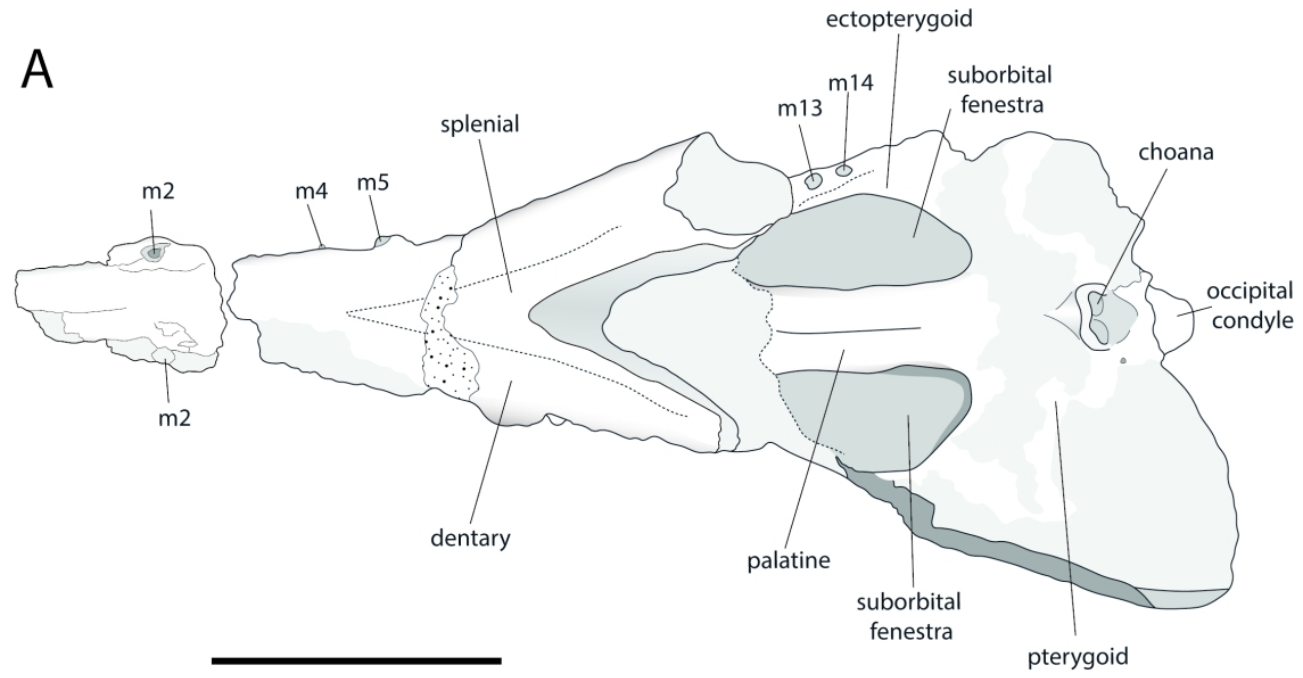

B

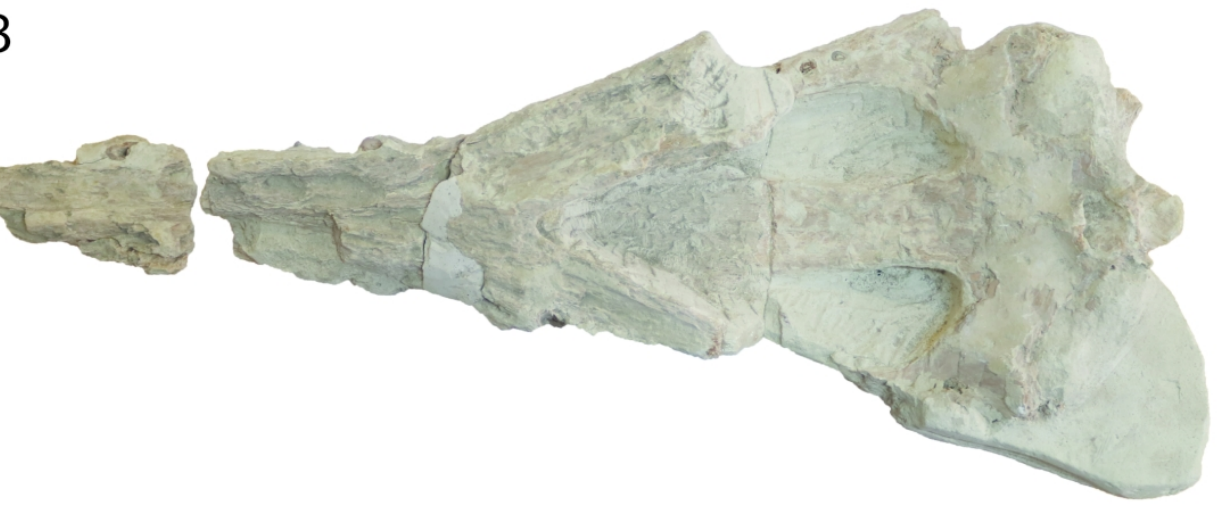

Figure 7. The holotype skull of 'Tomistoma' <I>gaudense (NMNH -T11228) in ventral view. A, interpretive drawing; B, photograph. Abbreviations: $\mathrm{m}$, maxillary alveolus/tooth. Scale bar $=100 \mathrm{~mm}$. 

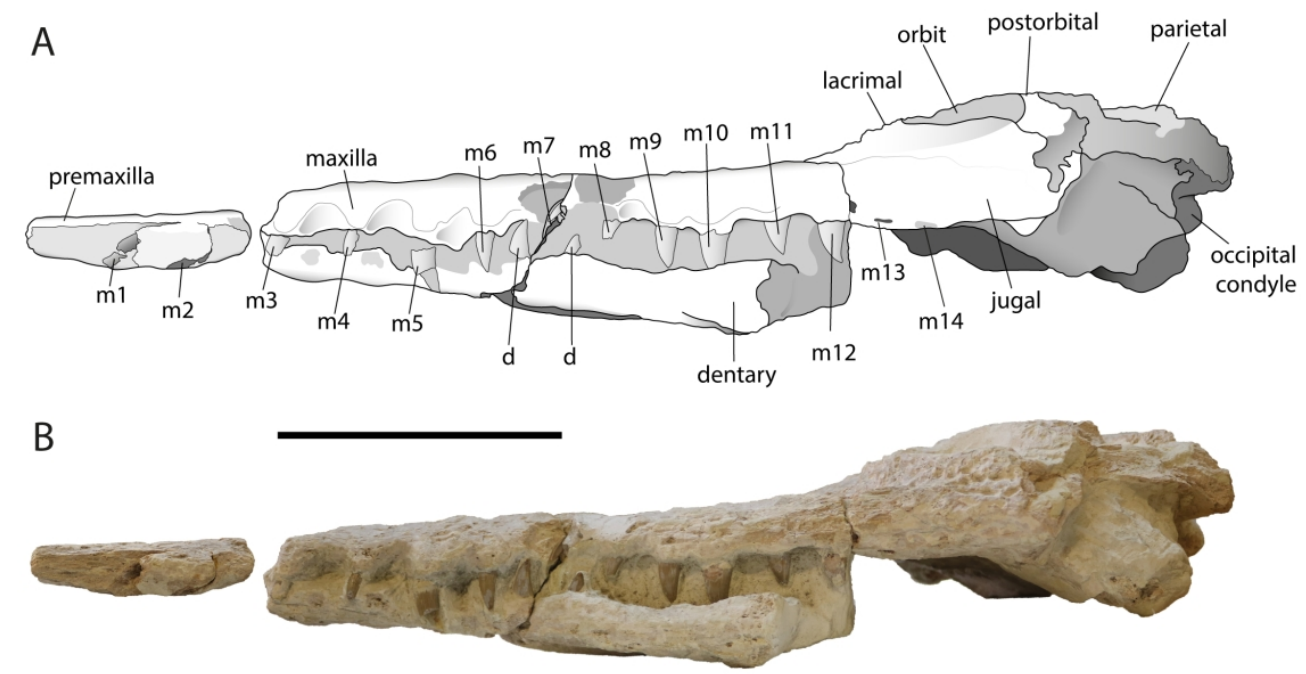

Figure 8. The holotype skull of 'Tomistoma' <I>gaudense (NMNH -T11228) in left lateral view. A, interpretive drawing; B, photograph. Abbreviations: m, maxillary alveolus/tooth; d, dentary alveolus/tooth. Scale bar $=100 \mathrm{~mm}$. 


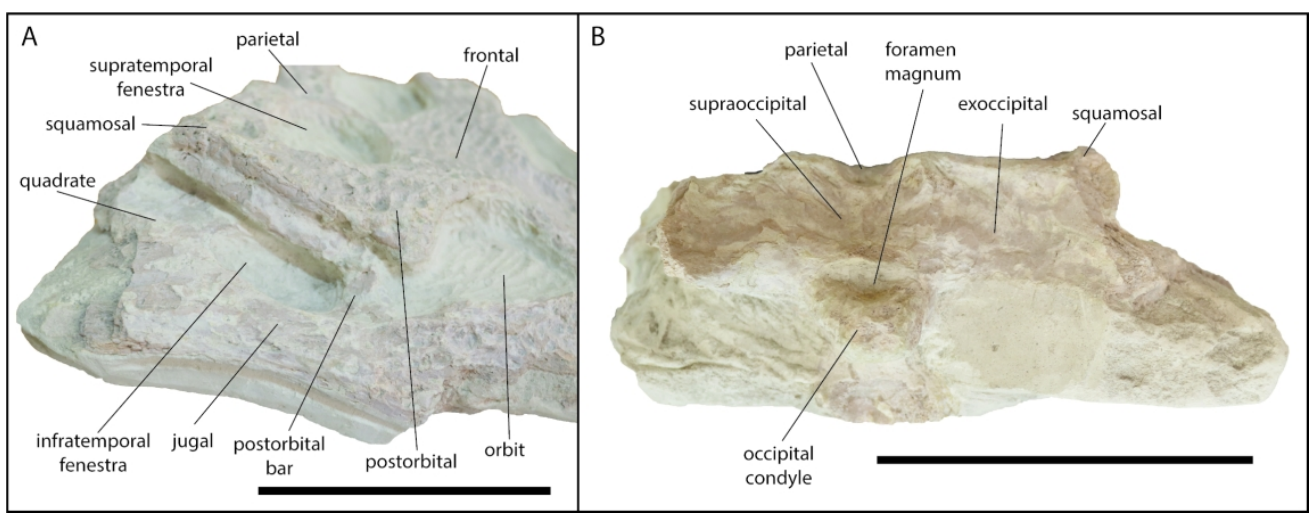

Figure 9. The posterior skull region of the holotype of 'Tomistoma' $<$ I $>$ gaudense (NMNH -T11228) in A, dorsolateral and B, posterior view. Scale bars $=100 \mathrm{~mm}$. 

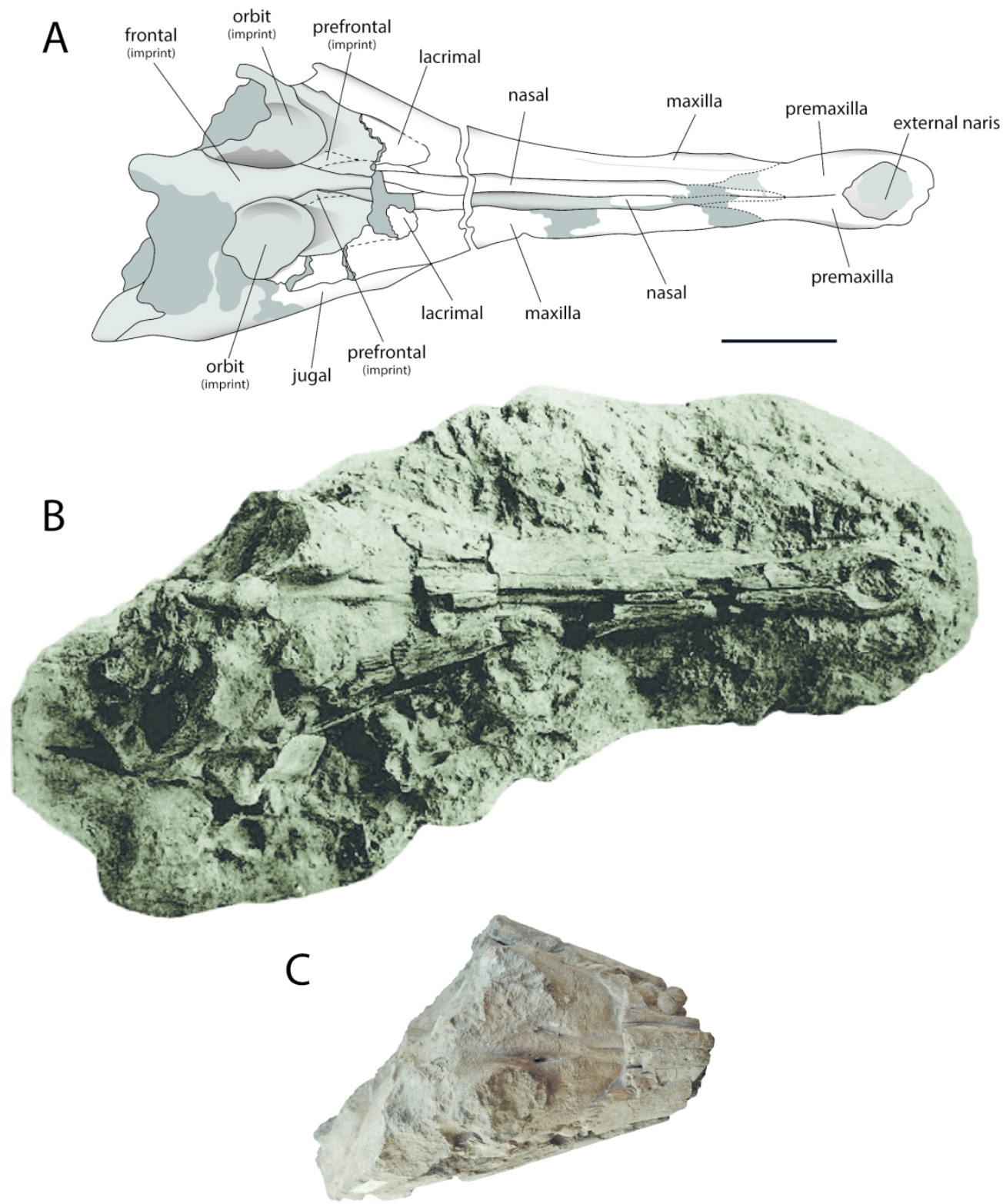

Figure 10. The holotype skull of 'Tomistoma' <I>calaritanum (MDLCA 148) in dorsal view. A, interpretive drawing of specimen before restoration; B, photograph of skull before restoration from the original plates of Capellini (1890b). C, photograph of skull in its current state. Scale bar $=100 \mathrm{~mm}$. 

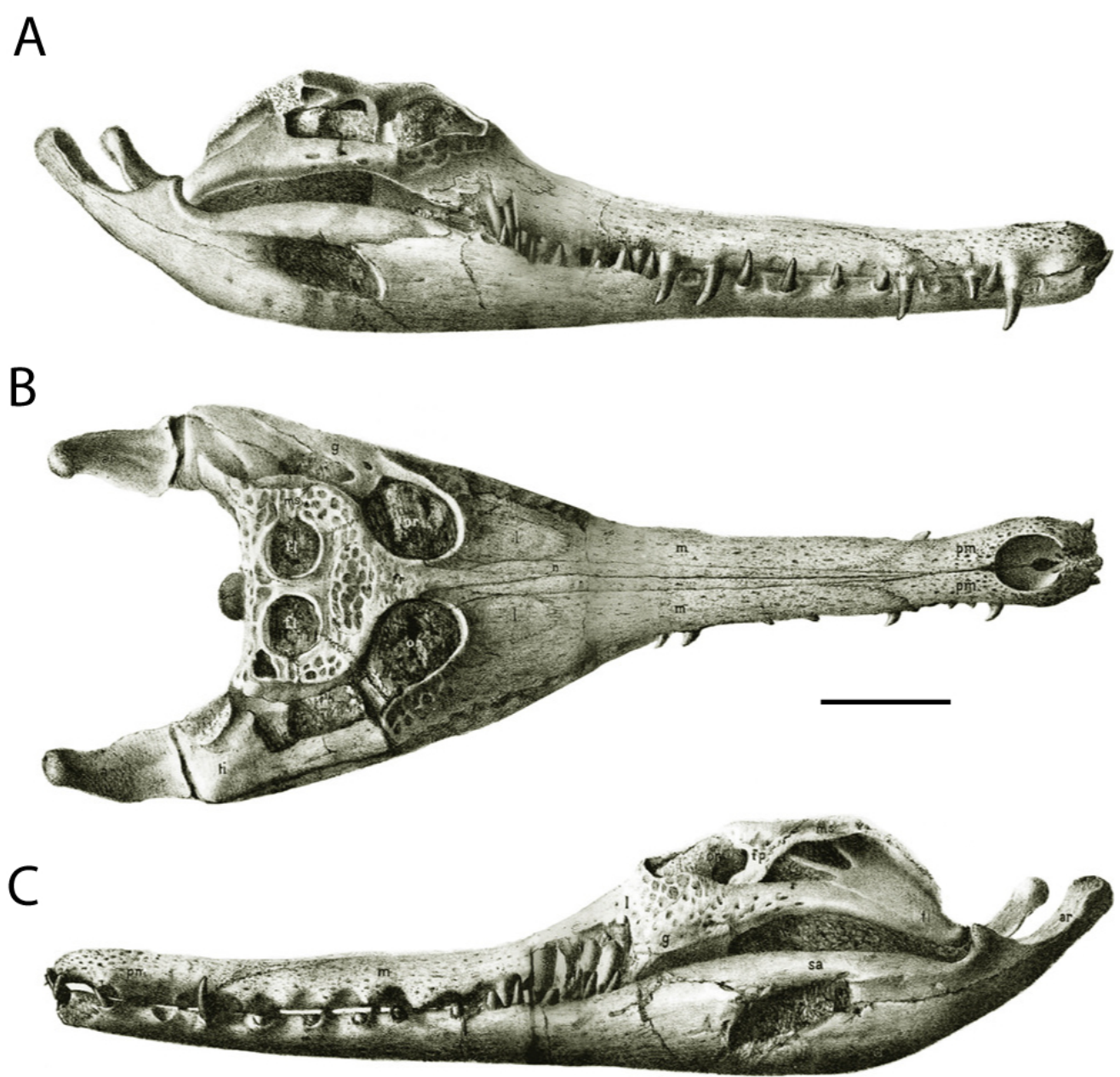

Figure 11. Capellini's (1890b) interpretive drawings of the restored holotype (MDLCA 148) of 'Tomistoma' $<$ I >calaritanum (MDLCA 148) in A, right lateral view; B, dorsal view. Scale bar represents $100 \mathrm{~mm}$. 


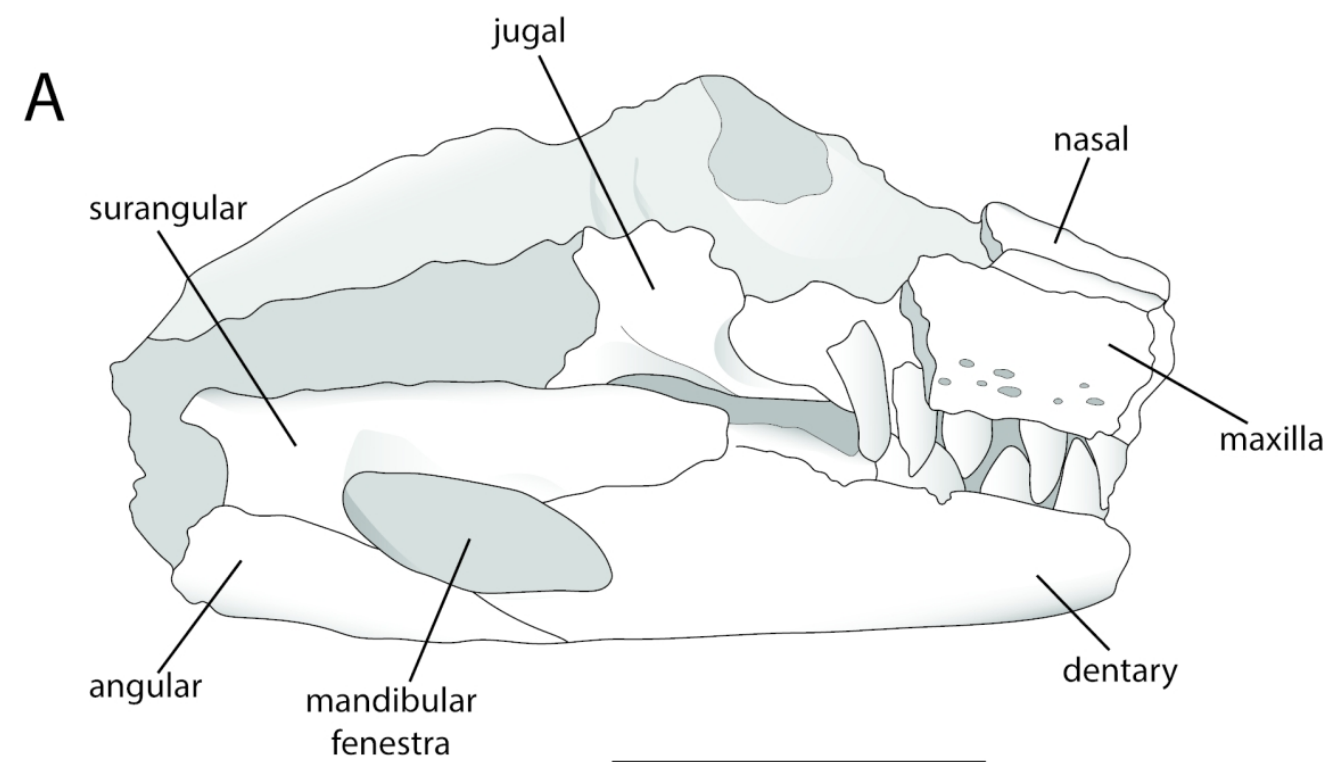

B

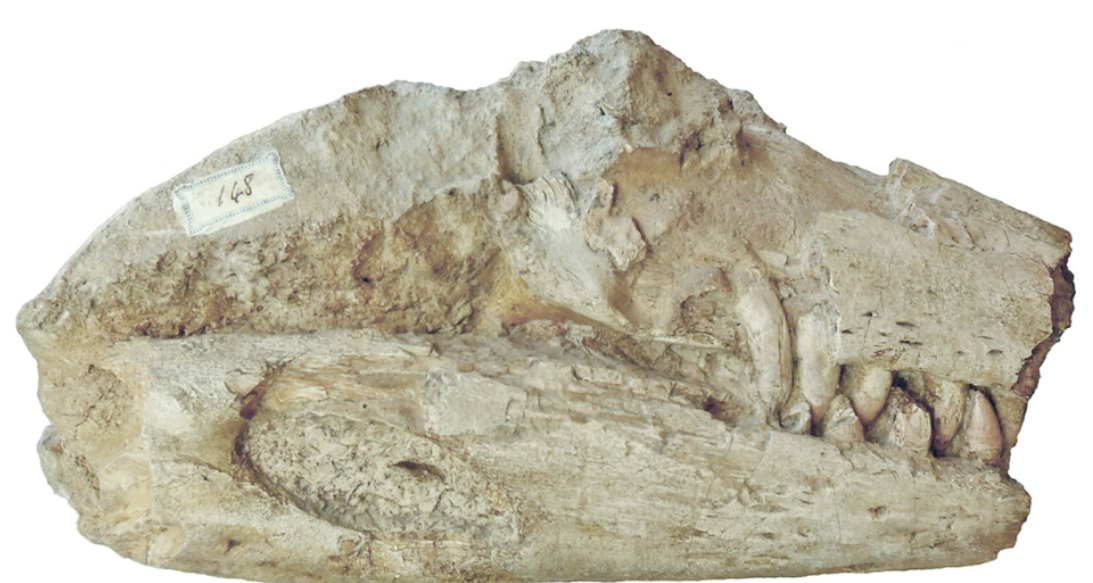

Figure 12. The holotype skull of 'Tomistoma' <I>calaritanum (MDLCA 148) in right lateral view. A, interpretive drawing; B, photograph. Scale bar $=100 \mathrm{~mm}$. 


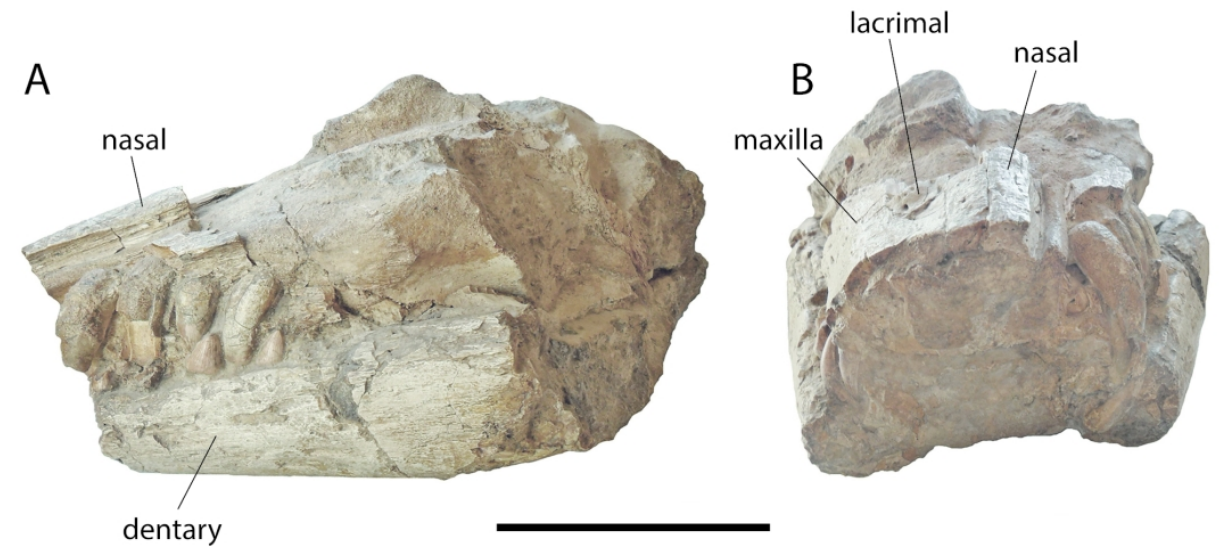

Figure 13. The holotype skull of 'Tomistoma' <I>calaritanum (MDLCA 148) in A, left lateral view; B, anterior view. Scale bar $=100 \mathrm{~mm}$. 

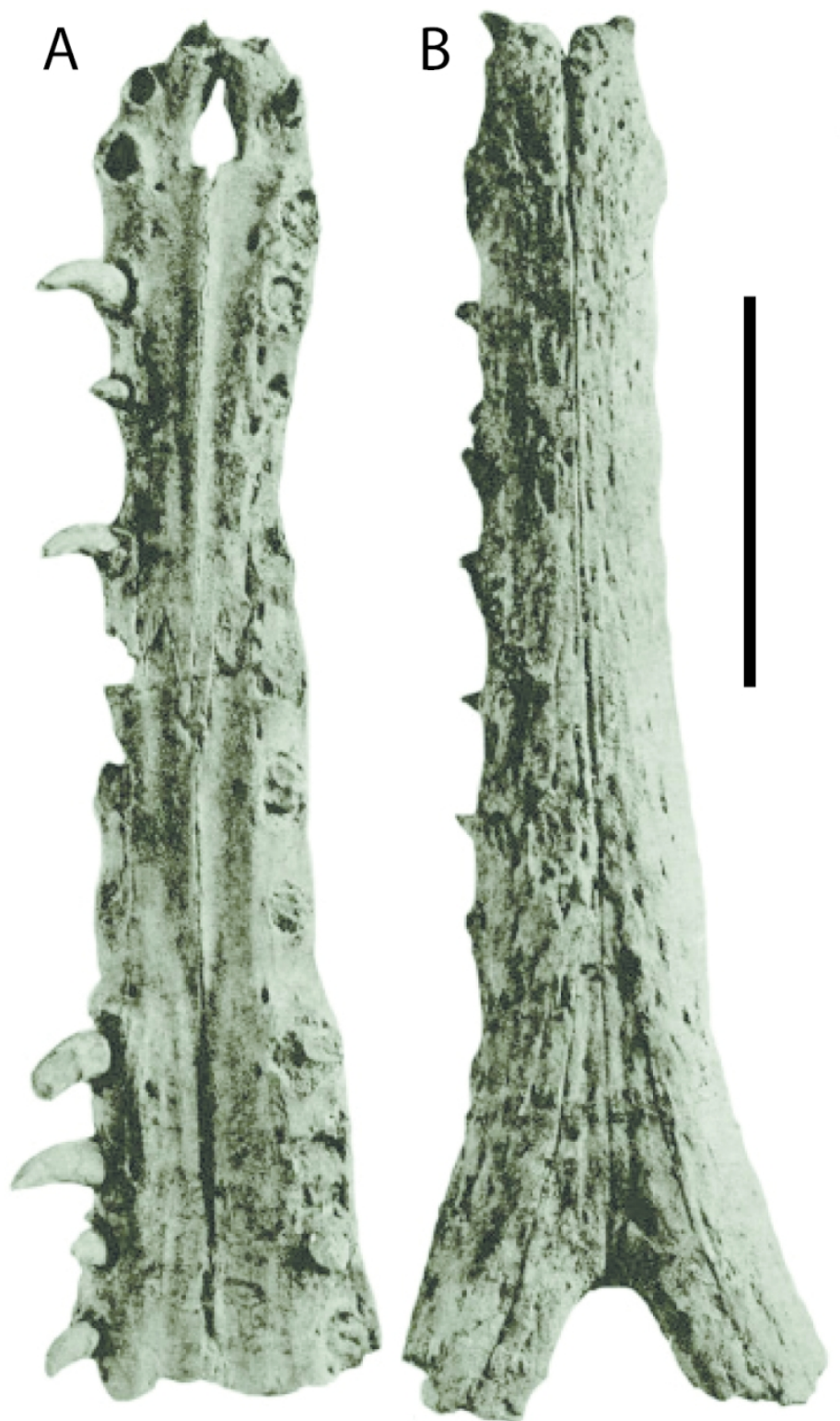

Figure 14. Lost type material of 'Tomistoma' <I>calaritanum from the original plates of Capellini (1890b). A, premaxillae and maxillae in ventral view; B, dentaries and splenials in ventral view. Scale bar $=100 \mathrm{~mm}$. 


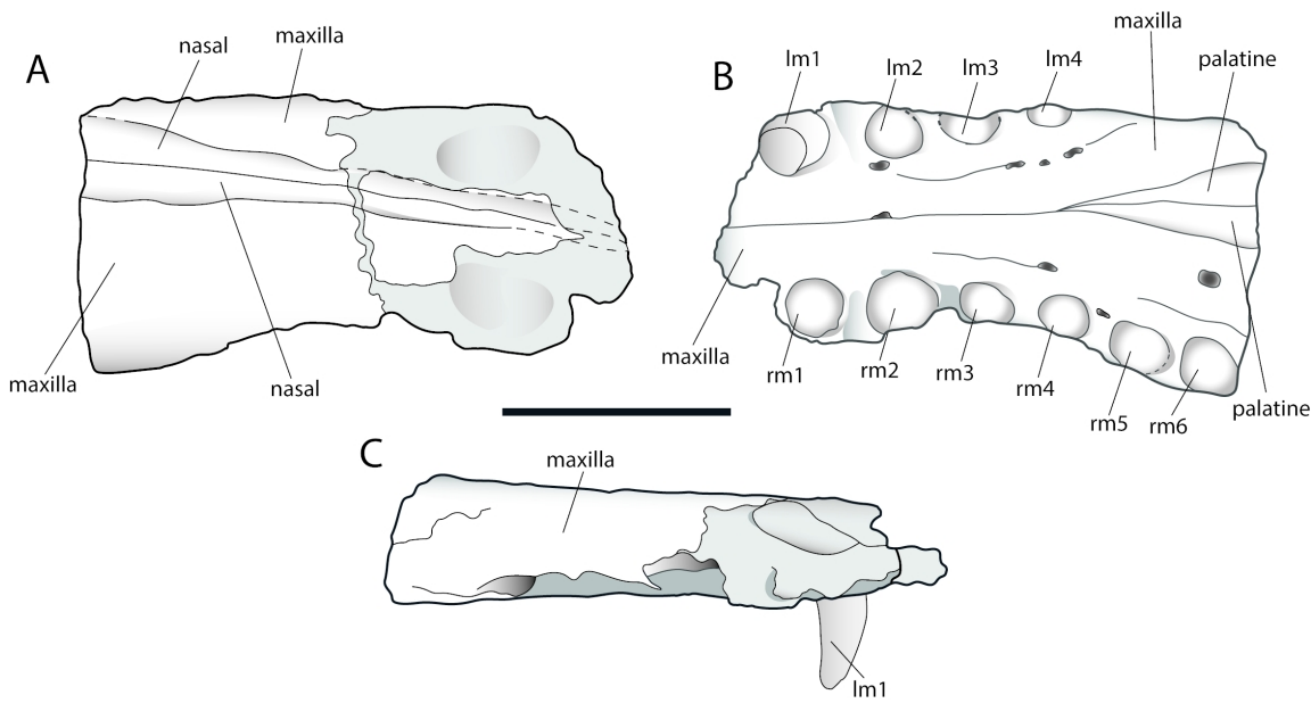

$\mathrm{D}$

E

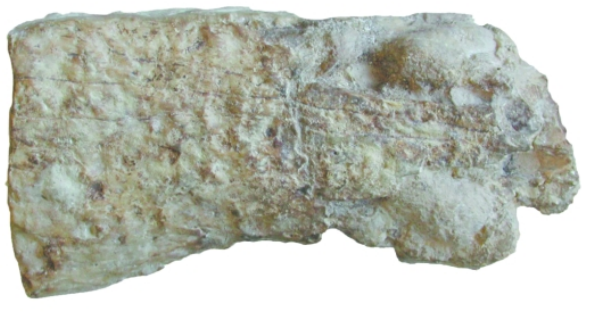

$\mathrm{F}$
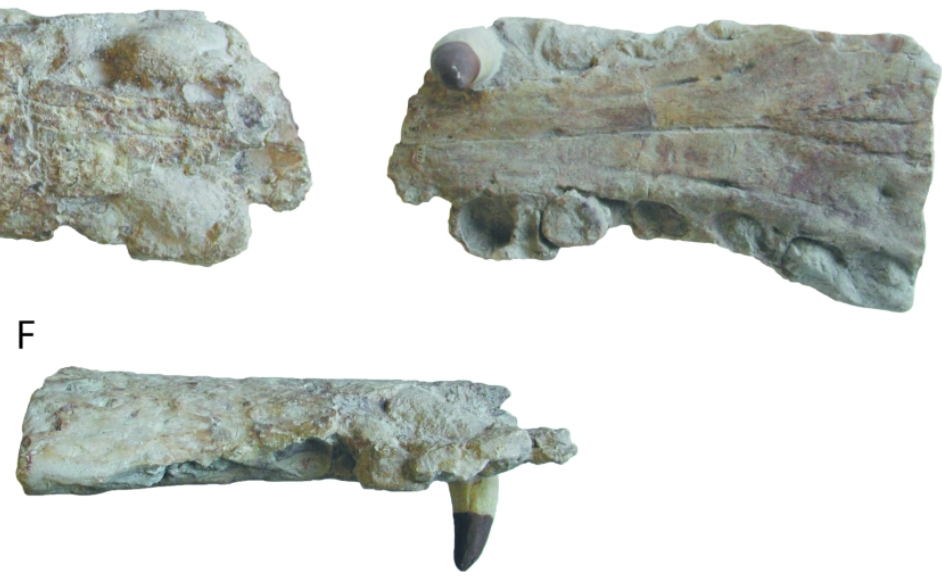

Figure 15. A cast of the lost holotype snout fragment of 'Tomistoma lyceense' (Cast \#2-4511). Line drawings in A, dorsal view; B, ventral view; C, right lateral view. Photographs in D, dorsal view; E, ventral view; F, right lateral view. Abbreviations: Im, left maxillary alveolus/tooth; rm, right maxillary alveolus/tooth. Scale bar $=100 \mathrm{~mm}$. 

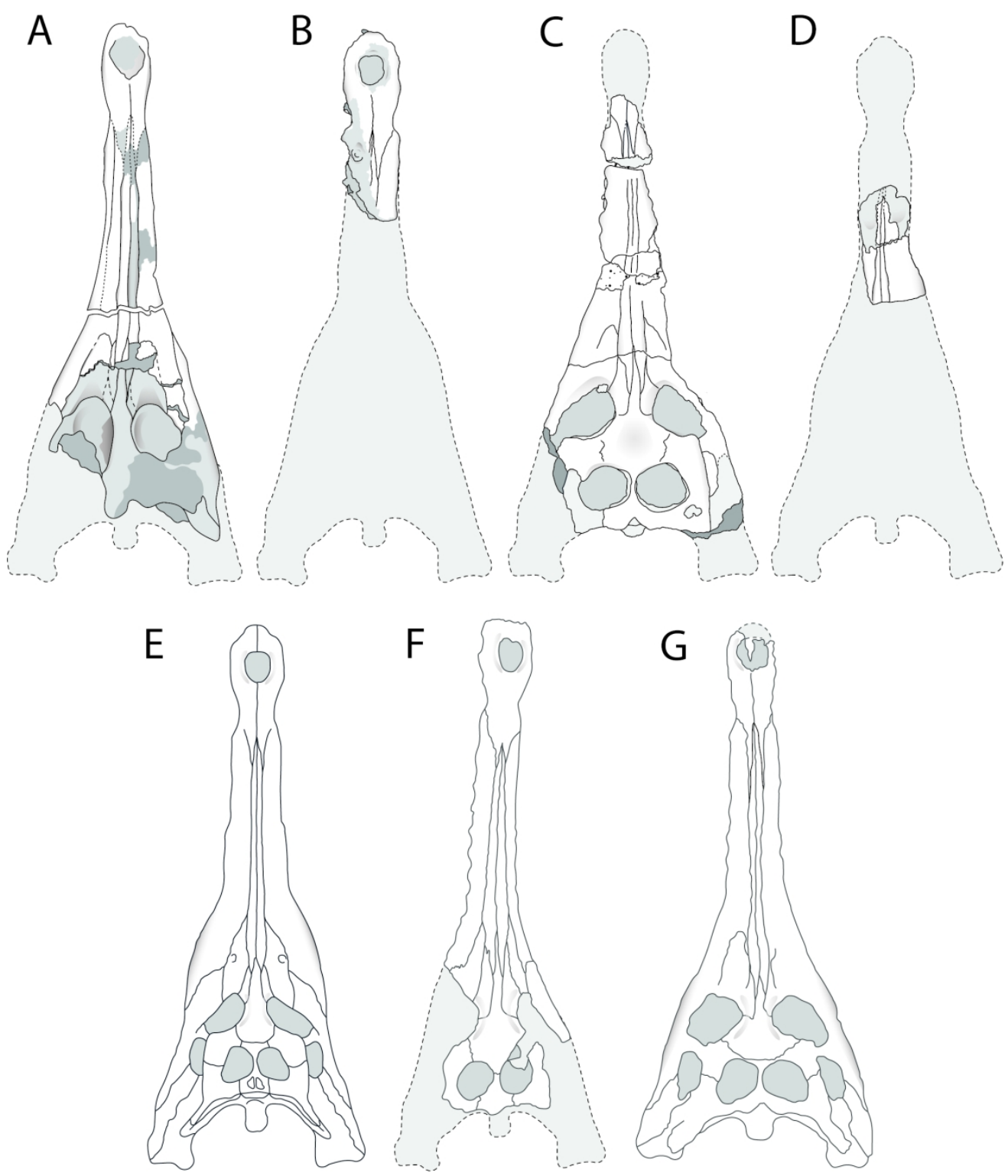

Figure 16. Comparisons of the overall skull morphology for several European and north African tomistomine taxa: A, 'Tomistoma' calaritanum; B, Melitosaurus champsoides; C, 'Tomistoma' <I>gaudense; D, '<I>Tomistoma license'; E, 'Tomistoma' <I>lusitanica; F, 'Tomistoma' <I>dowsoni; G, Gavialosuchus eggenburgensis. Skulls are not drawn to scale with each other. 
A

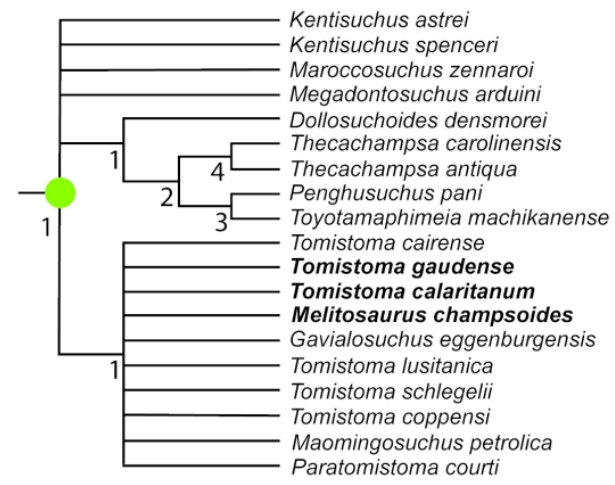

B

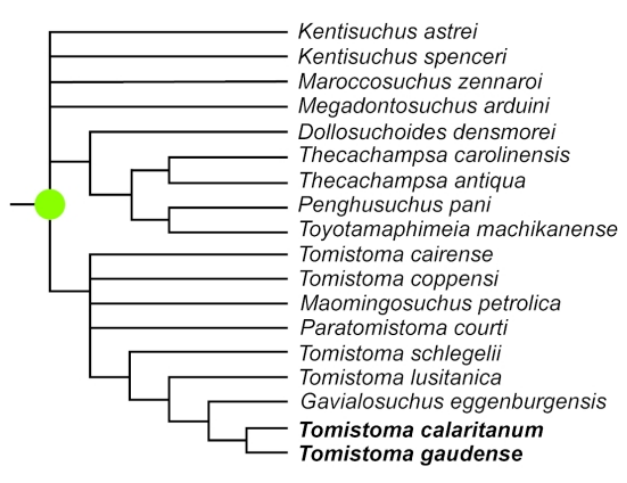

C

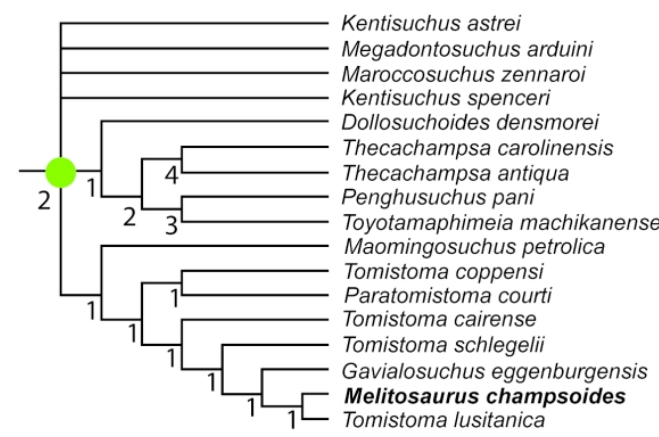

Figure 17. Strict consensus trees showing the relationships of tomistomines using equal weighting of characters. A, topology from addition of Melitosaurus champsoides, 'Tomistoma' calaritanum, and 'Tomistoma' gaudense. B, topology when Melitosaurus champsoides is pruned a posteriori. C, topology from addition of solely Melitosaurus champsoides. Numbers at the nodes indicate Bremer support values. Green circle indicates the node for Tomistominae. 
A

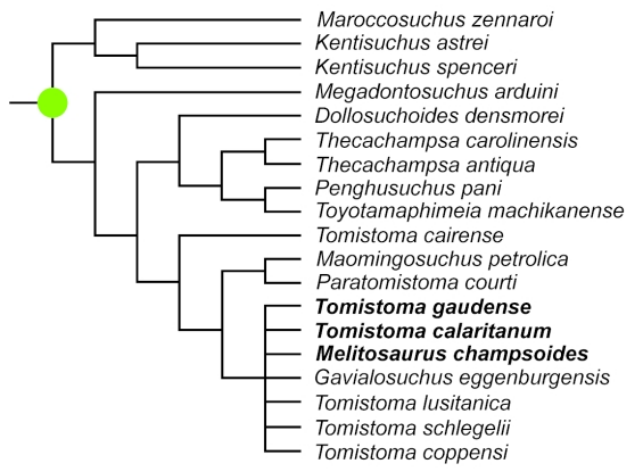

C

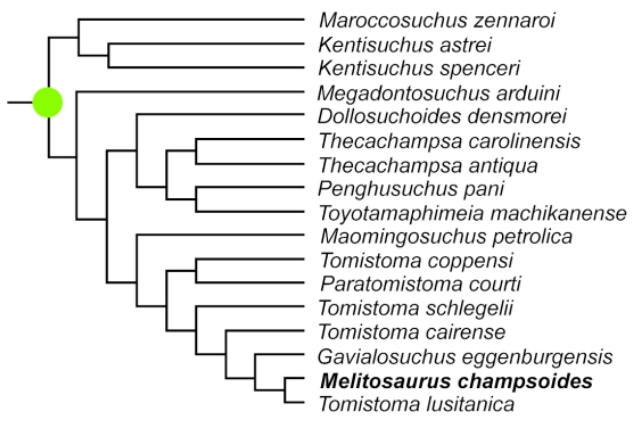

B

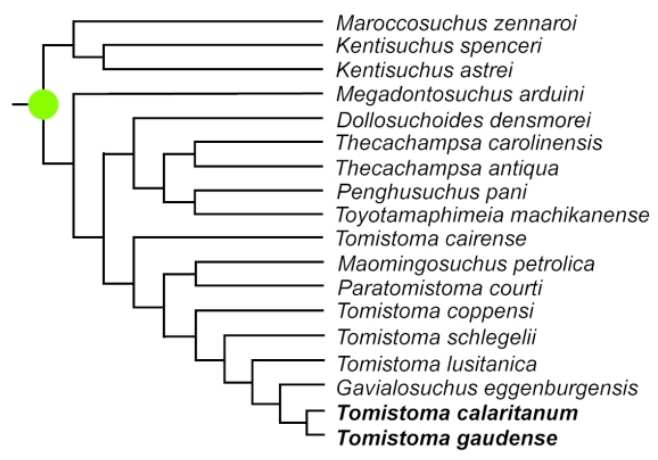

D

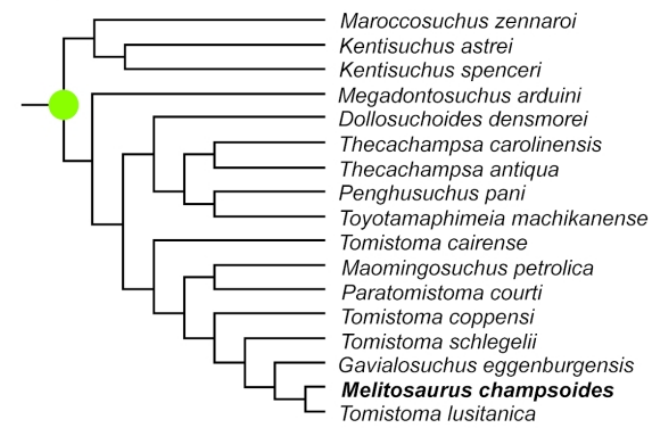

Figure 18. Strict consensus trees showing the relationships of tomistomines using extended implied weighting. A, topology from addition of Melitosaurus champsoides,

'Tomistoma' calaritanum, and 'Tomistoma' gaudense $(\mathrm{k}=4,8$, and 12). $\mathrm{B}$, topology when Melitosaurus champsoides is pruned a posteriori $(\mathrm{k}=4,8$, and 12$)$. $\mathrm{C}$, topology from addition of solely Melitosaurus champsoides at $\mathrm{k}=8$ and $\mathrm{k}=12$. $\mathrm{D}$, topology from the addition of solely Melitosaurus champsoides at $\mathrm{k}=4$. Green circle indicates the node for Tomistominae. 


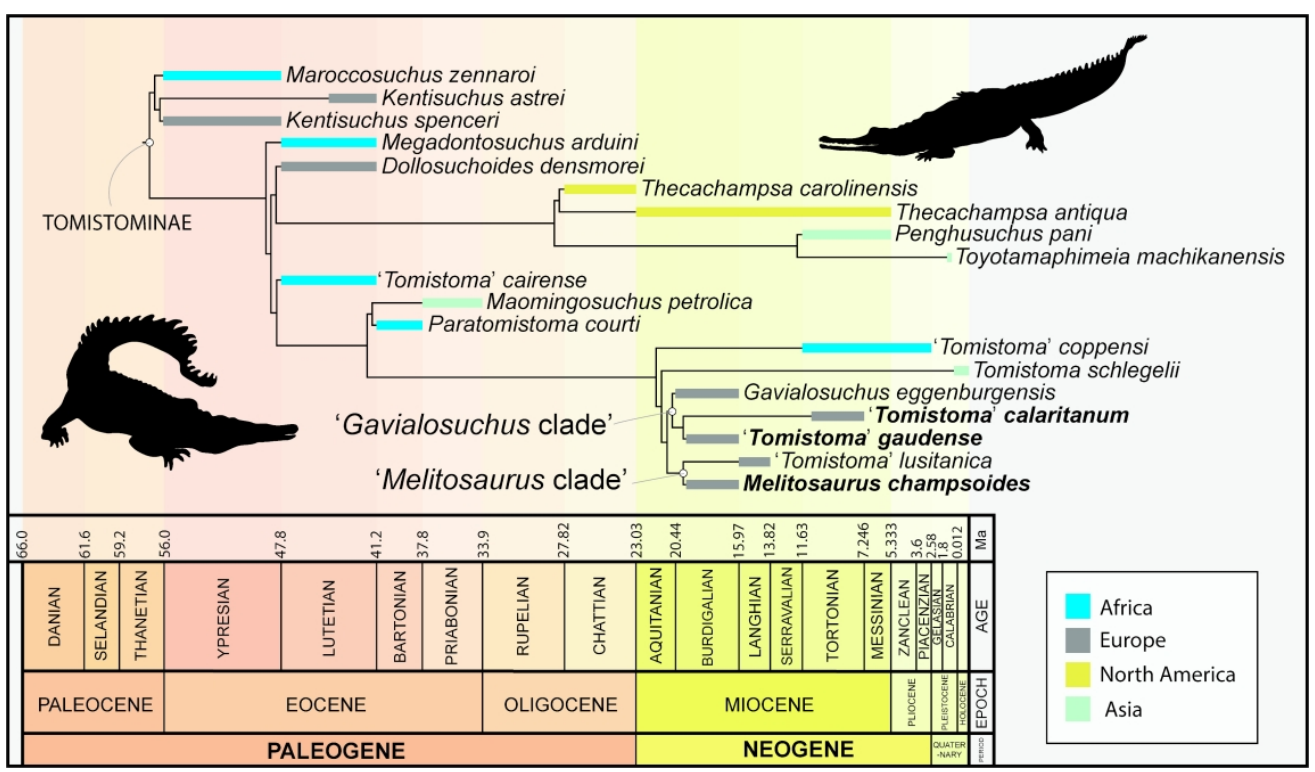

Figure 19. Time-calibrated phylogenetic topology showing the hypothesised relationships of tomistomines, based on extended implied weights analyses. 


\begin{tabular}{|c|c|c|c|}
\hline & \multicolumn{3}{|c|}{ Dimension (mm) } \\
\hline & $\begin{array}{c}\text { Melitosaurus } \\
\text { champsoides } \\
\text { NHMUK PV } \\
\text { OR41151 }\end{array}$ & $\begin{array}{c}\text { Tomistoma } \\
\text { gaudense } \\
\text { NMNH-T11228 }\end{array}$ & $\begin{array}{c}\text { Tomistoma } \\
\text { calaritanum } \\
\text { MDLCA } 148\end{array}$ \\
\hline $\begin{array}{l}\text { Maximum length of skull (articular to } \\
\text { anterior snout tip) }\end{array}$ & - & - & 831 \\
\hline Maximum width of skull & - & - & 318 \\
\hline Width of skull at orbits & - & 155 & 234 \\
\hline Maximum length of external naris & 50 & - & 54 \\
\hline Maximum width of external naris & 44 & - & 41 \\
\hline Anteroposterior length of orbit & - & 44 & 80 \\
\hline Mediolateral width of orbit & - & 52 & 75 \\
\hline $\begin{array}{l}\text { Anteroposterior length of supratemporal } \\
\text { fenestra }\end{array}$ & - & 46 & 47 \\
\hline $\begin{array}{l}\text { Mediolateral width of supratemporal } \\
\text { fenestra }\end{array}$ & - & 49 & 48 \\
\hline $\begin{array}{l}\text { Maximum length of infratemporal } \\
\text { fenestra }\end{array}$ & - & 42 & 58 \\
\hline Maximum width of infratemporal fenestra & - & 19 & 25 \\
\hline Maximum length of mandibular fenestra & - & - & 98 \\
\hline Maximum height of mandibular fenestra & - & - & 37 \\
\hline Maximum length of nasal & - & - & 354 \\
\hline Maximum width of nasal & - & 13 & 13 \\
\hline Maximum length of frontal & - & 117 & 175 \\
\hline Maximum width of frontal & - & 61 & 109 \\
\hline Maximum length of parietal & - & 54 & 59 \\
\hline Maximum width of parietal & - & - & - \\
\hline Maximum length of lacrimal & - & 65 & 91 \\
\hline Maximum width of lacrimal & - & - & 39 \\
\hline Maximum length of prefrontal & - & 58 & 63 \\
\hline Maximum width of prefrontal & - & 19 & 15 \\
\hline $\begin{array}{l}\text { Anterior tip of nasal to posterior tip of } \\
\text { external naris }\end{array}$ & 79 & - & 49 \\
\hline $\begin{array}{l}\text { Anterior tip of nasal to anterior tip of } \\
\text { snout }\end{array}$ & 176 & - & 134 \\
\hline $\begin{array}{l}\text { Posterior tip of premaxillae to anterior tip } \\
\text { of snout }\end{array}$ & 263 & - & 219 \\
\hline $\begin{array}{l}\text { Anterior tip of maxillae to anterior tip of } \\
\text { snout }\end{array}$ & 155 & - & 133 \\
\hline $\begin{array}{l}\text { Anterior tip of maxillae to anterior tip of } \\
\text { nasal }\end{array}$ & 17 & - & 1 \\
\hline Snout height at $3^{\text {rd }}$ maxillary tooth & 95 & 36 & 73 \\
\hline Snout width at $3^{\text {rd }}$ maxillary tooth & 94 & 50 & 64 \\
\hline $\begin{array}{l}\text { Anterior tip of prefrontal to anterior tip of } \\
\text { frontal }\end{array}$ & - & 10 & 45 \\
\hline $\begin{array}{l}\text { Anterior tip of frontal to anterior tip of } \\
\text { snout }\end{array}$ & - & - & 428 \\
\hline
\end{tabular}




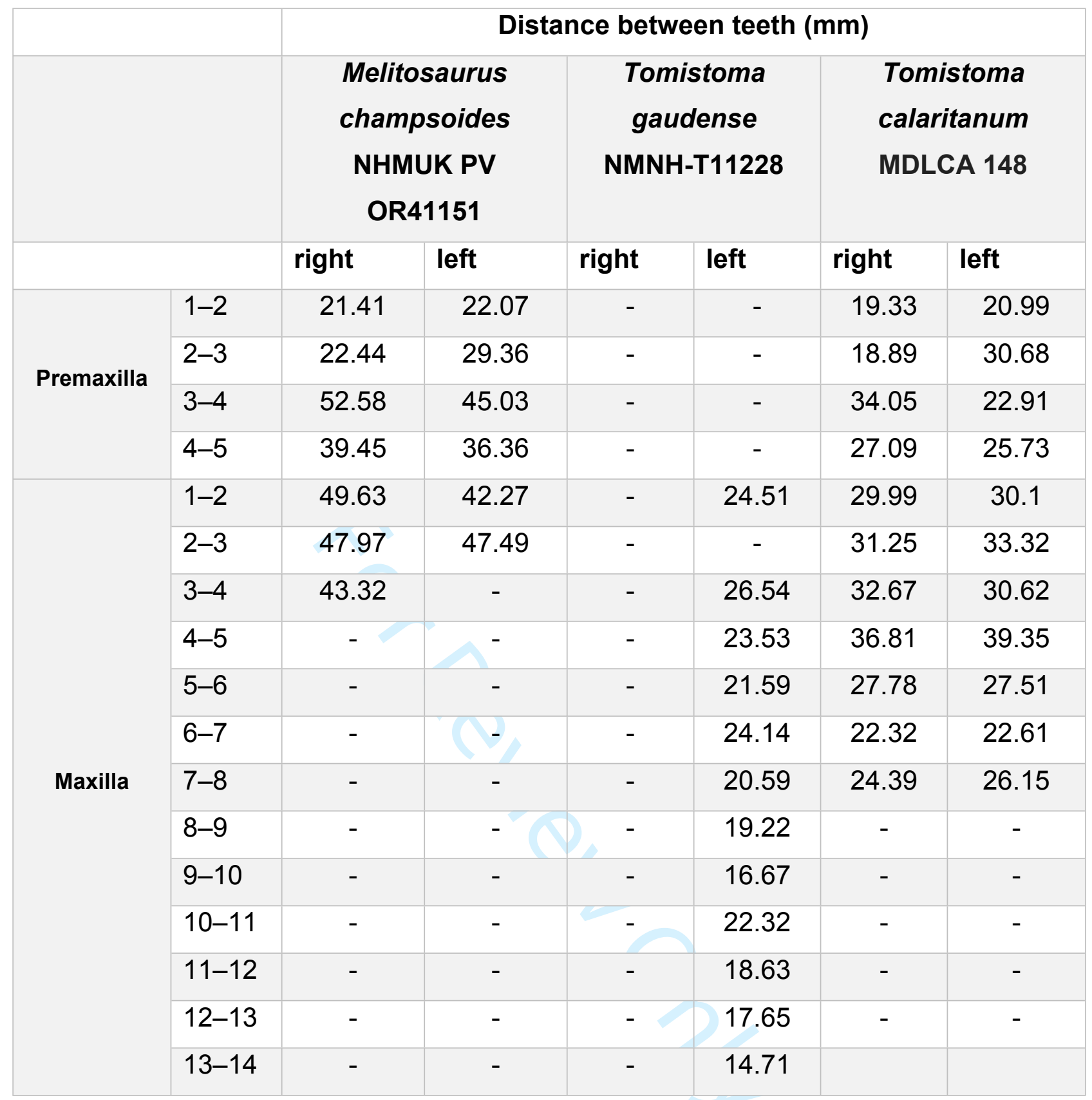




\begin{tabular}{|l|l|l|l|l|}
\hline Analysis & \multicolumn{1}{|c|}{ Weighting } & \multicolumn{1}{|c|}{ Taxa Included } & \multicolumn{1}{|c|}{ MPTs } & Tree Length \\
\hline $\mathbf{1}$ & Equal Weights & All taxa & 69039 & 1018 \\
\hline $\mathbf{2}$ & Equal Weights & Melitosaurus champsoides & 1458 & 1005 \\
\hline $\mathbf{3}$ & EIW $k=12$ & All taxa & 27 & 39.5 \\
\hline $\mathbf{4}$ & EIW $k=12$ & Melitosaurus champsoides & 3 & 39.1 \\
\hline $\mathbf{5}$ & EIW $k=8$ & All taxa & 27 & 52 \\
\hline $\mathbf{6}$ & EIW $k=8$ & Melitosaurus champsoides & 1 & 51.5 \\
\hline $\mathbf{7}$ & EIW $k=4$ & All taxa & 9 & 77.4 \\
\hline $\mathbf{8}$ & EIW $k=4$ & Melitosaurus champsoides & 1 & 76.9 \\
\hline
\end{tabular}




\section{A re-examination of the anatomy and systematics of the tomistomine crocodylians from the Miocene of Italy and Malta}

Cecily S. C. Nicholla*, Jonathan P. Rio ${ }^{b}$, Philip D. Manniona , and Massimo Delfino ${ }^{c, d}$

a Department of Earth Sciences, University College London, Gower Street, London, WC1E 6BT, UK

${ }^{b}$ Department of Earth Science and Engineering, Imperial College London, South Kensington Campus, London, SW7 2AZ, UK

c Dipartimento di Scienze della Terra, Università di Torino, Via Valperga Caluso 35, 10125 Torino, Italy

${ }^{d}$ Institut Català de Paleontologia Miquel Crusafont, Universitat Autònoma de Barcelona, Edifici ICTAICP, Carrer de les Columnes s/n, Campus de la UAB, 08193 Cerdanyola del Vallès, Barcelona, Spain

*Author for correspondence: cecily.nicholl@ucl.ac.uk 


\section{Supplementary Data}

The characters used in this analysis are those used in Jouve (2016), which themselves are mainly based on Brochu (1997a, b, 1999, 2000, 2004, 2010, 2011), with several modifications and additional characters from Norell (1988), Benton \& Clark (1988), Norell \& Clark (1990), Clark (1994), Brochu \& Gingerich (2000), Buscalioni et al. (2001, 2011), Wu et al. (2001), Hua \& Jouve (2004), Jouve (2004), Salisbury et al. (2006), Ösi et al. (2007), Jouve et al. (2008), Delfino et al. (2008), Pol et al. (2009), Shan et al. (2009), Brochu \& Storrs (2012), Brochu et al. (2012) and Jouve et al. (2015). The characters listed below are used in the analyses. Those in bold represent either minor or major modifications to previous characters or are new with respect to Jouve 2016. Characters $7,42,46,64,68,71,75,124,131,45,151$, $161,177,238$ are modified and 244 is new. Characters $7,30,37,62,64,75,78,81$, $87,91,95,103,124,145,151,152,153,156,161,169,171,173,174,176,177$, $179,194,195,206,238$ are ordered, and are identified by an [O].

\section{Characters}

1. Ventral tubercle of proatlas at least one half $(0)$, or less than one half (1) the width of the dorsal crest.

2. Proatlas boomerang shaped (0), strap shaped (1), or massive and block shaped (2).

3. Posterior half of axis neural spine wide (0), or narrow (1).

4. Axis neural arch lacks (0), or possesses (1) a lateral process ("diapophysis"').

5. Atlas intercentrum wedge shaped in lateral view with insignificant parapophyseal processes $(0)$, or plate shaped in lateral view with prominent parapophyseal processes at maturity (1). 
6. Axial hypapophysis located toward the center of centrum (0), or toward the anterior end of centrum (1).

\section{Hypapophyseal keels extend to 10 th vertebra behind atlas $(0), 11^{\text {th }}$ vertebra behind atlas (1), or $12^{\text {th }}$ vertebra behind atlas (2). [O]}

8. First postaxial cervical vertebra with prominent hypapophysis (0), or lacks prominent hypapophysis (1).

9. Neural spine on first postaxial cervical vertebra wide with dorsal tip at least half the length of the centrum without the cotyle (0), or narrow with dorsal tip acute and less than half the length of the centrum without the cotyle (1).

10. Proatlas with prominent anterior process (0), or lacks anterior process (1).

11. Anterior half of axis neural spine oriented horizontally (0), or slopes anteriorly (1).

12. Axis neural spine crested (0), or not crested (1).

13. Anterior sacral capitulum projects far anteriorly of tuberculum and is broadly visible in dorsal view (0), or anterior margins of tuberculum and capitulum nearly in same plane and capitulum largely obscured dorsally (1).

14. Dorsal margin of atlantal rib generally smooth with modest dorsal process $(0)$, or with prominent process (1).

15. Atlantal ribs lack (0), or possess (1) large articular facets for each other at anterior ends.

16. Atlantal ribs without $(0)$, or with (1) very thin medial laminae at anterior end.

17. Proatlas has tall dorsal keel (0), or lacks tall dorsal keel and has a smooth dorsal side (1). 
18. Presacral centra amphicoelous (0), or procoelous (1).

19. Axial hypapophysis with (0), or without (1) deep fork.

20. Axial rib tuberculum wide with broad dorsal tip (0), or narrow with acute dorsal tip (1).

21. Axial rib tuberculum contacts diapophysis late in ontogeny if at all (0), or early in ontogeny (1).

22. Scapular blade flares dorsally at maturity (0), or sides of scapular blade subparallel with minimal dorsal flare at maturity (1).

23. Deltoid crest of scapula very thin at maturity with sharp margin (0), or very wide at maturity with broad margin (1).

24. Scapulocoracoid synchondrosis closes very late in ontogeny (0), or relatively early in ontogeny (1).

25. Scapulocoracoid facet anterior to glenoid fossa uniformly narrow (0), or broad immediately anterior to glenoid fossa and tapering anteriorly (1).

26. Proximal edge of deltopectoral crest emerges smoothly from proximal end of humerus and is not obviously concave (0), or emerges abruptly from proximal end of humerus and is obviously concave (1).

27. Olecranon process of ulna narrow and subangular (0), or wide and rounded (1).

28. Dorsal margin of iliac blade rounded with smooth border (0), rounded with modest dorsal indentation (1), rounded with strong dorsal indentation (wasp-waisted) (2), narrow with dorsal indentation (3), or rounded with smooth border and posterior tip of blade very deep (4). 
29. M. teres major and M. dorsalis scapulae insert separately on humerus and scars can be distinguished dorsal to deltopectoral crest (0), or insert with common tendon and single insertion scar (1).

30. Interclavicle flat along length without dorsoventral flexure (0), with moderate dorsoventral flexure (1), or with severe dorsoventral flexure (2). [O]

31. Anterior end of interclavicle flat (0), or rod-like (1).

32. Supraacetabular crest narrow (0), or broad (1).

33. Limb bones relatively robust and hind limb much longer than forelimb at maturity (0), or limb bones very long and slender and forelimb and hind limb more equal in length at maturity (1).

34. Iliac anterior process prominent (0), or virtually absent (1).

35. Dorsal osteoderms not keeled (0), or keeled (1).

36. Dorsal midline osteoderms rectangular (0), or nearly square (1).

37. Accessory osteoderms absent (0), or maximum of one longitudinal row of transversely contiguous accessory osteoderms (1), or maximum of two longitudinal rows of transversely contiguous accessory osteoderms (2), or maximum of three sagittal longitudinal rows of transversely contiguous accessory osteoderms (3). [O]

38. Nuchal shield grades continuously into dorsal shield (0), differentiated from dorsal shield with four nuchal osteoderms (1), differentiated from dorsal shield with six nuchal osteoderms, four central and two lateral (2), or differentiated from dorsal shield with eight nuchal osteoderms in two parallel rows (3).

39. Ventral osteoderms present, polygonal (0), or present, square (1), or present, paired ossifications that suture together (2), or absent (3). 
40. Anterior margin of dorsal midline osteoderms with anterior process (0), or smooth and without process (1).

41. Splenial with anterior perforation for mandibular ramus of cranial nerve $V(0)$, or lacks anterior perforation for mandibular ramus of cranial nerve $\mathrm{V}(1)$.

\section{Mandibular ramus of cranial nerve $\mathbf{V}$ exits splenial anteriorly only (0), or splenial has singular perforation for mandibular ramus of cranial nerve $\mathbf{V}$ posteriorly (1).}

43. Splenial participates in mandibular symphysis and splenial symphysis adjacent to no more than one dentary alveoli (0), splenial excluded from mandibular symphysis and anterior tip of splenial passes ventral to Meckelian groove (1), splenial excluded from mandibular symphysis and anterior tip of splenial passes dorsal to Meckelian groove (2), participates in the mandibular symphysis over the length of two to five teeth (3); deep splenial symphysis, participates in the mandibular symphysis over the length of five to seven teeth, and forms wide "V" within symphysis (4), or deep splenial symphysis participates in the mandibular symphysis over the length of five to seven teeth, and splenial constricted within symphysis and forms narrow "V" (5), or deep splenial symphysis, longer than seven dentary alveoli (6).

44. Articular-surangular suture simple (0), or articular bears anterior lamina dorsal to lingual foramen (1), or articular bears anterior lamina ventral to lingual foramen (2), or bears laminae above and below foramen (3).

45. Lingual foramen for articular artery and alveolar nerve perforates surangular entirely (0), or perforates surangular-angular suture (1).

46. Coronoid bounds posterior half of foramen intermandibularis medius ( 0 ), or completely surrounds foramen intermandibularis medius at maturity (1). 
47. Angular-surangular suture contacts external mandibular fenestra at posterior angle at maturity $(0)$, or passes broadly along ventral margin of external mandibular fenestra late in ontogeny (1).

48. Anterior processes of surangular unequal (0), or subequal to equal (1).

49. Foramen aerum at extreme lingual margin of retroarticular process $(0)$, or set in from margin of retroarticular process (1).

50. Retroarticular process projects posteriorly (0), or projects posterodorsally (1).

51. Surangular extends to posterior end of retroarticular process (0), or pinched off anterior to tip of retroarticular process (1).

52. Alveoli for dentary teeth 3 and 4 nearly same size and confluent (0), fourth alveolus larger than third and alveoli are separated (1), or same size and separated (2).

53. Anterior dentary teeth strongly procumbent (0), or project anterodorsally (1).

54. Superior edge of coronoid slopes strongly anteriorly (0), or almost horizontal (1).

55. Inferior process of coronoid laps strongly over inner surface of Meckelian fossa (0), or remains largely on medial surface of mandible (1).

56. Coronoid imperforate (0), or with perforation posterior to foramen intermandibularis medius (1).

57. Dorsal projection of hyoid cornu flat (0), or rod-like (1).

58. Dorsal projection of hyoid cornu narrow with parallel sides (0), or flared (1).

59. Process of splenial separates angular and coronoid (0), or there is no splenial process between angular and coronoid (1). 
60. Sulcus between articular and surangular (0), or articular flush against surangular (1).

61. Surangular with spur bordering the dentary throw lingually for at least one alveolus length (0), or lacking such spur (1).

62. External mandibular fenestra absent (0), or present as narrow slit, no discrete fenestral concavity on angular dorsal margin (1), or present with discrete concavity on angular dorsal margin (2), present and very large; most of foramen intermandibularis caudalis visible in lateral view (3). [O]

63. Dorsal anterior projection of coronoid longer than ventral $(0)$, or ventral projection longer than dorsal (1).

\section{Mature skull table with no squamosal prongs (0), with significant squamosal prongs (1), or with very long squamosal prongs (2). [O]}

65. Surangular-dentary suture intersects external mandibular fenestra anterior to posterodorsal corner (0), or at posterodorsal corner (1).

66. Angular extends dorsally toward or beyond anterior end of foramen intermandibularis caudalis and anterior tip acute (0), or does not extend dorsally beyond anterior end of foramen intermandibularis caudalis and anterior tip very blunt (1).

67. Surangular-angular suture lingually meets articular at ventral tip (0), or dorsal to ventral tip (1).

68. Dentary gently curved (0), or linear (1) between 4th and 10 th alveoli.

69. Spina quadratojugalis prominent at maturity (0), or greatly reduced or absent at maturity (1). 
70. Postorbital bar massive and anteroposteriorly extended (0), or slender and rounded in cross section (1).

71. Palatine forms anterior margin of choanal opening (0), or choanal opening entirely surrounded by the pterygoid (1).

72. Choana projects posteroventrally (0), or anteroventrally (1) at maturity.

73. Pterygoid surface lateral and anterior to internal choana flush, with choanal margin (0), or pushed inward anterolateral to choanal aperture (1), or pushed inward around choana to form neck surrounding aperture (2), or everted from flat surface to form neck surrounding aperture (3).

74. Extensive exposure of prootic on external braincase wall (0), or prootic largely obscured by quadrate and laterosphenoid externally (1).

75. Quadratojugal forms posterior angle of infratemporal fenestra (0), quadratojugal-jugal suture lies at posterior angle of infratemporal fenestra (1), or jugal forms posterior angle of infratemporal fenestra (2). [O]

76. Postorbital neither contacts quadrate nor quadratojugal medially (0), contacts quadratojugal but not quadrate medially (1), contacts quadrate and quadratojugal at dorsal angle of infratemporal fenestra (2), contacts quadratojugal with significant descending process (3), or contacts quadrate but not quadratojugal medially (4).

77. Dentary tooth 4 occludes in notch between premaxilla and maxilla early in ontogeny (0), or occludes in pit between premaxilla and maxilla and there is no notch early in ontogeny (1).

78. All dentary teeth occlude lingual to maxillary teeth (0), occlusion pit between 7 th and $8^{\text {th }}$ maxillary teeth and all other dentary teeth occlude lingually (1), or dentary teeth occlude in line with maxillary toothrow (2). [0]

79. Naris projects anterodorsally (0), or dorsally (1). 
80. Quadratojugal extends to superior angle of infratemporal fenestra (0), or does not extend to superior angle of infratemporal fenestra and quadrate participates in fenestra (1).

81. Frontoparietal suture deeply within supratemporal fenestra and frontal prevents broad contact between postorbital and parietal (0), suture makes modest entry into supratemporal fenestra at maturity and postorbital and parietal are in broad contact (1), or suture on skull table entirely (2). [O]

82. Supraoccipital exposure on dorsal skull table small (0), points posteriorly to the caudal margin of the parietal (1), absent or nearly excluded from the dorsal skull table (2), large (3), or large such that parietal is excluded from posterior edge of table (4).

83. Quadratojugal sends long anterior process along lower temporal bar (0), or sends modest process or none at all along lower temporal bar (1).

84. Dorsal and ventral rims of squamosal groove for external ear valve musculature parallel (0), or squamosal groove flares anteriorly (1).

85. Palatine-pterygoid suture nearly at (0), or far from (1) posterior angle of suborbital fenestra.

86. Frontoparietal suture concavoconvex (0), or linear (1).

87. Supratemporal fenestra with fossa and dermal bones of skull roof do not overhang rim at maturity (0), dermal bones of skull roof overhang rim of supratemporal fenestra near maturity (1), or supratemporal fenestra closes during ontogeny (2). [O] 
88. Pterygoid ramus of ectopterygoid straight, posterolateral margin of suborbital fenestra linear (0), or ramus bowed, posterolateral margin of fenestra concave (1).

89. Largest maxillary alveolus in the "first wave" is no. 3 (0), no. 5 (1), no. 4 (2), no. 4 and no. 5 are same size (3), no. 6 (4), or maxillary teeth homodont (5), or maxillary alveoli increase in diameter posteriorly toward penultimate or ultimate alveolus (6), or no. 7 (7).

90. Lateral edges of palatines parallel posteriorly (0), or flare posteriorly, producing a shelf (1).

91. Ectopterygoid abuts the last two maxillary teeth (0), does not abut the maxillary teeth, and the ectopterygoid-maxillary suture parallels the toothrow (1), or maxilla broadly separates ectopterygoid from maxillary toothrow (2). [O]

92. Shallow fossa at anteromedial corner of supratemporal fenestra (0), or no such fossa and anteromedial corner of supratemporal fenestra smooth (1).

93. Lacrimal makes broad contact with nasal and there is no posterior process of maxilla (0), maxilla sends posterior process within lacrimal (1), maxilla sends posterior process between lacrimal and prefrontal (2), or between lacrimal and nasal (3).

94. Lateral edges of palatines smooth anteriorly (0), or with lateral process projecting from palatines into suborbital fenestrae (1).

95. External naris bisected by nasals (0), nasals contact external naris but do not bisect it (1), nasals excluded, at least externally, from naris and nasals and premaxillae still in large contact (2), nasals excluded from naris and nasals and premaxillae in weak contact (3), or nasals and premaxillae not in contact (4). [0]

96. Palpebral forms from single ossification (0), or from multiple ossifications (1).

97. Premaxilla has five teeth (0), or four teeth (1) early in post-hatching ontogeny. 
98. Posterior pterygoid processes tall and prominent (0), small and project posteroventrally (1), or small and project posteriorly (2).

99. Prefrontal pillar solid (0), or with large pneumatic sinus (prefrontal recess of Witmer 1997) (1).

100. Prefrontals separated by frontals and nasals (0), or prefrontals meet medially (1).

101. Dorsal surface of rostrum curves smoothly (0), or bears medial dorsal boss (1).

102. Caudal margin of otic aperture not defined and gradually merging into the exoccipital (0) or smooth and continuous with the paroccipital process (1), or caudal margin of otic aperture inset (2).

103. Margin of orbit flush with skull surface (0), dorsal edge of orbit upturned (1), or orbital margin telescoped (2). [O]

104. Medial parietal wall of supratemporal fenestra imperforate (0), or bearing foramina (1).

105. Maxilla has linear medial margin adjacent to suborbital fenestra (0), or bears broad shelf extending into fenestra, making lateral margin concave (1).

106. Surangular continues to dorsal tip of lateral wall of glenoid fossa (0), or truncated and not continuing dorsally (1).

107. Posterior rim of internal choana not deeply notched (0), or deeply notched (1).

108. Anterior face of palatine process rounded or pointed anteriorly (0), or invaginate (1).

109. Anterior ectopterygoid process tapers to a point (0), or is forked (1). 
110. Palatine process extends (0), or does not extend (1) significantly beyond anterior end of suborbital fenestra.

111. Maxillary foramen for palatine ramus of $\mathrm{CN}-\mathrm{V}$ small or not present $(0)$, or very large (1).

112. Quadrate with small ventrally reflected medial hemicondyle $(0)$, with small medial hemicondyle and dorsal notch for foramen aerum (1), with prominent dorsal projection between hemicondyles (2), or with expanded medial hemicondyle (3).

113. Basisphenoid thin (0), or anteroposteriorly long (1) anterior to the basioccipital.

114. Spina quadratojugalis low and near posterior angle of infratemporal fenestra (0), or high and between posterior and superior angles of infratemporal fenestra (1).

115. Laterosphenoid bridge comprised entirely of laterosphenoid (0), or with ascending process or palatine (1).

116. Ectopterygoid-pterygoid flexure disappears during ontogeny (0), or remains throughout ontogeny (1).

117. Lacrimal longer than prefrontal (0), prefrontal longer than lacrimal (1), or lacrimal and prefrontal both elongate and nearly the same length (2).

118. Palatine process generally broad anteriorly (0), or in form of thin wedge (1).

119. Basisphenoid not broadly exposed ventral to basioccipital at maturity and pterygoid short ventral to median eustachian opening (0), or basisphenoid exposed as broad sheet ventral to basioccipital at maturity and pterygoid tall ventral to median eustachian opening (1).

120. Medial jugal foramen small (0), or very large (1). 
121. Quadrate foramen aerum on mediodorsal angle (0), or on dorsal surface (1) of quadrate.

122. Sulcus on anterior braincase wall lateral to basisphenoid rostrum (0), or braincase wall lateral to basisphenoid rostrum smooth with no sulcus (1).

123. Skull table surface slopes ventrally from sagittal axis (0), or is planar (1), or is medially depressed (2) at maturity.

124. Incisive foramen extremely reduced and thin (0), small and less than half the greatest width of premaxillae (1), or large and intersects premaxillarymaxillary suture (2). [O]

125. Vomer entirely obscured by premaxilla and maxilla (0), or exposed on palate at premaxillary-maxillary suture (1).

126. Vomer entirely obscured by maxillae and palatines (0), or exposed on palate between palatines (1).

127. Significant ventral quadrate process on lateral braincase wall (0), or quadratepterygoid suture linear from basisphenoid exposure to foramen ovale (1).

128. Lateral carotid foramen opens lateral (0), or dorsal (1) to basisphenoid lateral exposure at maturity.

129. Basisphenoid not exposed extensively (0), or exposed extensively (1) on braincase wall anterior to foramen ovale.

130. Capitate process of laterosphenoid oriented laterally (0), or anteroposteriorly (1) toward midline.

131. Parietal and squamosal widely separated by quadrate on posterior wall of supratemporal fenestra (0), parietal and squamosal approach each other on 
posterior wall of supratemporal fenestra without actually making contact (1), or parietal and squamosal meet along posterior wall of supratemporal fenestra (2). [O]

132. Quadrate and squamosal not in contact on the external surface of the skull, posteriorly to the external auditory meatus (0), or quadratosquamosal suture extends dorsally along caudal margin of the external auditory meatus (1), or extends only to the caudoventral corner of the external auditory meatus (2).

133. Ectopterygoid extends along medial face of postorbital bar (0), or stops abruptly ventral to postorbital bar (1).

134. Two prominent projections (0), or single projection that is generally not prominent (1) on postorbital bar.

135. Maxillary toothrow laterally convex or linear (0), or laterally convex and flaring posterior to first six maxillary alveoli (1), or flaring laterally from $2^{\text {nd }}$ or $3^{\text {rd }}$ maxillary alveoli (2).

136. Medial process of prefrontal pillar expanded dorsoventrally (0), or anteroposteriorly (1).

137. Dorsal half of prefrontal pillar narrow (0), or expanded anteroposteriorly in dorsal half (1).

138. Medial process of prefrontal pillar wide (0), or constricted (1) at base.

139. Lateral edge of the jugal raises laterally to the postorbital bar and a gutter separates this edge from the postorbital bar (0), or lateral edge of the jugal raises laterally to the postorbital bar, and projects a shelf laterally to the postorbital bar, and the dorsal margin of the jugal is not gently convex dorsally, but shows a gentle step in lateral view (1), or lateral edge of the jugal raises laterally to the postorbital bar, but there is no or shallow gutter between the latter and postorbital bar, and the dorsal margin of the jugal is not gently convex 
dorsally but exhibits a step in lateral view (2), or no jugal lateral edge laterally to the postorbital bar, jugal not widens laterally and presence of a prominent notch on the ventral margin of the orbit (3).

140. Mature skull table with broad lateral curvature (0), with nearly straight lateral sides (1), or strong lateral curvature of the squamosal and only squamosal (2).

141. Exoccipital with very prominent boss on paroccipital process and process lateral to cranioquadrate opening short $(0)$, or exoccipital with small or no boss on paroccipital process and process lateral to cranioquadrate opening long (1).

142. Premaxillary surface lateral to naris smooth (0), or with deep notch lateral to naris (1).

143. Canthi rostrales absent or very modest (0), or very prominent (1) at maturity.

144. Preorbital ridges absent or very modest (0), or very prominent (1) at maturity.

145. Dorsal premaxillary processes short and not extending beyond third maxillary alveolus (0), or extending from the third to fifth maxillary alveolus (1), or extending beyond the fifth maxillary alveolus (2). [O]

146. Anterolateral border of the suborbital fenestra narrow (0), or very broad and at least twice wider than the diameter of the adjacent tooth (1).

147. Lateral eustachian canals open dorsal (0), or lateral (1) to medial eustachian canal.

148. Surface of maxilla within narial canal imperforate (0), or with multiple cecal recesses (1).

149. Ectopterygoid extends (0), or does not extend (1) to posterior tip of lateral pterygoid flange at maturity. 
150. Squamosal does not extend (0), or extends (1) ventrolaterally to lateral extent of exoccipital and quadrate.

\section{Otoccipitals terminate dorsal to basioccipital tubera (0), send slender process ventrally to basioccipital tubera (1), or send robust process ventrally and participate in basioccipital tubera (2). [O]}

152. Internal choana not septate (0), with septum that remains recessed within choana (1), or with septum that projects out of choana (2). [O]

153. Posterior margin of the foramen incisivum far posterior to the last premaxillary tooth (0), posterior to the posterior margin of the penultimate premaxillary tooth (1), posterior to the posterior margin of the tooth anterior to the penultimate premaxillary tooth (2), or at the level or anterior to the tooth anterior to the penultimate premaxillary tooth (3). [O]

154. Parietal with sinus communicating with pneumatic system (0), or solid and without sinus (1).

155. Ventral scales have (0), or lack (1) follicle gland pores.

156. Ventral collar scales not enlarged relative to other ventral scales (0), in a single enlarged row (1), or in two parallel enlarged rows (2). [0]

157. Median pelvic keel scales form two parallel rows along most of tail length (0), form single row along tail (1), or merge with lateral keel scales to form $Y$-shaped keel (2).

158. Lingual osmoregutatory pores small (0), or large (1).

159. Tongue with (0), or without (1) keratinized surface.

160. M. caudofemoralis with single head (0), or with double head (longus and brevis) 
161. Naris anteroposterior length to mediolateral width ratio is <1 (0) 1 to 1.5 (1) or $>1.5$ (2). [O]

162. Surangular-articular suture oriented anteroposteriorly (0), or bowed strongly laterally (1) within glenoid fossa.

163. Postorbital-squamosal suture oriented ventrally (0), or passes medially (1) ventral to skull table.

164. Anterior foramen for palatine ramus of cranial nerve VII ventrolateral (0), or ventral (1) to basisphenoid rostrum.

165. Edge of the maxillary tooth lower or at the same level than the space between toothrow (0), or edge of the maxillary tooth alveoli higher than the space between the toothrows (toothrow underlined) (1).

166. Ventral border of the exoccipital: convex and ventrally projected, hiding the posterior opening of the cranioquadrate passage from the occipital view (0), straight, sharpen or smoothly convex and does not hide the posterior opening of the cranioquadrate passage from occipital view (1).

167. Occipital surface sloped, visible in dorsal view (0), or vertical and not visible in dorsal view (1) at maturity.

168. Ventral premaxilla-maxilla suture short and ends posteriorly before the $3^{\text {rd }}$ maxillary teeth $(0)$, or elongated and extends or exceeds the $3^{\text {rd }}$ maxillary alveoli (1).

169. Less than 18 teeth (0), 18 to 22 teeth (1), or more than 22 teeth (2) on maxilla. [O]

170. Lateral edge of the skull table at the level of the postorbital-squamosal suture 
situated laterally at the same level as (0), or medially to (1) the quadrate condyle in dorsal view at maturity.

171. Frontal ends posterior (0), at the same level (1), or extends well anterior (2) to the anterior extension of the prefrontal. [O]

172. Maxillary posterior process without tooth, short or absent (0), or long, longer than the distance between the three last teeth (1) in ventral view.

173. The ectopterygoid does not extend (0), extends anteriorly beyond the anterior quarter of the suborbital fenestra (1), or is such extended that it nearly excludes the maxillary from the margin of the suborbital fenestra (2). [O]

174. Anterior process of jugal extends anterior or at the same level as (0), well posterior to the anterior process of frontal (1), or does not exceeds the anterior margin of the orbit (2). [O]

175. Anterior process of frontal extending far anterior (0), or at the same level or posterior (1) to the anterior margin of the orbit.

176. Symphysis less extended posteriorly than the level of the thirteenth dentary tooth (0), extended between the level of the fourteenth and twentieth tooth (1), or extended beyond the twenty first tooth (2). [O]

\section{Ratio of the mediolateral width of the interorbital bar to the skull width at} the same level is $<0.2(0), 0.2$ to $0.3(1)$, or $>0.3(2)$. [O]

178. Ventral margin of jugal strongly convex dorsally (0), or straight (1).

179. Posterior edge of the supratemporal fenestra very thick, thicker than the lateral margin (0), as thick as the lateral margin (1), thinner than the lateral margin (2), or forms a thin crest (3). [O] 
180. Presence (0), or absence (1) of a medial crest on the basioccipital.

181. Posterior process of jugal ends posterior to (0), anterior or at the level as (1) the posterior margin of the basioccipital tubera.

182. Absence (0), or presence (1) of a posterior dentary process between splenial and angular on the ventral side.

183. Infratemporal fenestra not or slightly (0), or largely (1) visible in ventral view, laterally to the pterygoid flange.

184. Postorbital bar strongly inclined laterally (0), or vertical and not visible in dorsal view (1).

185. Dorsal margin of the articular on retroarticular process largely visible in lateral view (0), or slightly or not visible in lateral view (1).

186. Posterior margin of the orbit anterior to the posterior margin of the suborbital fenestra (0), or posterior or at the same level as the posterior margin of the suborbital fenestra (1).

187. Posterior surface of basioccipital ventral to the occipital condyle long, flat and nearly vertical $(0)$, or short and gently curved (1).

188. Absence (0), or presence (1) of a smooth medial depression ventral to the basioccipital and posterior to the medial eustachian foramen.

189. Ventral processes of the exoccipital oriented ventrally or medioventrally (0), or oriented lateroventrally (1) in occipital view.

190. Antorbital fenestra present (0), or absent (1).

191. Distance between the tip of the snout and the anteriormost position of the 
premaxilla-maxilla suture in dorsal view is longer (0), or shorter (1) than the distance between the anteriormost position of the premaxilla-maxilla suture in dorsal view and the posterodorsal extremity of the premaxilla.

192. Length of the posterior process of the premaxilla: distance between the posterior margin of the external nares to the posterodorsal extremity of the premaxilla is less than twice longer (0), or at least twice longer (1) than the length between the tip of the snout and the posterior margin of the external nares.

193. Anterolateral margin of the suborbital fenestra longer (0), or as long as, or shorter (1) than the posterolateral margin.

194. Teeth and alveoli of maxilla and/or dentary circular in cross-section (0), or posterior teeth laterally compressed (1), or all teeth compressed (2). [O]

195. Dentary symphysis extends to fourth or fifth alveolus (0), or sixth through eighth alveolus (1), or behind eighth alveolus (2). [O]

196. Largest dentary alveolus immediately caudal to fourth is 13 or $14(0), 13$ or 14 and a series behind it (1), 11 or 12 (2), no differentiation (3), or behind 14 (4).

197. Anterolateral limit of the maxilla-premaxilla suture in dorsal view: at the level as or posterior (0), or far anterior (1) to the posterior margin of the external nares.

198. Supratemporal fenestra small and rounded (0), large, quadrangular, much wider than long, and posterior margin straight and laterally oriented (1), or wider than long, and posterior margin straight and posterolaterally oriented (2) at maturity.

199. Foramen aereum small (0), comparatively large (1), or absent (2).

200. Anterior margin of suborbital fenestra: exceeds strongly (0), or does not exceed (1) the level of the anterior margin of orbit. 
201. Lateral posterior tuberosity of supraoccipital not visible (0), or visible in dorsal view (1).

202. Relative position of the three last premaxillary teeth: curves laterally or aligned in an anteroposterior line (0), or aligned in a posteromedial line (1).

203. Size of the first to tenth maxillary teeth: variation, homodontie (0), or only one tooth larger, other ones being of nearly same size (1).

204. Position of the last premaxillary tooth relative to the tooth immediately anterior: posterior (0), posterolateral (1), or posteromedial (2).

205. Premaxillae do not contact each other or in weak contact (0), or contact largely each other (1) posterior to the external nares.

206. Anterior margin of the choana anterior (0), or at the level as the posterior margin of the suborbital fenestra (1), or far posterior to the posterior margin of the suborbital fenestra and posterior margin of the choana anterior or at the level as the posterior margin of the pterygoidian wing (2), or posterior margin of the choana posterior to the posterior margin of the pterygoidian wing (3). [O]

207. Posterolateral margin of squamosal horizontal or nearly so (0), or upturned to form a discrete horn (1).

208. Lateral margin of the orbit lateral (0), or medial or at the level as the lateral margin of the maxillary waves at the level of the 3-6 teeth (1).

209. Ventral surface of quadrate smooth or with simple muscle scars (0), or with developed ridges that form a folded surface rising ventrally to the quadrate surface and placed at its posteromedial margin (1), or with a protuberant bulky insertion near the contact with quadrate that may extend toward the center of the quadrate (2). 
210. Vertical ridge on occipital surface of paroccipital process just lateral to distal end, absent (0), or present (1).

211. Posterior margin of the choanae thick (0), or as a thin lamina (1).

212. Height of peduncle of neural arch on caudal cervical vertebrae approximately equivalent to that of peduncle on neural arch of each of the thoracic, sacral and cranial-most caudal vertebrae (0), or considerably greater (1).

213. Cervical vertebrae all amphicoelous (0) or some amphicoelous and some procoelous (1), or all procoelous (2).

214. Caudal vertebrae all amphicoelous (0), or first caudal vertebra opisthoceolous or procoelous, remainder of caudal vertebrae amphicoelous (1), or first caudal vertebra opisthoceolous or procoelous, remainder of caudal vertebrae procoelous, with the degree of procoely decreasing terminally (2), or first caudal vertebra biconvex, remainder of caudal vertebrae procoelous, with the degree of procoely decreasing terminally (3).

215. Distal extremity of the ulna expanded transversely with respect to the long axis of the bone; maximum width equivalent to that of the proximal extremity $(0)$, or proximal extremity of the ulna considerably wider than the distal extremity (1).

216. Maxillary and dentary teeth with smooth carinae (0), or serrated (1).

217. Cervical and anterior dorsal centra lack (0), or bear (1) deep pits on the ventral surface of the centrum.

218. External naris of reproductively mature males remains similar to that of females (0), or develops bony excrescence (ghara) (1).

219. External naris opens flush with dorsal surface of premaxillae (0), or circumscribed by thin crest (1). 
220. Maxilla terminates in palatal view anterior to lower temporal bar (0), or comprises part of the lower temporal bar (1).

221. Penultimate maxillary alveolus less than (0), or more than (1) twice the diameter of the last maxillary alveolus.

222. Prefrontal dorsal surface smooth adjacent to orbital rim (0), or bearing discrete knob-like processes (1).

223. Anterior tip of frontal forms simple acute point (0), or forms broad, complex sutural contact with the nasals (1).

224. Premaxillary interalveolar space homogeneous (0), or second tooth separated from the first and close to the third (1).

225. Premaxillary teeth: all of nearly same size or increase in size up to the last $(0)$, penultimate is the largest (1), or penultimate and antepenultimate nearly equal in size (2).

226. Prefrontal does not send (0), or sends (1) a process within the nasal.

227. Largest maxillary tooth in the second "wave", posterior to the $9^{\text {th }}$ tooth : $9^{\text {th }}$ to $11^{\text {th }}(0), 12$ or posterior (1), or homodont (2).

228. Anterior margin of the coronoid far anterior (0), or levelled or posterior (1) to the anterior margin of the foramen intermandibularis caudalis when exists, or the anterodorsal process of the angular on the medial surface of the mandible.

229. Iris greenish/yellowish (0), or brown (1).

230. Two or more (0), or one (1) row of postoccipital osteoderms.

231. Palatine-maxillary suture intersects suborbital fenestra at its anteromedial margin or maxilla sends a medial process that exceeds posteriorly the anterior 
margin of the suborbital fenestra $(0)$, or intersects the suborbital fenestra nearly at its anteriormost limit, and no posteromedial maxillary process (1).

232. Frontal lacks (0), or bears (1) prominent midsagittal crest between orbits.

233. All cervical neural spines anteroposteriorly broad (0), or posterior neural spines thin and rod-like (1).

234. Postorbital bar continuous with anterolateral edge of skull table (0), or inset (1).

235. Maxillary teeth not widely spaced, and $7^{\text {th }}$ and $8^{\text {th }}$ teeth not more spaced than other teeth (0), maxillary teeth widely spaced and $7^{\text {th }}$ and $8^{\text {th }}$ teeth not more spaced than other teeth (1), maxillary teeth not widely spaced, and distance between $7^{\text {th }}$ and $8^{\text {th }}$ maxillary teeth wider than other intervals (2), or maxillary teeth widely spaced, and distance between $7^{\text {th }}$ and $8^{\text {th }}$ maxillary teeth wider than other intervals (3).

236. Primary choanae rounded or oval (0), or triangular in shape, and anterior margin sharp anteriorly (1).

237. Pterygoid at least $50 \%$ wider than its minimal length (0), or nearly as wide as its minimal length (1).

\section{Ratio of the mediolateral width of the supratemporal fenestral bar to the width of the skull table at the same level is $<0.1(0), 0.1$ to $0.175(1)$, or $>$ 0.175 (2). [O]}

239. Posterior dorsal jugal foramen, at the base of the postorbital bar: small or absent (0), or large (1).

240. Dentary long ventral to mandibular fenestra, sharp and acute in the angular (0), or dentary short ventral to mandibular fenestra (1). 
241. Lateral carotid foramen opens posteroventrally on the occipital surface (0), or opens ventral on the exoccipital crest separating the basicranium from the occipital surface (1).

242. Lacrimal nearly twice wider (0), or nearly as wide as the prefrontal (1).

243. Posterior process of the ectopterygoid forked, with a posterior process on the jugal and another on the postorbital pillar (0), or posterior process of ectopterygoid not forked, without any distinct process on the jugal (1).

\section{Ratio of the anteroposterior length of the supratemporal fenestra to the anteroposterior length of the orbit is $<0.5(0), 0.5$ to $0.75(1)$, or $>0.75(2)$.}

\section{References}

Benton M. J. \& Clark J. M. 1988. Archosaur phylogeny and the relationships of the Crocodilia. In: Benton MJ, ed. The Phylogeny and Classification of the Tetrapods. Oxford: Clarendon Press, 295-338.

Brochu C. A. 1997a. Phylogenetic systematics and taxonomy of Crocodylia. Unpublished Ph.D. Dissertation. Austin: University of Texas, 540 pp.

Brochu C. A. 1997b. Morphology, fossils, divergence timing, and the phylogenetic relationships of Gavialis. Systematic Biology 46: 479-522.

Brochu C. A. 1999. Phylogenetics, taxonomy, and historical biogeography of Alligatoroidea. Journal of Vertebrate Paleontology Memoir 6: 9-100.

Brochu C. A. 2000. Phylogenetic relationships and timing of Crocodylus based on morphology and fossil record. Copeia 46(3): 657-673. 
Brochu C. A. 2004a. A new Late Cretaceous gavialoid crocodylian from Eastern North America and phylogenetic relationships of thoracosaurs. Journal of Vertebrate Paleontology 24: 610-633.

Brochu C. A. 2004b. Alligatorine phylogeny and the status of Allognathosuchus Mook, 1921. Journal of Vertebrate Paleontology 24(4): 857-873.

Brochu C. A. 2006. Osteology and phylogenetic significance of Eosuchus minor (Marsh, 1870) new combination, a longirostrine crocodylian from the late Paleocene of North America. Journal of Paleontology 80: 162-186.

Brochu C. A. 2010. A new alligatorid from the Lower Eocene Green River Formation of Wyoming and the origin of caimans. Journal of Vertebrate Paleontology 30(4): 1109-1126.

Brochu C. A. 2011. Phylogenetic relationships of Necrosuchus ionensis Simpson, 1937 and the early history of caimanines. Zoological Journal of the Linnean Society 163: S228-S256.

Brochu C. A. \& Gingerich P. D. 2000. New Tomistomine crocodylian from the Middle Eocene (Bartonien of Wadi Hitan, Fayum Province, Egypt). Contribution from the Museum of Paleontology, the University of Michigan 30: 251-268.

Brochu C. A. \& Storrs G. W. 2012. A giant crocodile from the Plio-Pleistocene of Kenya, the phylogenetic relationships of Neogene African crocodylines, and the antiquity of Crocodylus in Africa. Journal of Vertebrate Paleontology 32(3): 587-602.

\begin{abstract}
Brochu C. A., Parris D. C., Grandstaff B. S., Denton R. K. \& Gallagher W. B. 2012. A new species of Borealosuchus (Crocodyliformes, Eusuchia) from the Late Cretaceous-early Paleogene of New Jersey. Journal of Vertebrate Paleontology 32(1): 105-116.
\end{abstract}

Buscalioni A. D., Ortega F., Weishampel D. B. \& Jianu C. M. 2001. A revision of the Crocodyliform Allodaposuchus precedens from the upper Cretaceous of the Hateg 
basin, Romania. Its relevance in the phylogeny of Eusuchia. Journal of Vertebrate Paleontology 21(1): 74-86.

Buscalioni A. D., Piras P., Vullo R., Signore M. \& Barbera, C. 2011. Early eusuchia crocodylomorpha from the vertebrate-rich Plattenkalk of Pietraroia (Lower Albian, southern Apennines, Italy). Zoological Journal of the Linnean Society 163: S199_ S227.

Clark J. M. 1994. Patterns of evolution in Mesozoic Crocodyliformes. In: Fraser NC, Sues HD, eds. In the Shadow of the Dinosaurs, Early Mesozoic Tetrapods. Cambridge and New York: Cambridge University Press, 84-97

Delfino M., Codrea V., Folie A., Dica P., Godefroit P. \& Smith T. 2008. A complete skull of Allodaposuchus precedens Nopcsa, 1928 (Eusuchia) and a reassessment of the morphology of the taxon based on the Romanian remains. Journal of Vertebrate Paleontology 28 (1): 111-122.

Hua S. \& Jouve S. 2004. A primitive marine gavialoid from the Paleocene of Morocco. Journal of Vertebrate Paleontology 24(2): 344-353.

Jouve S. 2004. Etude des Crocodyliformes fini Crétacé-Paléogène du Bassin des Oulad Abdoun (Maroc) et comparaison avec les faunes africaines contemporaines: systématique, phylogénie et paléobiogéographie. Unpublished Ph.D. Dissertation. Paris: Muséum National d'Histoire Naturelle, 651pp.

Jouve S., Bardet N., Jalil N-E., Pereda Suberbiola X., Bouya B. \& Amaghzaz M. 2008. The oldest African crocodylian: phylogeny, paleobiogeography, and differential survivorship of marine reptiles through the Cretaceous-Tertiary boundary. Journal of Vertebrate Paleontology 28: 409-421.

Jouve S., Bouya B., Amaghzaz M. \& Meslouh S. 2014. Maroccosuchus zennaroi (Crocodylia: Tomistominae) from the Eocene of Morocco: phylogenetic and palaeobiogeographical implications of the basalmost tomistomines. Journal of Systematic Palaeontology 12: 1-25. 
Jouve, S. 2016. A new basal tomistomine (Crocodylia, Crocodyloidea) from Issel (Middle Eocene; France): palaeobiogeography of basal tomistomines and palaeogeographic consequences. Zoological Journal of the Linnean Society, 177(1), pp.165-182.

Norell M. A. 1988. Cladistic approaches to paleobiology as applied to the phylogeny of alligatorids. Unpublished Ph.D. Dissertation. New Haven: Yale University, 279 pp.

Norell M. A. Clark J. M. 1990. A reanalysis of Bernissartia fagesii, with comments on its phylogenetic position and its bearing on the origin and diagnosis of the Eusuchia. Bulletin de l'Institut Royale des Sciences Naturelles de Belgique, Sciences de la Terre 60: $115-128$.

Pol D., Turner A. H. \& Norell M. A. 2009. Morphology of the Late Cretaceous Crocodylomorph Shamosuchus djadochtaensis and a Discussion of Neosuchian Phylogeny as Related to the Origin of Eusuchia. Bulletin of the American Museum of Natural History 371: 1-103.

Ösi A., Clark J. M. \& Weishampel D. B. 2007. First report on a basal eusuchian crocodyliform with multicusped teeth from the Upper Cretaceous (Santonian) of Hungary. Neues Jahrbuch für Geologie und Paläontologie, Abhandlungen 243(2): 169-177.

Salisbury S. W., Molnar R. E., Frey E. \& Willis P. M. A. 2006. The origin of modern crocodyliforms: new evidence from the Cretaceous of Australia. Proceedings of the Royal Society, B 273(1600): 2439-2448.

Shan H-Y., Wu X-C., Cheng Y-N \& Sato T. 2009. A new tomistomine (Crocodylia) from the Miocene of Taiwan. Canadian Journal of Earth Sciences 46(7): 529-555.

Wu X-C., Russell A. P. \& Brinkman D. B. 2001. A review of Leidyosuchus canadensis Lambe, 1907 (Archosauria: Crocodylia) and an assessment of cranial 
variation based upon new material. Canadian Journal of Earth Sciences 38(12): 1665-1687. 